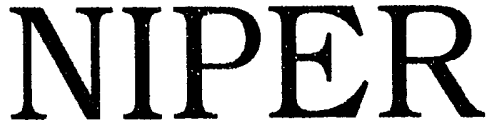

Commitment to Excellence

\section{MONTHLY PROGRESS REPORT}

FOR

APRIL 1993

\author{
Work Performed for the \\ U.S. Department of Energy \\ Under Cooperative Agreement DE-FC22-83FE60149
}

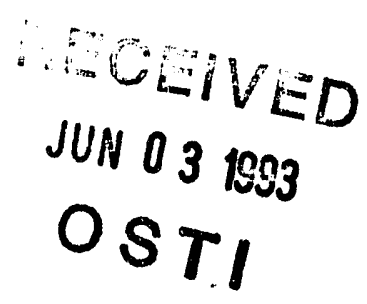

National Institute for Petroleum and Energy Research II T Research Institute - P. O. B ox 2128 Bartlesville, Oklahoma 74005-2128 • (918) $336-2400$ 


\title{
MONTHLY PROGRESS REPORT \\ for April 1993
}

\author{
Work Performed for the \\ U.S. Department of Energy \\ Under Cooperative Agreement \\ DE-FC22-83FE60149
}

\begin{abstract}
DISCLAIMER
This report was prepared as an account of work sponsored by an agency of the United States Government. Neither IIT Research Institute nor the United States Government nor any agency thereof, nor any of their employees, makes any warranty, expressed or implied, or assumes any legal liability or responsibility for the accuracy, completeness, or usefulness of any information, apparatus, product, or process disclosed, or represents that its use would not infringe privately owned rights. Reference herein to any specific commercial produch, process, or service by trade name, trademark, manufacturer, or otherwise, does not necessarily constitute or imply its endorsement, recommendation, or favoring by the United States Government or any agency thereof. The views and opinions of authors herein do not necessarily state or reflect those of the United States Government or any agency thereof.
\end{abstract}

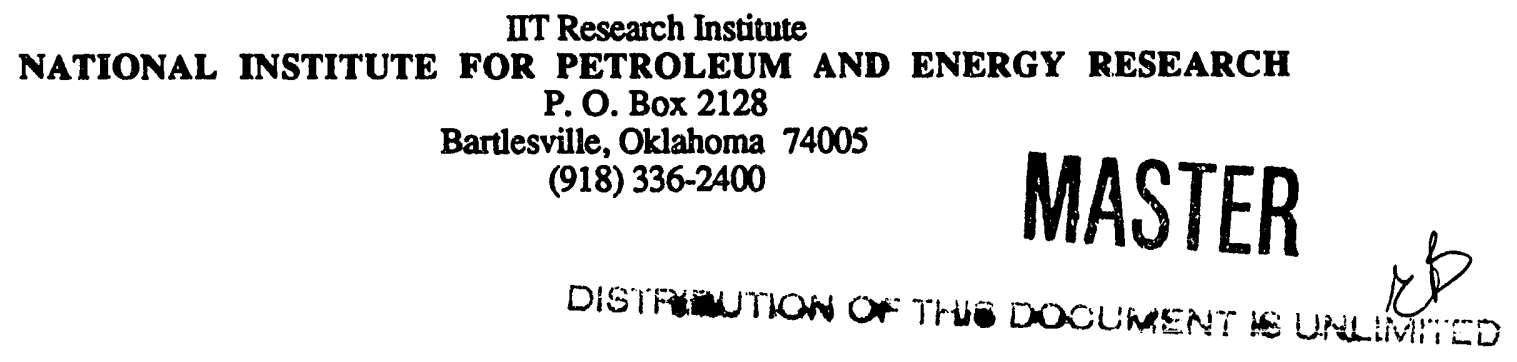




\section{FOREWORD}

The Monthly Progress Report for April 1993, NIPER-686, is submitted in accordance with the provisions of Cooperative Agreement DE-FC22-83FE60149 between the Department of Energy and the IIT Research Institute.

The status of a new project, designated as SGP72 and funded under the Supplemental Government Program, is included in this report. The objectives of the project are to achieve effective coordination of technology transfer efforts among $\mathrm{DOE}$ and the diverse organizations that are part of the petroleum industry and to provide feedback to DOE regarding technology needs of the petroleum industry. 
| 


\section{TABLE OF CONTENTS}

Foreword iii

Summaries

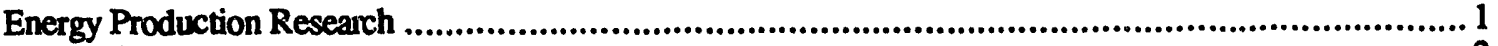

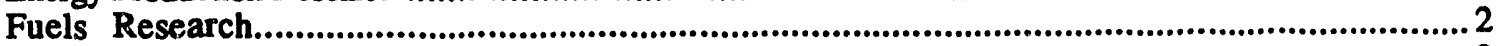

Base Program Funding and Manpower ................................................................................. 3

Base Program

Energy Production Research ..........................................................................................5

BE1. Reservoir Assessment and Characterization ....................................................................5

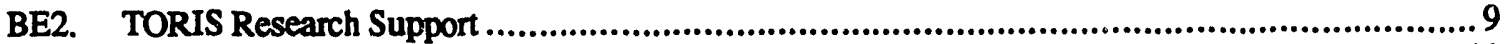

BE3. Development of Improved Microbial Flooding Methods ....................................................11

BE4A. Deveopment of Improved Chemical Flooding Methods...............................................................13

BEAB. Development of Improved Alkaline Flooding Methods......................................................15

BE4C. Mobility Control and Sweep Improvement in Chemical Flooding ...........................................17

BE5A. Gas Flood Performance Prediction Improvement ................................................................19

BE5B. Mobility Control, Profile Modification, and Sweep Improvement in Gas Flooding......................21

BE9. Three-Phase Relative Permeability Research..........................................................................23

BE11A. Thermal Processes for Light Oil Recovery ..................................................................25

BE11B. Thermal Processes for Heavy Oil Recovery ........................................................................27

BE12. Imaging Techniques Applied to the Study of Fluids in Porous Media .....................................29

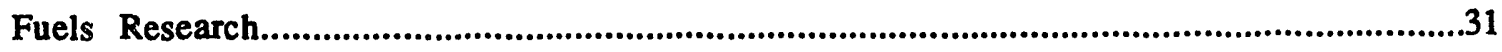

BFR2. Development of Analytical Methodology for Analysis of Heavy Crudes ...............................31

BFR3. Thermochemistry and Thermophysical Properties of Organic Nitrogen- and Diheteroatom-Containing Compounds ...........................................................................33

Supplemental Government Program.......................................................................................................35

SGP13. Microbial-Enhanced Waterflooding Field Project ...........................................................35

SGP37. Feasibility Study of Heavy Oil Recovery in the Midcontinent Region: Oklahoma,

Kansas, and Missouri......................................................................................................37

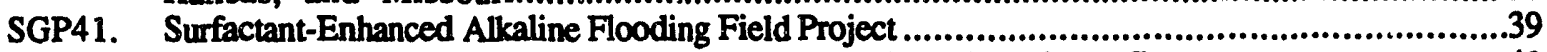

SGP49. Process-Engineering Property Measurements on Heavy Petroleum Components..........................41

SGP50. Development and Application of Petroleum Production Technologies .....................................43

SGP56. Upgrade BPO Crude Oil Data Base .............................................................................45

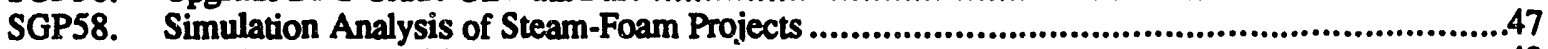

SGP61. DOE Education Initiative Project ..................................................................................49

SGP63. Field Application of Foams for Oil Production Symposium.........................................................51

SGP64. Technology Transfer to Independent Producers .....................................................................53

SGP69. Compilations and Analysis of Ouicrop Data from the Muddy and Almond Formations................55

SGP72. Implementation of Oil and Gas Technology Transfer Initiative.....................................................57

SGP73. Horizontal Well Production from Fractured Reservoirs .......................................................59 
$\underline{\underline{\underline{z}}}$ 


\section{SUMMARY}

\section{ENERGY PRODUCTION RESEARCH}

Organization and coordination of the technology transfer conference, New Technology for Independent Producers, to be held in Denver, CO, May 6-7, 1993, has continued. NIPER personnel will chair the Reservoir Characterization and Biotechnology sessions and present eight papers at the meeting, four of which reflect work conducted in project BE1. Talks to be presented by the project staff personnel include subjects such as the effects of rservoir heterogeneity on oil recovery efficiency, reservoir characterization for EOR potential evaluation, application of standard petrographical analysis, and application of hydrogeochemical techniques to reservoir characterization. (BE1)

The compiled BOAST simulator has been tried on several one- and two-dimensional (1-D and 2-D) simulations. On 2-D data sets involving approximately 3,000 grid blocks, the simulator takes about 30 minutes to perform 600 trials before reaching terminating conditions. For a 1-D data set involving 40 grid blocks, the simulator takes 33 seconds to perform 1,000 trials before reaching endpoint. During this 33 second run, the simulator output 36 data files showing the 1-D oil, water, and gas saturations and how the flood front traversed the length of the model during the simulation. Now that the simulator is working properly, it will be used to study 1-D and 2-D models based on permeability, porosity, capillary pressure, and saturation distributions representative of real rock systems under study in the laboratory. (BE9)

A topical report, entitled "Evaluation of NIPER Thermal EOR Research, State of the Art and Research Needs," (NIPER 675) has been delivered to the BPO. This report summarizes NIPER's thernal recovery research over the past 10 years, analyzes contributions of the research, describes the transfer of the technology to potential users, defines current trends in thermal research and thermal oil production, and identifies areas where NIPER can contribute to future advances in thermal oil production. (BE11A)

Numerical simulation of a steamflood in the Taylor-Ina (TX) field is in progress. The feasibility of improving steamflood performance with $\mathrm{CO}_{2}$ as an additive is being investigated. A literature survey of a steamflood using $\mathrm{CO}_{2}$ was undertaken to collect the requisite data for simulation. The Computer Modeling Group's phase behavior model (CMG PROP) will be used in modeling $\mathrm{CO}_{2}$-steam phase behavior. (BE11B)

A paper, entitled "Imaging Technology Applied to Rock and Fluid Imaging in Cores," will be presented at the New Technology for Independent Producers Workshop to be held in Denver, CO, May 6-7. (BE12)

Report NIPER-606, "Estimates of Future Regional Heavy Oil Production at Three Production RatesBackground information for Assessing Effects on the U.S. Refining Industry," has been delivered to the BPO. In addition, an update of trends in heavy oil production and refining in California was presented and published in the Proceedings of the American Chemical Society Symposium on Enhanced Oil Recovery, that was held in Denver, CO, Mar. 28-Apr. 2. (SGP37)

Nineteen students have accepted offers to participate in the summer intern program. Each student has been notified as to safety training, seminars, and meetings planned for the summer. Topics of the seminars include geology, primary and secondary recovery, EOR, biotechnology, and environmental issues associated with petroleum production. The teacher-intems from NIPER and Phillips Petroleum Co. also plan to attend the seminars. (SGP50)

Information pertaining to the curriculum of the Oil and Gas Exploration module was presented to Mike Benard, president of the Midcontinent Oil and Gas Association, and Mickey Thompson, executive vice-president of the Oklahoma Independent Peteroleum Association. Both gentlemen displayed considerable interest in the curriculum and suggested that NIPER present additional information on the module at future meetings of their respective organizations. (SGP61)

The papers, extended abstracts of poster session presentations, and summary of a panel discussion have all been assembled into the Proceedings of the symposium on the field application of foams (NIPER-699). The Proceedings will be available for distribution following publication as a DOE/FE report. (SGP63)

An organizational meeting was held in Austin, TX, Jan. 18, to discuss formation of an industry committee to facilitate transfer of oil and gas technology to the domestic petroleum industry. This meeting was conducted as part of a new SGP project established to implement an oil and gas technology transfer initiative. Participants of the 
meeting included representatives from the petroleum industry, societies, and trade associations and observers from DOE and the national laboratories. Representatives from TIPRO, TORP, Illinois Geological Survey, and New Mexico Petroleum Recovery Research Center made brief presentations relating to ongoing technology programs. A majority of those attending selected the name of the coordinating committee to be the Petroleum Technology Transfer Council. (SGP72)

\section{FUELS RESEARCH}

Cat cracking of Lagomedio $>650^{\circ} \mathrm{F}$ resid, and chromatographic fractions thereof, has been completed. Solid and liquid products from those runs are currently being analyzed. Analysis of Brass River products also has been completed; those data are being entered into the computer for calculation of material balances. (BFR2)

A journal article, entitled "The Thermodynamic Properties of Thianthrene and Phenoxathiin," has been accepted for publication in the Journal of Chemical Thermodynamics. (BFR3)

A commercial zone-refining apparatus has been received and assembled. Testing and determination of operating parameters has begun. A sample of 1,2,3,4-tetrahydrofluoranthene, synthesized by Oklahoma State University, will be zone refined once the apparatus is operational. (SGP49) 
BASE PROGRAM

FINANCIAL STATUS OF THE PROJECT FOR APRIL

Total Appropriation:

Less Capttal Equipment:

Appropriation Balance:

Brpenditures for the Month:

Total Expenditures to Date:

Net Available:

Capital Equipment Expenses and Commits:
$5,000,000$

197,600

$4,802,400$

617,434

3,282,711

$1,717,200$

23,543
MANPOWER STATUS OF THE PROJECT FOR APRH

Total Man-hours:

Man-hours used thls Month:

8,117

Total Man-hours used to Date:

Net Avallable:
63,283

44,552

18,731
Legend for Key Milestones

$\mathbf{X}=$ Wark Completed

$\mathbf{C}=$ Planned Completion Date

C'a Revined Completion Date

C"= Completed Ahead of Schedule
Finnedal Stutus

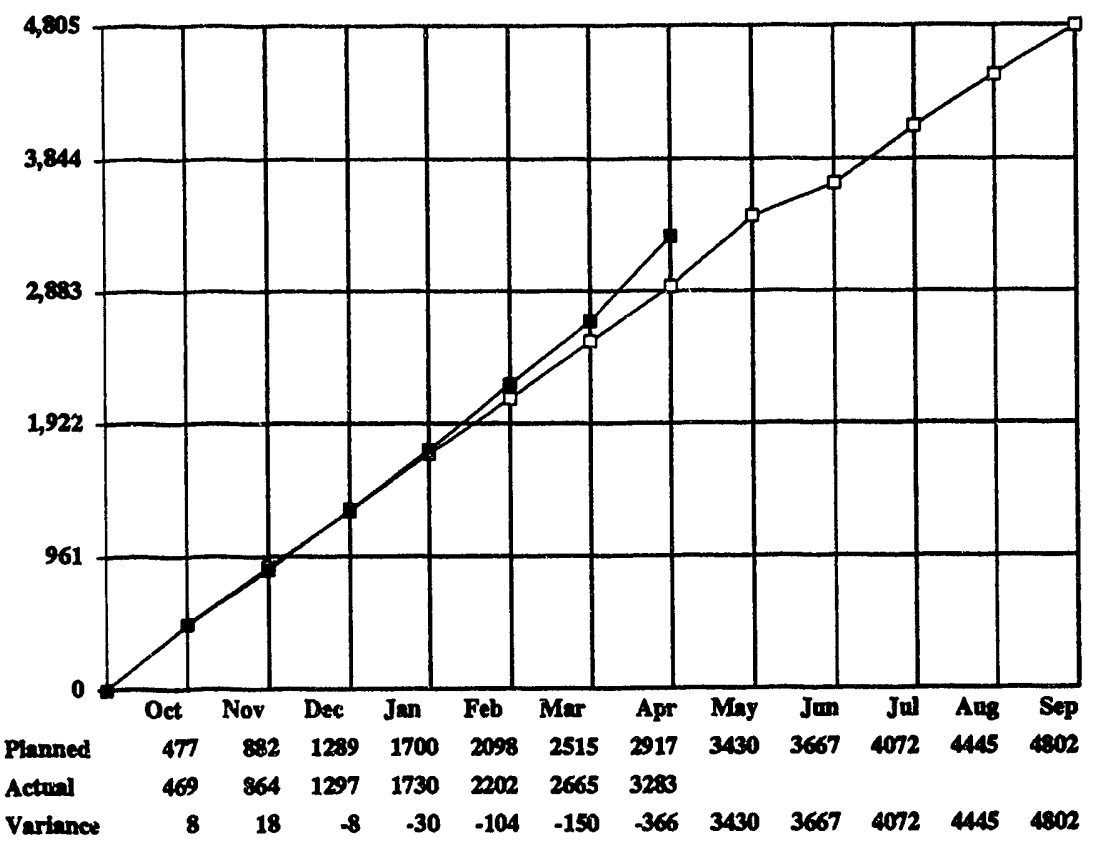

Manpower Status

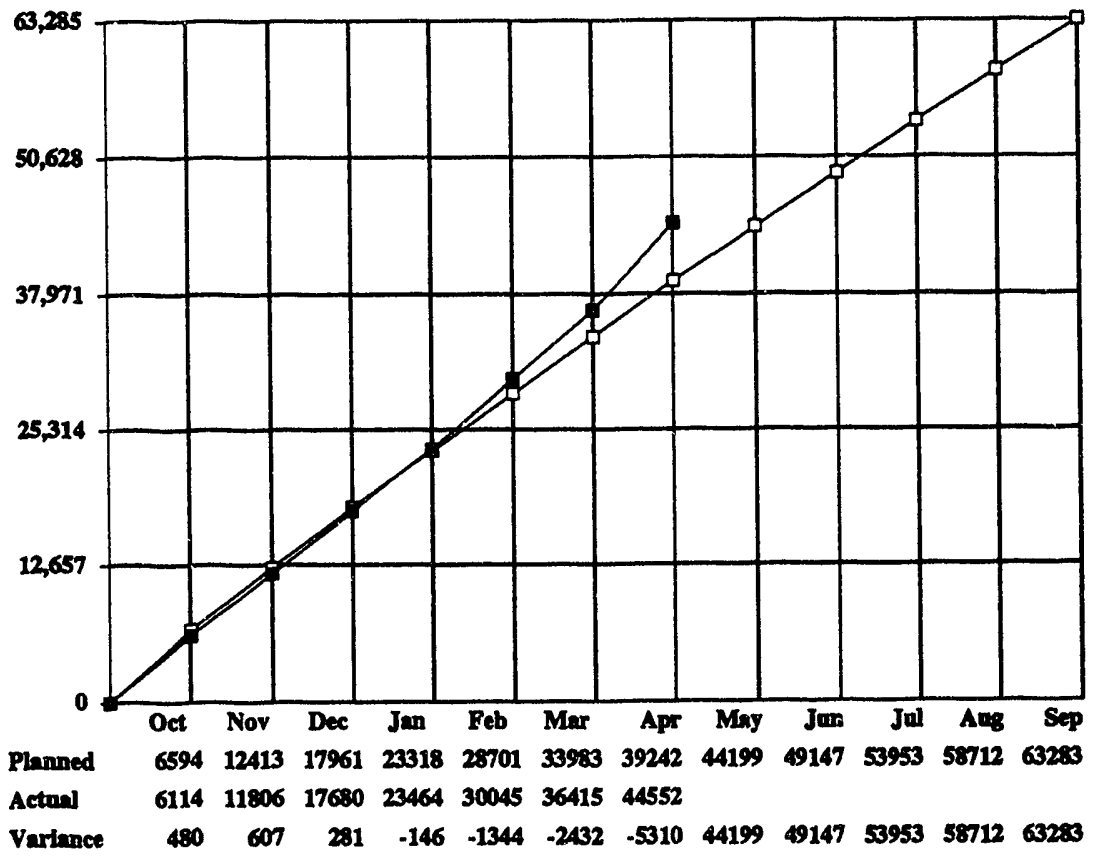


FINANCLIL STATUS OF THE PROJECT FOR APRIL

Total Approprintion:

Less Cappltal Equipment:

Appropriation Balance:

Expendttures for the Month:

Total Rrpendtures to Date:

Net Available:

Capital Equipment Expenses and Commits:

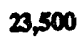

771,500

108,673

569,476

225,524

4,488

Annual Plan Project BE1

Reservodr Ascessment and Characterization

MANPOWER STATUS OF TEE PROJECT FOR APRIL

Total Man-hours:

Min-hours used this Month:

Total Man-hours weed to Date:

Net Avallable:
1,531

9,500

7,713

1,787
Legend for Key Malestones

$X=$ Wark Completed

$C=$ Planmed Completion Date

$C=$ Revised Completion Date

C'= Completed Ahead of Schedule

Key Millestone Status

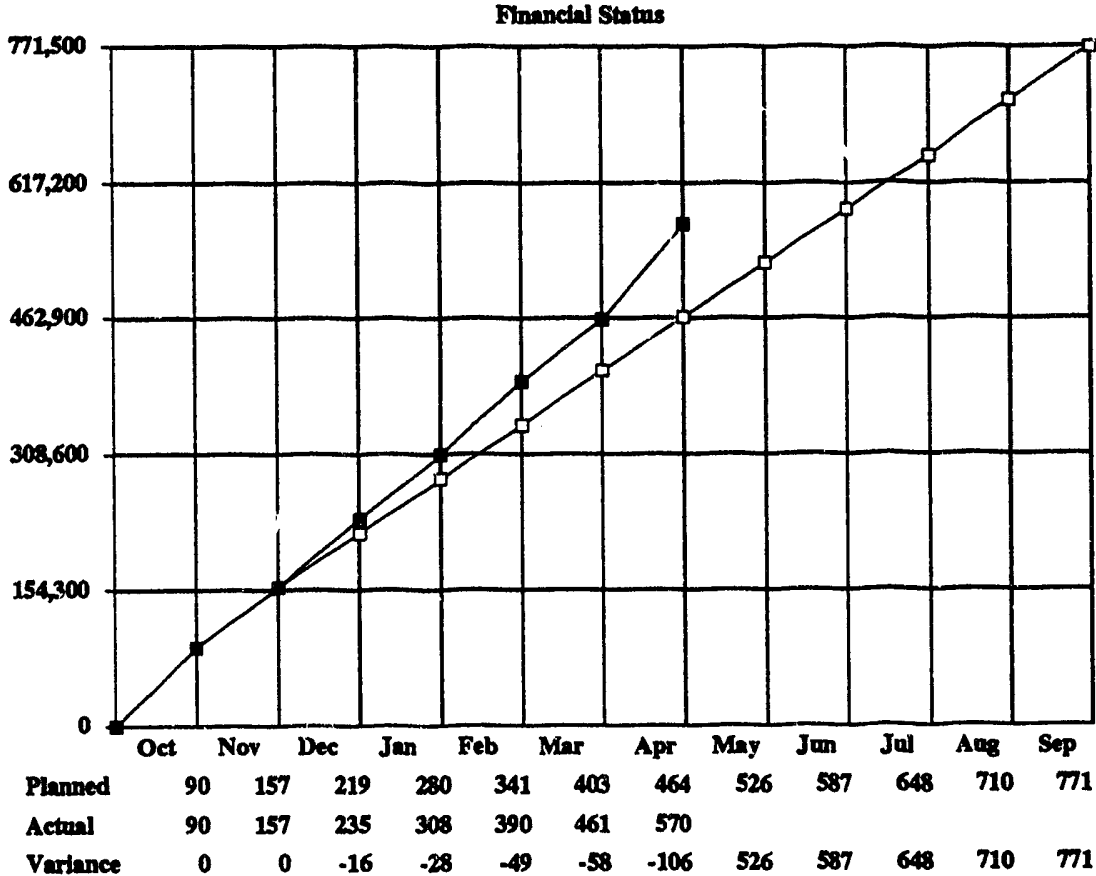

Mampowar Statos

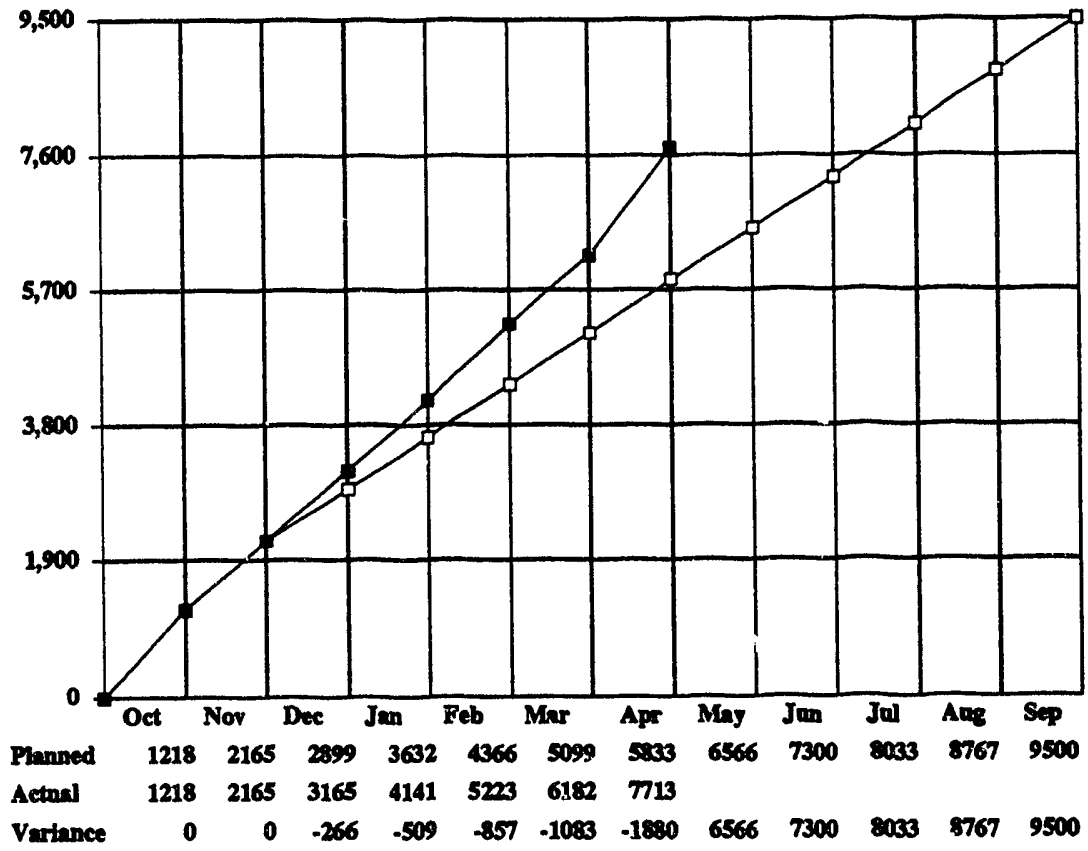

1 Submit Status Report on Project Environmental, Safety, and Health Asceomant

2 Complete Summary of Shoreline Barrier Deposts and Evaluation of Efrective On Recovery Procesces

3 Complete Updated Data Base on Patrick Draw Field and Annotated Bbllography on Shoreline Barrier Depodits

4 Prepare Chapter for NIPER Final Report Summartaing Accouplth ments of Project BE1 (Dratt Complete by April 15)

5 Status Repart Describing Plan for Charactertaing Chas 1, FluvialDominated Deltale Reservoirs

6 Promote Information Exchange \& Camplete Technology Transes Activities
XXX XXC

$\begin{array}{llllll}\mathbf{X X X} & \mathbf{X X X} & \mathbf{x x x} & \mathbf{X X X} & \mathbf{x x x} & \mathbf{x x x}\end{array}$ C $\mathbf{X x x} \quad \mathbf{x x x} \quad \mathbf{x x x} \mathbf{x x x}$ C $\mathbf{X X X} \mathbf{X X X}$ $\mathrm{XXX}$ C C

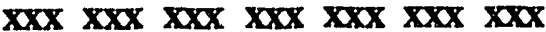




\section{ENERGY PRODUCTION RESEARCH}

\section{BE1. RESERVOIR ASSESSMENT AND CHARACTERIZATION}

\section{Accomplishments}

The objectives of this project are (1) to develop geological and engineering methods to predict mobile oil saturation distribution and quantify reservoir architecture and flow unit geometry for application to targeted infill drilling and EOR and (2) to synthesize $r$ 'servoir and production characteristics of shoreline barrier reservoirs and to determine similarities and differences and the degree to which information from one reservoir can be applied to another.

Milestone 2-Decline curve analysis of production data from Patrick Draw (WY) field is being evaluated for its potential use as a reservoir characterization tool. The decline curve analysis offers reliable reserve estimates and provides accurate calculation of reservoir parameters such as the drainage area or the skin factor which are of critical importance in any enhanced oil recovery operation. Parameters obtained from decline curve analysis may be compared with those obtained from seismic or wireline log interpretations for a greater degree of confidence before initiating an expensive EOR project.

Estimations of reservoir parameters from the decline curve data are based on a trial and error approach in which values of certain parameters have to be known before others can be calculated. Decline curve analysis and comparison of reservoir parameters were performed on Monell wells 1 and 14 from Patrick Draw field. Porosities and pay thicknesses previously determined from core-log correlations indicate that Monell 14 is located in a much more uniform part of the reservoir as compared to Monell 1 which is located in an area of significaint depositional and structural heterogeneities. Decline curve analyses drainage radii of $333 \mathrm{ft}$ for Monell 1 and 2,100 ft for Monell 14 support the previous findings. A large negative skin factor of -4.5 in Monell 14 suggests a significant effect of stimulation in this well as compared to that in Monell 1 which had a skin factor of 0 . The OOIP in Monell 1 was estimated to be 1.088 MMBBLs compared to 4.966 MMBBLs in Monell 14. The type curve match for well Monell 14 suggested that the drainage is characteristic of a layered reservoir with no communication between layers. In contrast, the values calculated for well Monell 1 indicate that the effect of layering is small. While the actual values of these parameters will depend upon the accuracy of the input parameters like formation pressure or water saturation, analysis of decline curves can independently provide information about relative variations of certain reservoir parameters in a producing field.

Milestone 3-Report NIPER-622, "Annotated Bibliography of Selected References on Shoreline Barrier Island Deposits With Emphasis on Patrick Draw Field, Sweetwater County, Wyoming," is in preparation.

Milestone 4-The section of the final report summarizing the FY93 research activities and accomplishments has been completed. A draft of the entire report is nearly complete.

Milestone 6-Organization and coordination for the technology transfer conference, New Technology for Independent Producers, Denver, CO, May 6-7, 1993, has continued. NIPER personnel will chair the Reservoir Characterization and Biotechnology sessions and present eight papers at the meeting, four of which reflect work conducted in project BE1. Text and figures for the preprints, as well as slides and talks have been prepared. Talks to be presented by project staff personnel include subjects such as the effects of reservoir heterogeneity on oil recovery efficiency, reservoir characterization for EOR potential evaluation, application of standard petrographical analysis, and application of hydrogeochemical techniques to reservoir characterization.

The paper, entitled "Integration of a Geological-Engineering Model with Production Performance: A Case Study at Patrick Draw Field, Wyoming," was accepted by SPE for presentation in the Development Geology and Geophysics Poster Session of the 1993 SPE Annual Meeting at Houston, TX, Oct. 3-6.

A proposal has been submitted to the DOE Office of Fossil Energy for a cooperative project with Russia to optimize petroleum production in both countries. The application of modern technologies for advanced reservoir characterization and improved oil recovery to enhance production from known reservoirs was emphasized in the proposal, drawing heavily on technology developed in BE1 and related SGP projects supported by DOE. 
Energy.

Four proposals for the Small Business Innovative Research program were reviewed for the Department of

A tour of NIPER facilities was conducted for a group of Tulsa University professors and students. Presentations regarding the reservoir characterization research program and the petrographic image analysis and CT laboratories were provided by staff personnel.

\section{Mannower and Finguncial Status}

Financial expenditures and manpower are higher than predicted due to the early milestone completion dates and greater than anticipated efforts required in organizing a technology transfer conference.

\section{Statrus of Project Milestones}

Project milestones are on schedule. 
BE2

FINANCLAL STATUS OF THE PROJECT FOR APRIL

Total Appropriation:

Less Cupttal Equipment:

Apipropitation Balance:

Expesultitures for the Month:

Totel Expenditures to Date:

Net Available:

Cupital Bgutpment Expenses and Commits:

17,000

323,000

196,671

143,329

o

Annuwl Pian Project BE2

TORIS Research Support

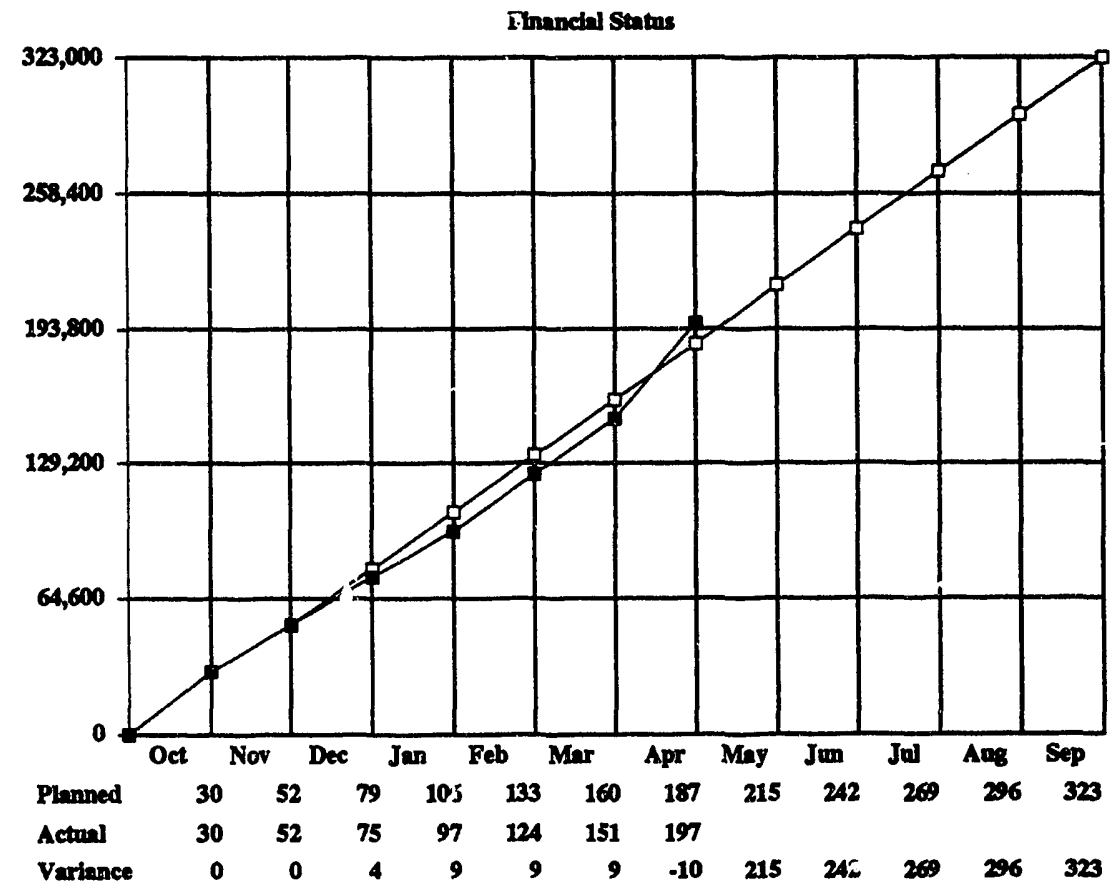

MANPOWER STATUS OF THE PROJECT FOR APRII

Total Mnn-hours:

Mren-hours nsed this Month:

Total Man-hours used to Date: Net Available:
Legend for Key Millestones

$\mathrm{X}=$ Work Completed

C = Piamed Complettion Date

$C=$ Revised Completion Date

$C^{\prime}=$ Completed Ahead of Schedule

Key Mortone Status
3,600

2,347

1,250

$535 \quad \begin{array}{r}3,600 \\ 2,347 \\ 1,253\end{array}$

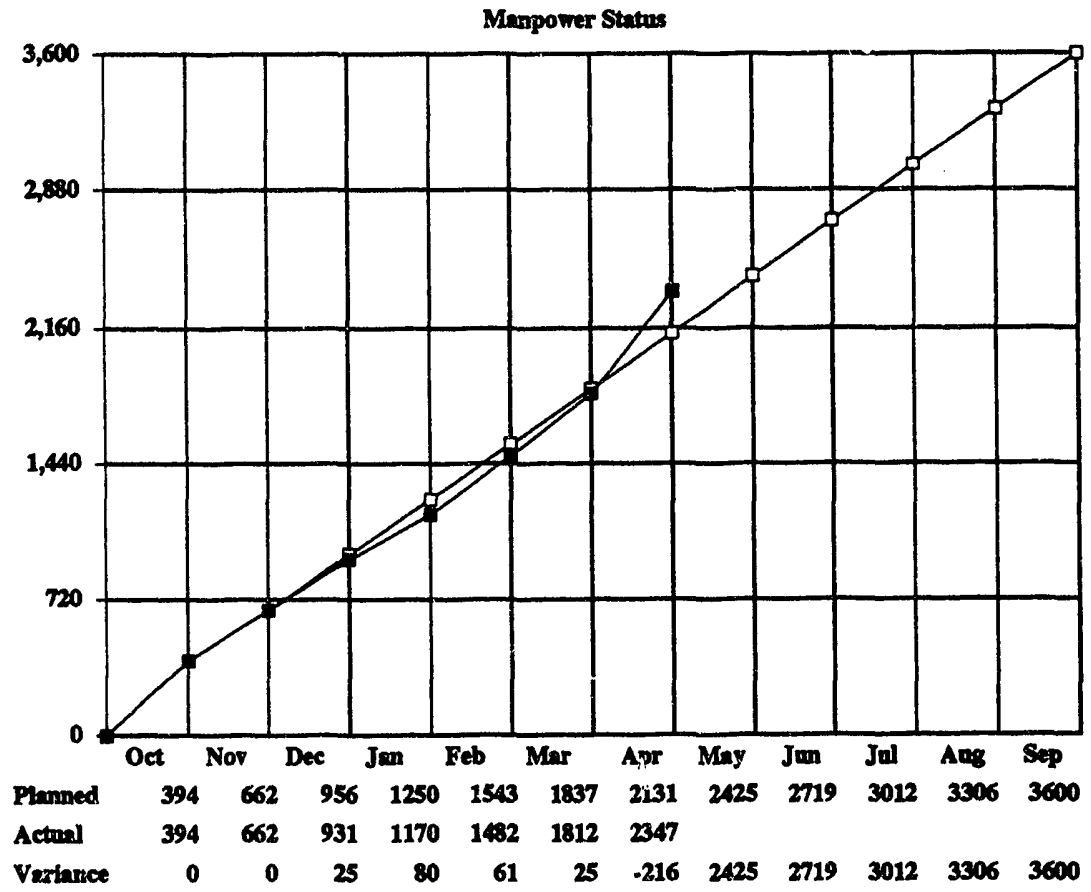

1 Submtt Statos Report on Project kinvironmental, Safety, and Health Assement

2 Status Repart on Reviev of the INGRES Version af the EOR Project Datu Buse and Assearment of Future Needs

3 Prepere Chapter for NIPER Final Report Summartag Accomplithments of Project BE2 (Draft complete by Apell 15)

4 Complete FY93 Research Suppart of EOR Project Data Base

5 Complete FY93 Support of RSVR Reservoir Data Base

6 Complete FY93 Computer Modeling Research Support

7 Status Repart Summariatog 1991 Datu Collected for Incestive Projects 8 Topical Report Defining Ecttmated Conndence Level of the TORIS EOR Predietive Models

\section{$\mathbf{X X X} \mathbf{X X C}$}

$\operatorname{xxx} \mathbf{x x x} \mathbf{x x x} \mathbf{x x x}$ $\mathbf{X X X}$ $\mathbf{C}^{\prime}$

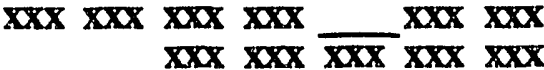
c

$\mathbf{X X X} \times \mathbf{X X X} \times \mathbf{X X X X}$

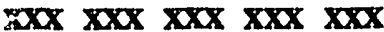
C 


\section{BE2. TORIS RESEARCH SUPPORT}

\section{Accomplishments}

The objective of this project is to provide research support to the DOE Program Manager for the Tertiary Oil Recovery Information System (TORIS) in the areas of enhanced oil recovery (EOR) project and reservoir data base management, EOR project technology and trends analysis, and computer simulation.

Milestone 3-The work on the BE2 chapter for the NIPER final report was a priority task during the month, and the initial draft is nearing completion.

Milestone 4-Research support of the EOR Project Data Base consisted of correcting and updating the two versions. While updating the INGRES version, some of the errors found in the S2k version were identified as already corrected. At least some the unexpected corrections relate to the method of forming the INGRES version from the S2k version-dates were disaggregated to eliminate date-related errors. A detailed analysis of what data were changed and why, as well as updating the INGRES version, will continue.

Milestone 7-Letters requesting 1992 and 1991 (when appr.priate) data on the Tertiary Incentive Projects were mailed in February. Forty-nine responses have already been received for 1992, three for 1991, and two for 1990. Of the total fifty-four forms, 43 are active, leaving 11 either terminated, abandoned, shut-in, or sold. Production and injection data from most of the responses were entered into a working file.

Milestone 8-Work under this task has concentrated on comparing oil production from 15 steam projects in the Tertiary Incentive Program to estimated oil production of the TORIS model. Since there are more steam projects than any other EOR process, this will provide the best opportunity to statistically estimate the accuracy of the model. Aggregated results show excellent agreement between the TORIS model and the selected projects. Unfortunately, the variation of actual and simulated oil production between the model and the actual project is significant. After rigorous review of all the project data, a series of reruns of the projects has been made to ensure that the starting oil in place is appropriately represented. Although results for specific projects changed during this review, the statistical results changed very little. Since the total oil production is in good agreement, it was decided that sampling should be expanded to as many steam projects as possible.

\section{Manpower and Financial_Status}

Manpower and financial expenditures are on schedule.

Status of Project_Milestones

Project milestones are on schedule. 
BE3

FINANCLAL STATUS OF THE PROJECT ROR APRIL

Total Approprtation:

Less Capital Equphonent: 3,000

Appropertation Balance: 317,000

Expenditures for the Month:

Total Expenditures to Date:

Net Avalloble:

Capttal Equijement Expenses and Commits:
320,000

27,709

171,548

148,452

3,729

Annual Flan Project BE3

Developenent of Improved Mierobial

Flooding Methods

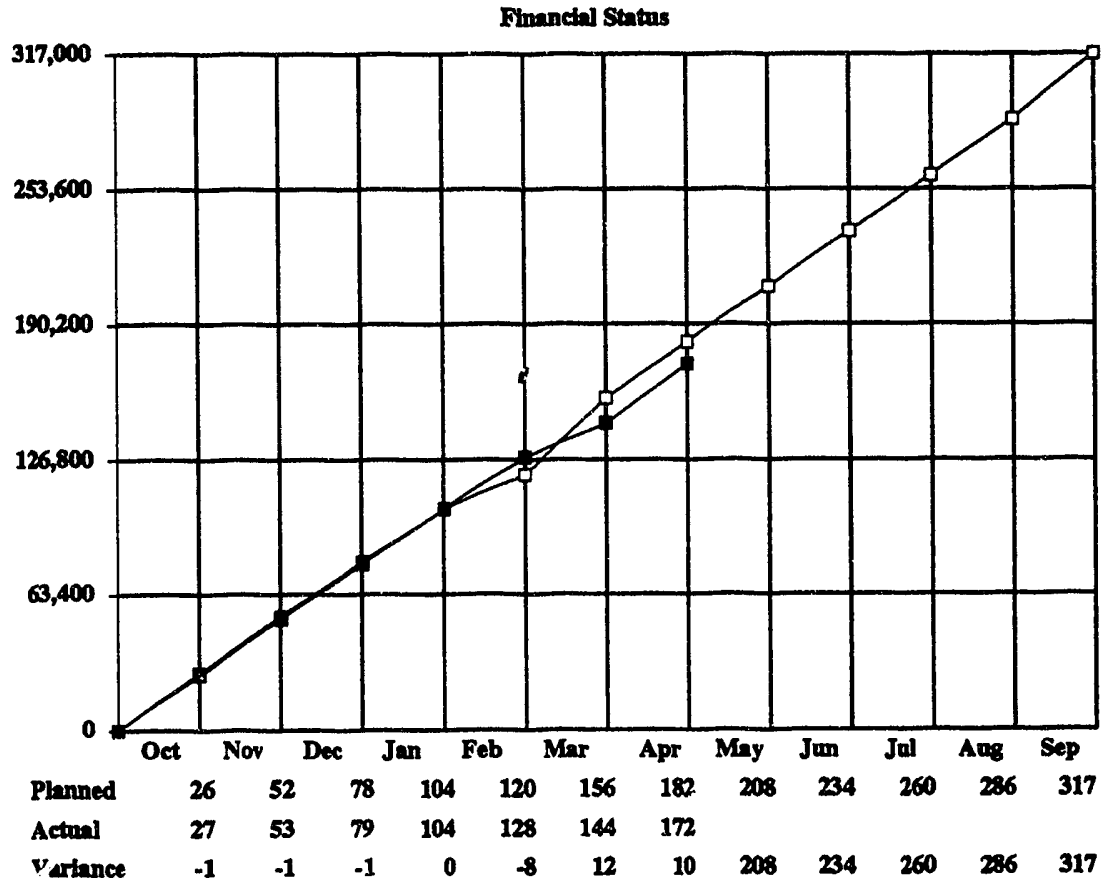

MANPOWER STATUS OF THE PROJECT FOR APRH

Total Man-hours:

Man-hours used this Manth:

Total Man-hours used to Date:

Net Avallables
567

5,580

3,532

2,048
Legend for Key Millestones

$X=$ Wart Completed

C = Plamed Completion Date

$C=$ Revied Completion Date

C"s Completed Ahead or Schedule

Key Millestone Status

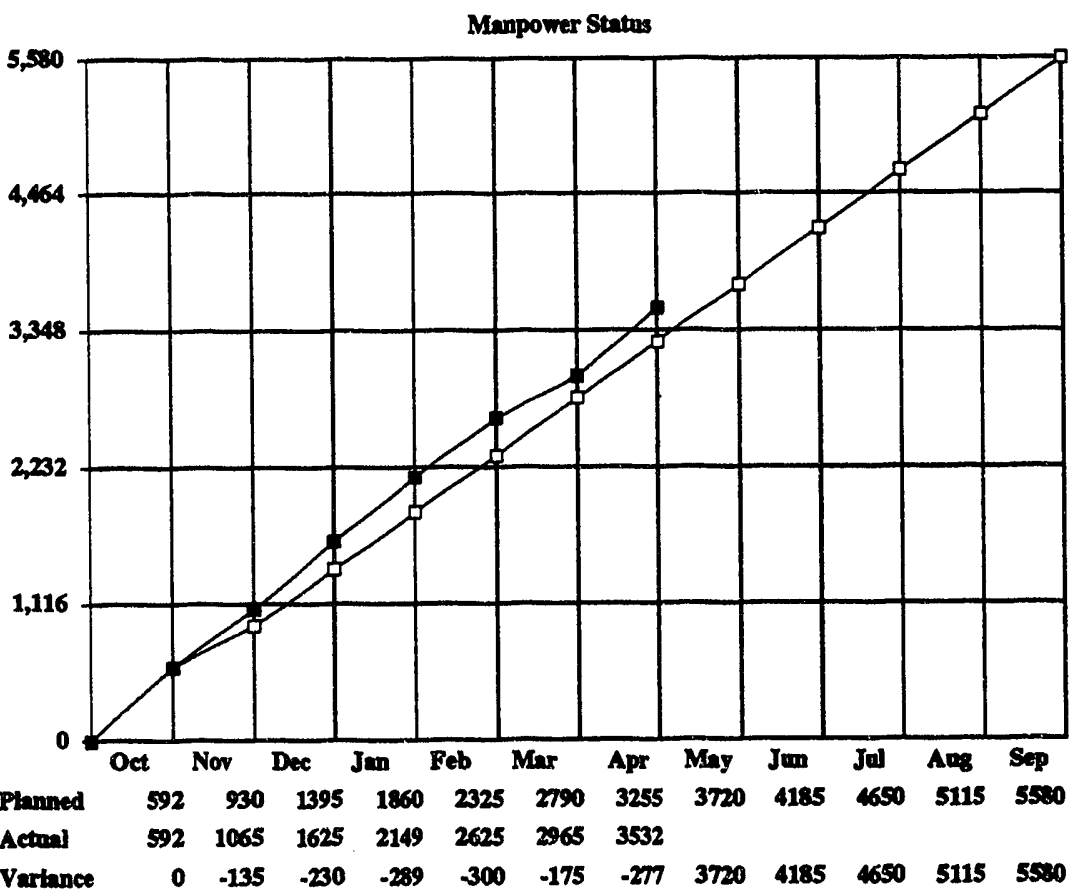

1 Submit Status Report on Proj zet Environmental, Safety, and Health Assesement

2 Complete Evaluation of Mieroblal Systems in Parons Medin Uating CTNMR-Imaghing Techniques

3 Complete Experments Invertigating the Role of Microbbal Polymer Production m On Becovery

4 Prepare Chapter for NIPER Final Report Summartating Accomplishments of Project BE3 (Draft complete by Aprll 15)

5 Fimalize Development of Mathematical Dewariptions for Use in MEOR Predictive Stmulator

6 Provkle Suppart to DOE's Cooperative Effort with Venezaela by Presenttho Project Research Results at Amnex XIII Meetings

7 Topical Report Describing Development of Mathematical Descriptions for Predileting Mechaniams of Merobial OR Recovery

XXc

$\mathbf{X X X} \quad \mathbf{X X X} \mathbf{X X X} \mathbf{X x x} \mathbf{x x x} \mathbf{x x x}$ C

$\mathbf{X X X} \quad \mathbf{X X X} \mathbf{X X X} \quad \mathbf{X X X} \quad \mathbf{X X X} \quad \mathbf{X X X}$ C

$\mathbf{X X X} \quad \mathbf{X X X} \times \mathbf{X X X} \quad \mathbf{X X X} \quad \mathbf{X X X} \quad \mathbf{X X X}$ C $\operatorname{XXX} \quad \mathbf{X X X} \times \mathbf{X X X} \quad \mathbf{X X X} \quad \mathbf{X X X} \quad \mathbf{X X X}$ C 


\section{BE3. DEVELOPMENT OF IMPROVED MICROBIAL FLOODING METHODS}

\section{Accomplishments}

The FY93 objectives of this project are (1) to continue development of an engineering methodology for use in the design and application of microbial methods and (2) to improve oil recovery methods and refine modeling procedures for predicting the effectiveness of such methods in field applications.

Different types of microorganisms can improve oil recovery in various ways. NIPER's research has focused primarily on surfactant and gas-producing microbes that are capable of improving microscopic oil displacement efficiency. Microorganisms can also be used to plug high-permeability zones and cause fluid diversion. During the past 2 years, microbial retention experiments have been conducted with surfactant and gas-producing microbes to determine the effects of microbial adsorption and clogging in porous media. These experiments have been used to define parameters and values for the numerical MEOR simulator.

Research for FY93 will continue with laboratory experiments designed to meet both near- and mid-term objectives. Based upon the laboratory data, mathematical models are being develnped to predict microbial transport, metabolism, oil recovery, and permeability modification. The resulting models can then be used to predict the behavior of microbial EOR processes under actual reservoir conditions. Injection strategies for maximizing incremental oil recovery are also being developed.

Milestone 2-A coreflood experiment is in progress using a microbial species of Leuconostoc. This species produces polymer when fermenting sugar and should not produce gas in the coreplug. By comparing NMR images obtained during this coreflood with previously acquired images in corefloods using gas-producing microbes, it may be possible to determine and quantify gas distribution in the pores. The results of this experiment will not be available until next month.

Milestone 3-A coreflood was conducted with a polymer-producing microorganism to compare the results of oil recovery efficiency and pressure drop across the core during waterflooding with results obtained previously using NIPER 6 Clostridium - a producer of gas, acids, and surfactant. Results with the polymer-producer showed no significant pressure drop increase across the core compared to NIPER 6. The experiment will be repeated with another polymer-producing microorganism using a longer shut-in time. review.

Milestone 4-The chapter on microbial EOR processes for the NIPER final report has been written and is in

A paper, entitled "Basics of Microbial EOR Processes," has been prepared for presentation at the New Technology for Independent Producers seminar to be held in Denver, CO, May 6-7.

Milestone 5-Evaluation of the retention test data continued this month. Problems encountered with the glass beadpack have been resolved, and it can now be used for a retention test using NIPER 6 microbial species.

Manpower and_Financial_Status

Manpower and financial expenditures are on schedule.

Status of Project Milestones

Project milestones are on schedule. 
BEAA

FINANCIAL STATUS OF THE PROJECT FOR APRII

Total Appropriation:

Less Capttal Equipment:

Approprtation Balance:

Expenditures for the Month:

Total Expenditures to Date:

Net Avaliable:

Capital Equipment Expenses and Commits:

Annual Plan Project BEAA

Flooding Methods

22,000

618,000
Development of Improved Chemicel
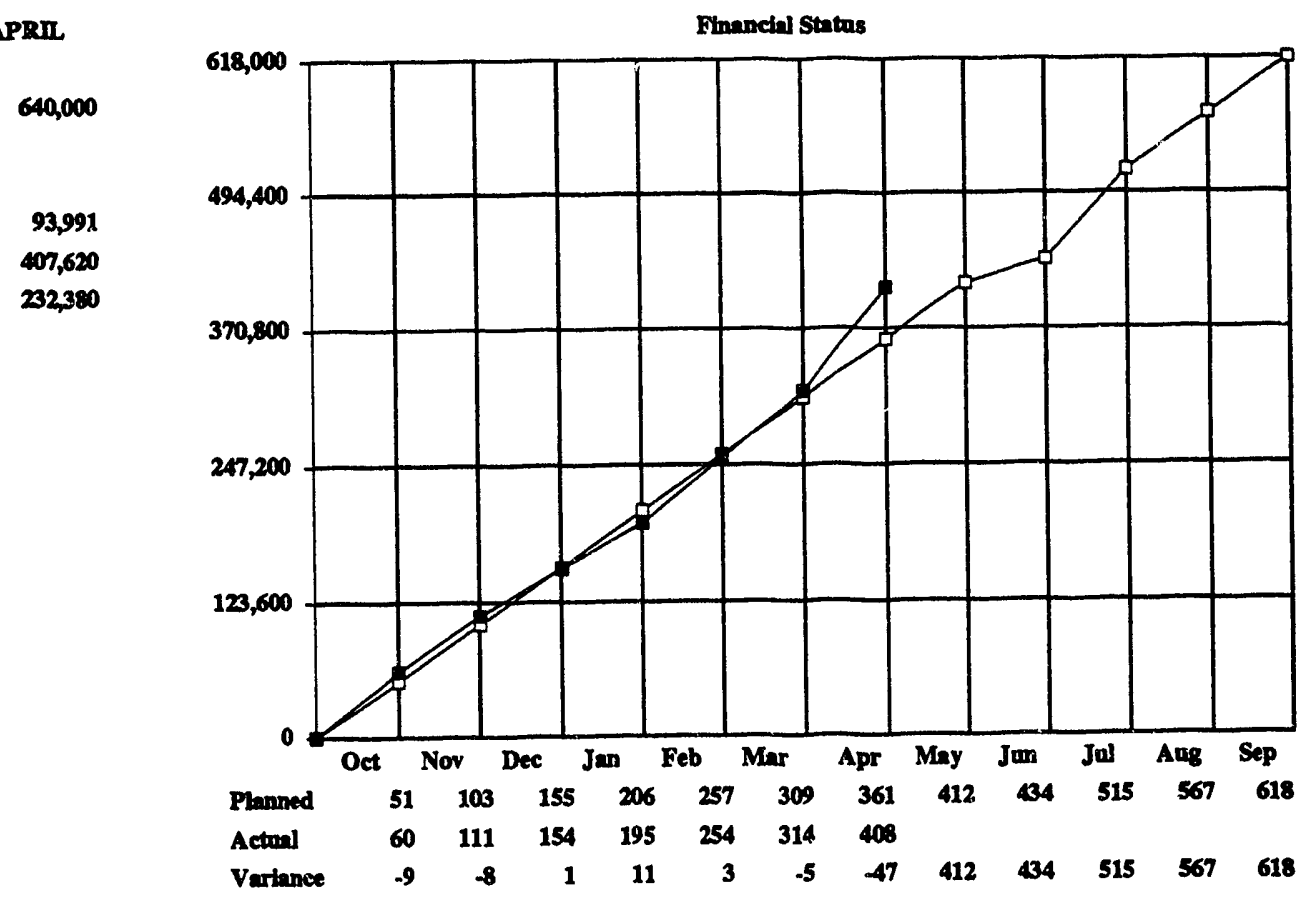

MANPOWER STATUS OF THE PROJECT FOR APRI

Total Man-hours:

407,620

32,350

, 000

991

Men-hours used this Month:

1,388

9,000

Total Man-hours used to Date:

6,023

Net Available:

2,977

\author{
Legend for Koy Millestones \\ $\mathrm{X}=$ Wark Completed \\ C a Punned Completion Date \\ $C=$ Revised Complettion Date \\ $C^{\prime}=$ Completed Ahead of Schedule
}

Key Millestone Statns

1 Status Report on En vtronmental, Safety, and Health Revier

2 Evajuntion of Mined Surfictunts for use in Clase 1 Reservoirs

3 Throngh CT-Imaged Careflood Expertments, Determbe Effective-

ness of Mbred Surfietunt Systems for On Recovery

4 Determine Adsorption Characteristics of Milxed Surhetant Systems

5 Conduct CT-Imaghing Experiments to Determine Optimum Injectant Slug Stze for OIf-bank Formation and Mobllization

6 Develop Surfactant Duta Bese to Fellitate Dedign of Chemical

Flooding Syatems \& Submit Status Report on Its Erectivenes

7 Prepare Chapter for NIPER Final Report (Drant by April 19)

8 Top. Rpt. Describling Adsorption Studies of Mitred Surfinetunt Systems

9 Top. Rpt. Describing Buicettreness of Mixed Surfectant Syatems

for Use in EOR

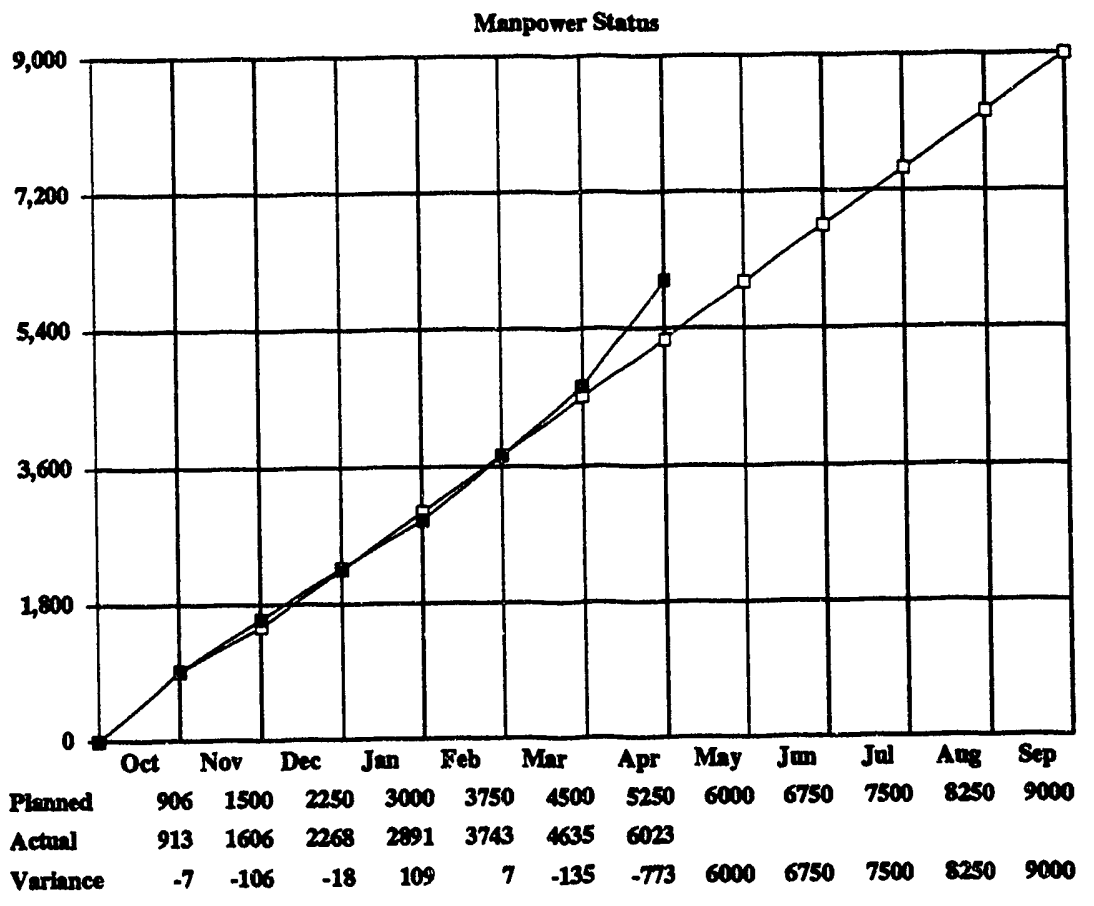

$\operatorname{XxX} \mathbf{X X C}$

XXX XXX XXX XXX XXX XXX XXX C

XXX $\quad$ XXX $\quad$ XXX $\quad$ XXX $\quad$ XXX $\quad$ XXX $\quad$ XXX C

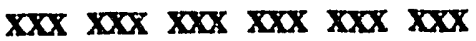
C

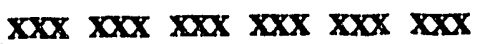
C

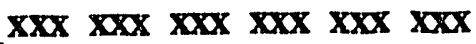

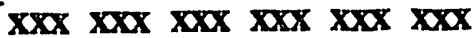
C C 


\section{BE4A. DEVELOPMENT OF IMPROVED CHEMICAL FLOODING METHODS}

\section{Accomplishments}

The objectives of this project are (1) to determine the applicability of advanced EOR technologies, based on mixed surfactant systems, to improve oil recovery from Class 1 and other DOE-targeted reservoirs; (2) to adapt surfactant EOR technology to different salinity and temperature ranges by developing surfactant systems that are tolerant to changes in chemical composition in selected reservoirs; and (3) to develop cost-effective systems for selected applications using low concentration surfactants with alkaline additives or other sacrificial agents. The studies will focus on problem areas which adversely affect performance and economics of chemical EOR and thus achieve a balance between cost and oil recovery effectiveness.

Milestone 2-Salinity scans are being conducted on selected combinations of the anionic surfactant TRS 10410/IBA and nonionic surfactants in the Genapol and Igepal series, with different alkane hydrocarbons (n-octane, $n$ decane, and n-dodecane) and at different temperatures. Similar scans are being conducted with the nonionic surfactants alone (at different HLB values) using the different alkanes. These experiments are being performed to quantify and correlate the oil and water solubilization parameters of these surfactant systems and to compare the values of optimal salinity obtained using this method with the results from earlier PIT studies over a range of temperatures from room temperature up to $60^{\circ} \mathrm{C}$. Phase behavior observations over the conditions considered will be made over a period of 1 week per temperature. This will give the oil-brine-surfactant mixtures time to equilibrate.

Milestone 3-The minipermeameter was used to determine permeability variations in an oil-wet core from North Burbank Unit, Osage County, Oklahoma. Average air permeability of this core was approximately $50 \mathrm{mD}$. The core appeared to be relatively uniform before cleaning. However, after cleaning, a narrow, dark band extended through the core. Average permeability in the area of the dark band ranged from 10 to $14 \mathrm{mD}$. Regions of higher permeability ( 50 to $65 \mathrm{mD}$ ) could be found on either side of the band. Thin sections will be prepared to determine mineralogical differences that might account for the color change during cleaning. This core is being prepared for evaluation of the effect of iododecane (an oil additive to increase the CT-density of the oil phase during chemical coreflood experiments) on oil saturation distribution calculations using oil-wet core.

Milestone 4-The primary objective of this milestone is to determine the adsorption behavior of mixed surfactant systems. The system currently being tested consists of a 1:1 mixture of Stepan's B-100 (anionic surfactant) and Igepal DM-530 (nonionic surfactant) at a total surfactant concentration of $2 \%$. The adsorbent is Davison Grade 62 silica gel, with a specific surface area of $330 \mathrm{~m}^{2} / \mathrm{g}$. Preparation of calibration curves for the analytic technique using these mixed surfactants is near completion. Preliminary bottle adsorption tests of the unmixed surfactants indicate that the nonionic surfactant will adsorb to the extent of 500-600 milligrams surfactant per gram of solid, while the anionic adsorption is in the range of 0.8 to 1.0 gram surfactant per gram of solid. Static tests are underway to determine the adsorption characteristics of these surfactant mixtures.

Milestone 5-Two CT-monitored corefloods were designed to determine the effect of changing surfactant slug injection size (at constant polymer concentration) on oil-bank formation and propagation. Surfactant slug sizes of 0.4 and $0.2 \mathrm{PV}$ of a $0.4 \%$ total-concentration mixed surfactant system were used. Problems occurred with polymer injection during the test using the $0.4 \mathrm{PV}$ system in that the concentration of polymer was only $500 \mathrm{ppm}$ rather than the designed concentration of $3,500 \mathrm{ppm}$. As a result, this test will have to be repeated.

Milestone 6-Work on the surfactant data base is continuing. A subset of 175 references has been selected for critical review. Detailed information on 30 of these references has been entered into the data base.

Milestone 7-The first draft of the chemical flooding research chapter for the NIPER final report has been completed and submitted for editorial review.

\section{Mannower and Financial_Status}

Manpower and financial expenditures are higher than planned because of efforts of senior staff personnel in completing the first draft of the 10-year final report.

Status of Project_Milestones

Project milestones are on schedule. 
FWNANCLAL STATUS OF THE PROJECT FOB APRIL

Total Appropriation:

Lew Capital Equipment:

Appropitation Balance: 3,500

196,500

Fonenditures for the Month:

Total Expenditures to Datis:

Net A rallable:

Captial Equipment Expenses and Commits:
200,000

25,669

102,923

97,077

2,665
Annoal Plan Project BEAB

Development of Improved Alkaline

Flooding Methods

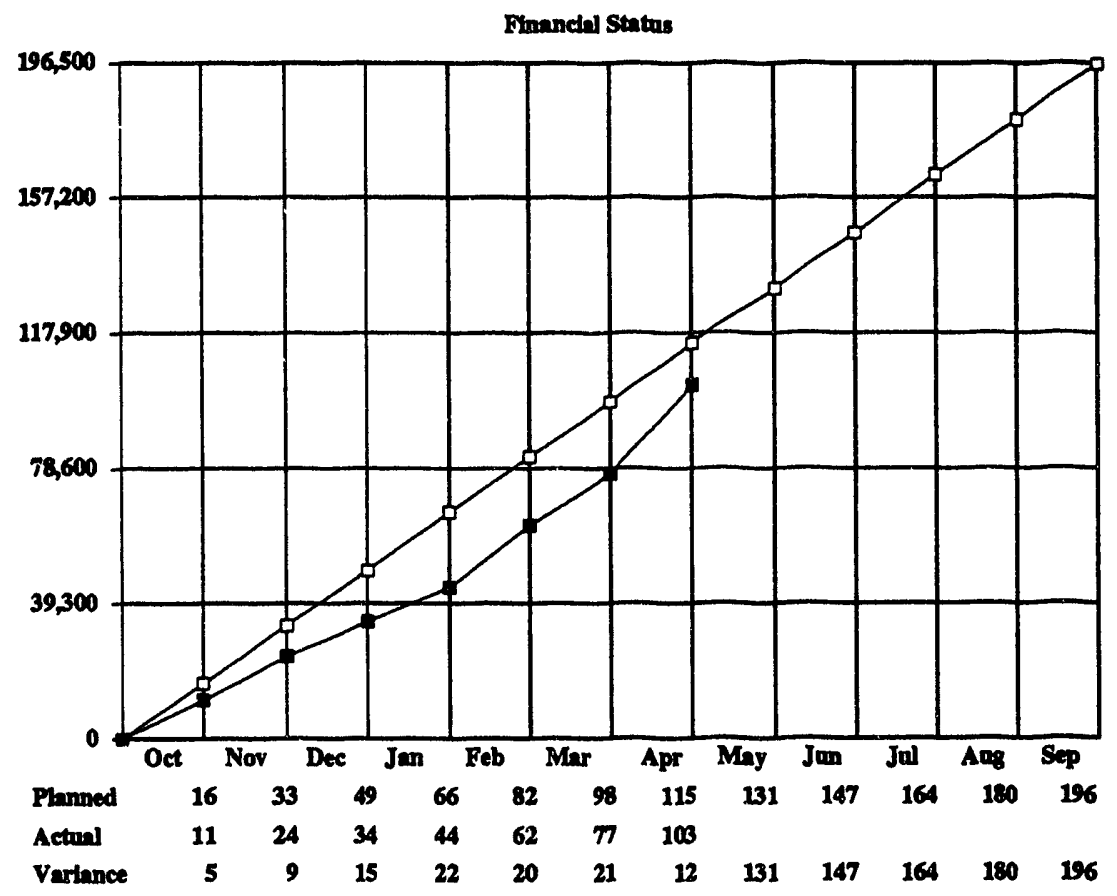

MANPOWER STATUS OF THE PROJECT FOR APRII

Total Man-hours:

Men-hours need this Month:

Total Man-bours used to Date:

Net Avallable:
Legend for Krey Miliettones

$X=$ Wark Completed

C a Planned Completion Dute

$C=$ Revibed Complettion Date

C"= Completed Ahead of Schedule

Koy Millestone Status
2,700

1,540 1,160

$410 \quad$

1,540
1,160

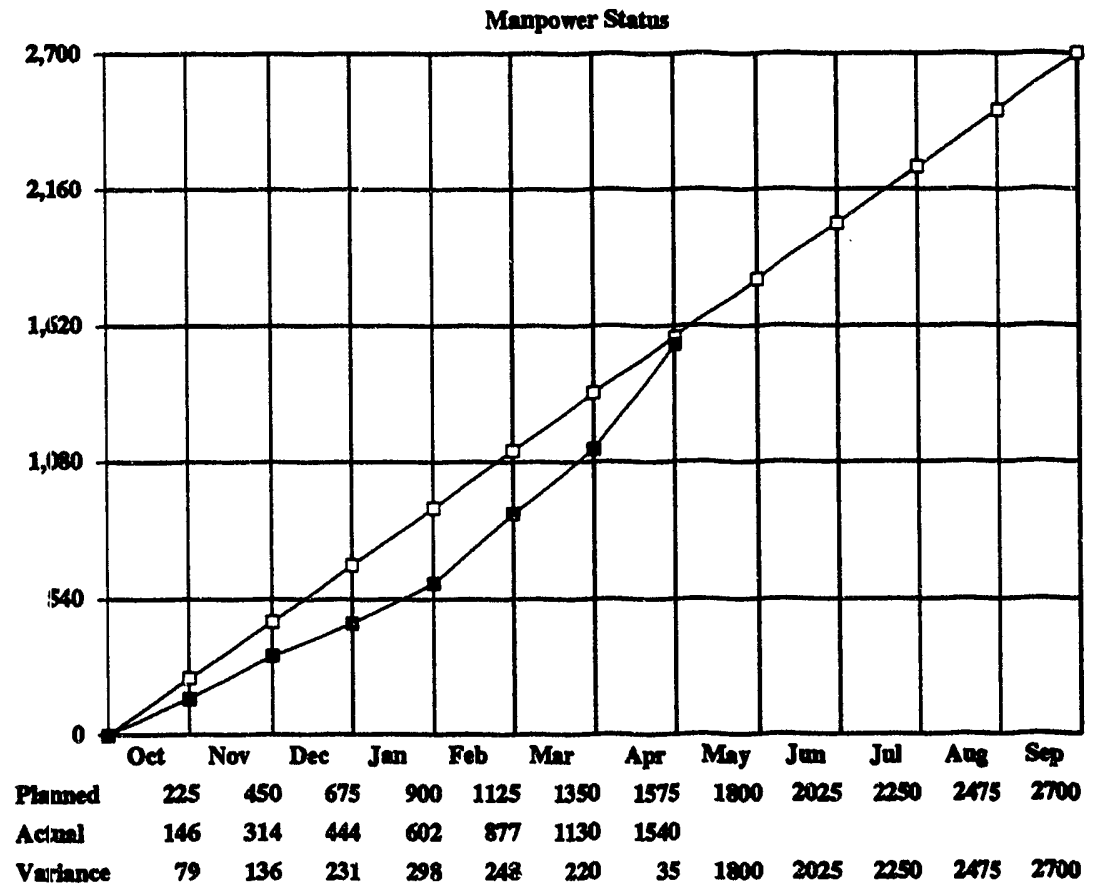

1 Submit Status Report on Project Envirummental, Safety, and Health

Asecoment

2 Coaclade Study on Disperdon/lnterections Avodated with Soriactomt-Buhnunced Alkaline Flooding Systems

3 Complete Tranefer of Surfactant-Bnhanced Allolline Flooding Technology to Independent On Producears

4 Prepere Chapter for NIPER Final Report Snnmartiting Accomplithments of Projed BEAB (Draft Complete by April 15)

5 Topieal Repart Deweribing Charactertatios of Dieperdoms Amsociated wh Sarinctant \& Alloline Chanteal Systems

\section{XXc}

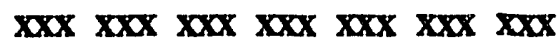
C

XXX XXX XXX XXX XXX XXX XXC"

$\mathbf{X x X} \quad \mathbf{X X X} \quad \mathbf{x x x} \quad \mathbf{x x x}$ c 


\section{BE4B. DEVELOPMENT OF IMPROVED ALKALINE FLOODING METHODS}

\section{Accomplishments}

The objectives of this project are to develop improved alkali-surfactant flooding systems and to provide support for an SGP field project. The specific objectives for FY93 are to improve the stability of alkali-surfactant flooding systems by designing combinations of chemicals that will curtail the loss of surfactant from chemical interactions. Most of the tests are being performed with crude oil from the Tucker sand (a Cherokee group sand) of Hepler (KS) oil field, the site of a alkaline/surfactant/polymer field project.

Milestone 2-The BPO approved a change in the objective of this milestone because it was found that characterization of dispersions typical of surfactant-enhanced alkaline systems was more complicated and time intensive than anticipated. The revised objective incorporates the use of CT scanning for the accurate determination of oil saturations in field cores partially swept with surfactant-enhanced alkaline chemical formulations. This research is necessary because heterogeneities in midcontinent field cores make it difficult to predict accurately the final oil saturations that result after application of chemical flooding methods.

A core from Hepler (KS) oil field, which was previously characterized by minipermeameter measurements, was selected for further study. This core was selected because it had a more uniform permeability distribution (between 100 to $225 \mathrm{mD}$ ) than many cores from Hepler field, and thus had better potential for good sweep efficiency during chemical flooding.

The interfacial tension (IFT) between oil and injected fluids was measured using a surfactant concentration of $0.1 \%$ Chevron CF-100 surfactant, which is a lower surfactant concentration than was used for prior chemical floods with Hepler oil and core. Surfactant concentration was reduced in an effort to improve economics and reduce frontend costs during the field pilot test. Minimum IFT was about $90 \mu \mathrm{N} / \mathrm{m}$, and was fairly insensitive to the $\mathrm{NaHCO}_{3}$ concentration.

Injection and propagation of a slug of brine ( $0.3 \mathrm{PV})$ containing $\mathrm{NaI}$ tracer was monitored with the CT scanner. The results indicated considerable dispersion, but gross channeling of injected fluid was not observed. After displacement of the tracer-containing slug, the core was oil flooded to residual water saturation and again monitored by CT. Brine was displaced by the oil without observing any gross channeling. The next step will be to waterflood, followed by chemical flooding.

Milestone 3-Completed.

Milestone 4-Final report preparation was continued with a written section on the accomplishments of surfactant-enhanced alkaline flooding research during this year, which will be a part of Chapter 4 of the NIPER final report.

\section{Manpower and Financial_Status}

Manpower and financial expenditures are on schedule.

\section{Status of Project Milestones}

Milestone 3 was completed in March with presentation of project results at the Tenth TORP conference in Wichita, KS, and at the FDD sandstone reservoir workshop in Norman, OK. The other project milestones are on schedule. 
BEAC

FINACLAL STATUS OF TER PROJECT FOR APRIL

Total Appropitation:

Lem Capital Equipenent:

Appropertation Balance:

Expenditures for the Month:

Total Expendtitures to Date:

Net Avallable:

Cupitul Equifenent Expenses and Committs:
2,100

237,900

240,000

28,560

124,572

115,428

o
Annad Plan Project BEAC

Mobnity Control and Sweep Improvement

in Chemical Floodting
Fimunetai Sthtos

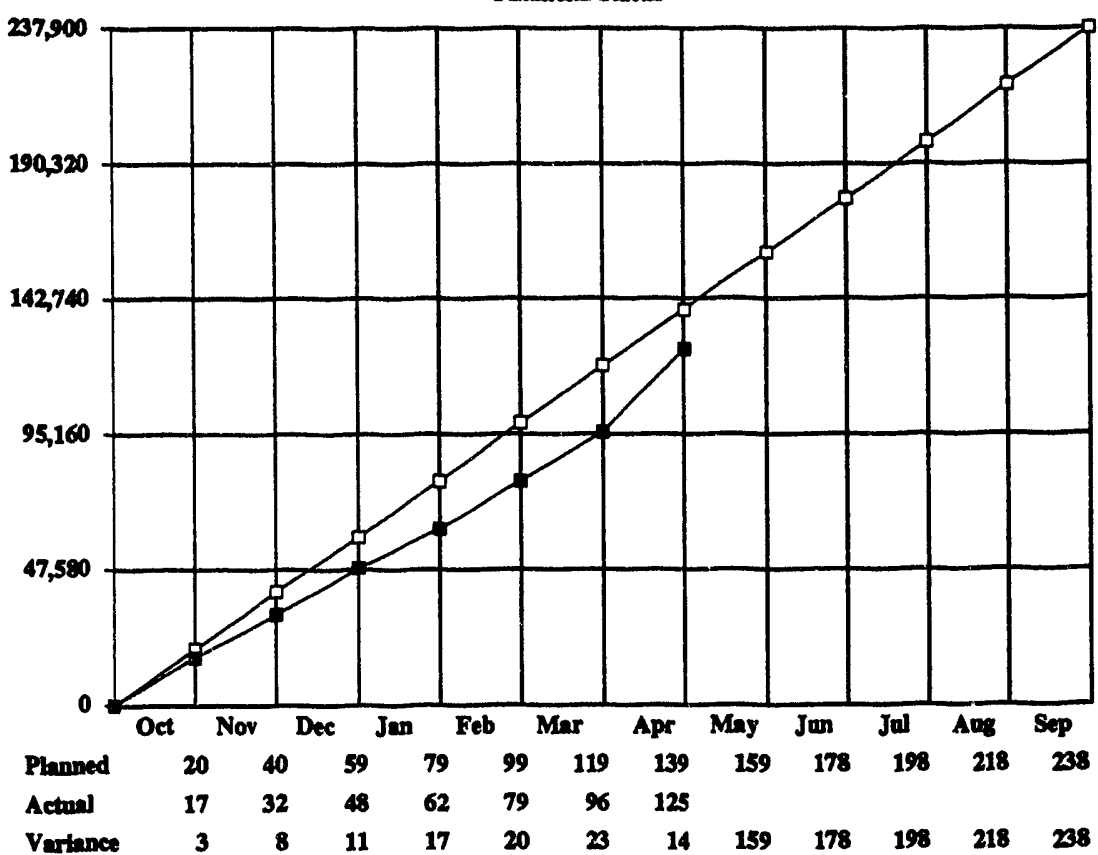

MANPOWER STATUS OF THE PROJECT FOR APRII

Total Man-hours:

Men-hours weed this Month

Toul Mnp-hours ased to Date:

Net Avallable:

2,340
1,436
904

Lezend for Koy MBestones

$X=$ Wart Completed

$\mathbf{C}=$ Plamed Completion Date

$C=$ Revined Completton Date

C"s Completed Alead of Seliedule

Foy Milleatone Statios

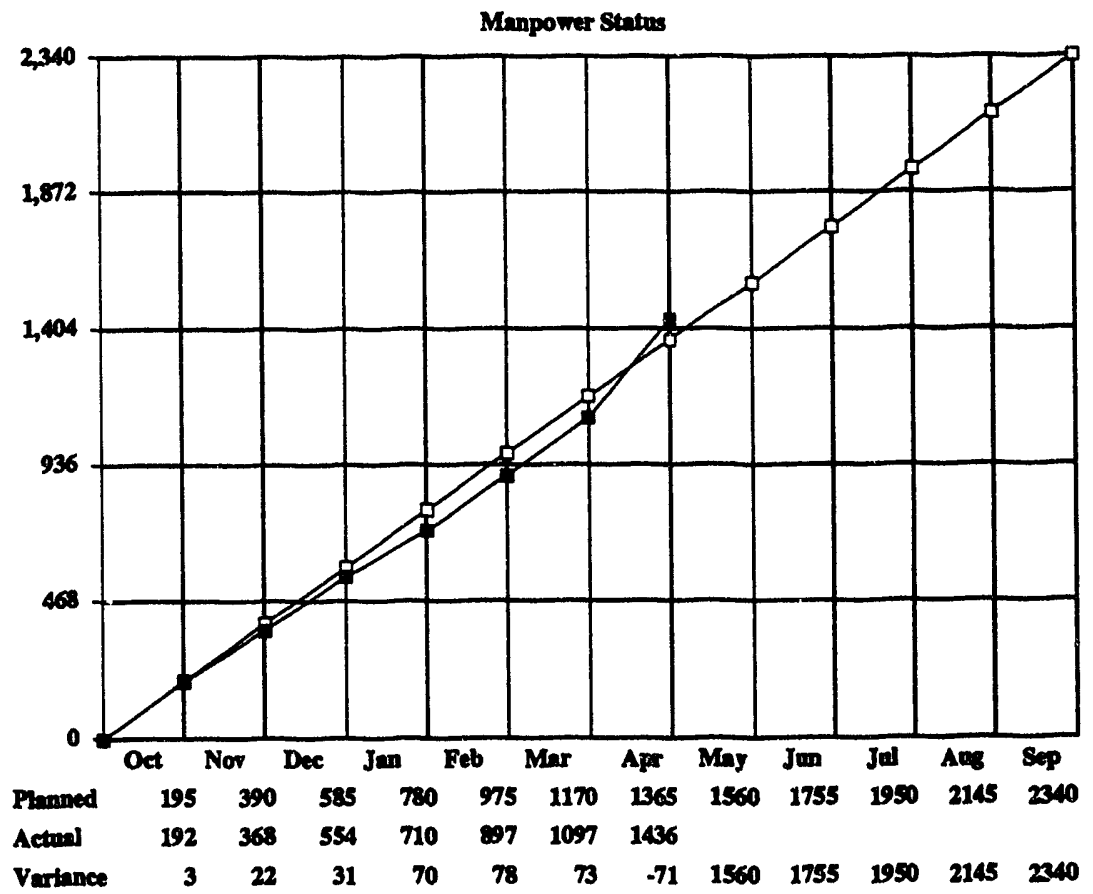

Xxc

XXX XXX XXX XXX XXX XXX XXX C

$\mathbf{X X X}$ $\mathbf{X X X} \mathbf{X X X} \quad \mathbf{X X X} \times \mathbf{X X X} \times \mathbf{X X X}$ C C $\mathbf{X x X} \mathbf{X x x} \times \mathbf{X x x}$ C C 


\section{BE4C. MOBILITY CONTROL AND SWEEP IMPROVEMENT IN CHEMICAL FLOODING}

\section{Accomplishments}

The objectives of this project are to develop improved methods for maintaining effective mobility control throughout the reservoir in chemical flooding and to use NIPER's permeability modification simulator to design a cost-effective gel treatment using polymer gel systems. Specific objectives in FY93 are (1) to determine the effect of lamination angle on polymer retention in unfired Berea cores, (2) to compare simulation results using the permeability modification simulator with field performance, and (3) to convert the permeability modification simulator for use with an BM-PC/80386 or compatible microcomputer.

Milestone 2-Brine permeability measurements and a coreflood were conducted on an unfired rectangular Berea sandstone core to determine the permeability and level of polymer retention. The core had dimensions of $23.88 \mathrm{x}$ $3.81 \times 3.81 \mathrm{~cm}$ and was cut at $30^{\circ}$ from the direction of laminations. The porosity was $19 \%$ and brine permeability was $160 \mathrm{mD}$. The brine was made with $2 \% \mathrm{KCl}$. A $3.5 \mathrm{PV}(232 \mathrm{~mL})$ slug of $\& 1,000$-ppm biopolymer solution in $2 \% \mathrm{KCl}$ was then injected and followed by $9.93 \mathrm{PV}(657 \mathrm{~mL})$ of $2 \% \mathrm{KCl}$. The injection rate used was $3.8 \mathrm{~mL} / \mathrm{hr}$ or $1.08 \mathrm{ft} / \mathrm{d}$ (apparent shear rate $=10 \mathrm{sec}^{-1}$ ). Results showed that the maximum amount of polymer retention during polymer flow was $1,143 \mathrm{~kg} / \mathrm{acre} / \mathrm{m}$, compared to $1,200 \mathrm{~kg} / \mathrm{acre} / \mathrm{m}$ in an unfired Berea sandstone core that was cut along the direction of laminations. This amount was $40 \%$ higher than that in a similar but fired Berea core (816 $\mathrm{kg} / \mathrm{acre} / \mathrm{m}$ ). The post-brine flood showed that irreversible polymer retention was $370 \mathrm{~kg} / \mathrm{acre} / \mathrm{m}$, which was lower than that in an unfired Berea sandstone core $(402 \mathrm{~kg} / \mathrm{acre} / \mathrm{m})$ also cut along the direction of laminations.

Milestone 3-Analysis of the field data from a pilot field that had been treated with gelled polymer showed that more information on the top zone would be required in order to determine the permeability distribution. This additional information was requested from an independent oil producer.

Milestone 5-The first draft of the mini-summary and analysis of research results on polymer flooding and permeability modification obtained during the past 9 years, along with recommendations for future research on polymer flooding and permeability modification, has been completed and is in review.

Manpower and Financial_Status

Manpower and financial expenditures are on schedule.

Status of Proiect Milestones

Pmject milestones are on schedule. 
FINANCIAL STATUS OF THE PROJECT FOR APRIL

Tulal Apperopratition:

Leser Capital Equipment:

Appropitation Balance:

Expenditures for the Month:

Total Expenditures to Dates

Net Avallable:

Cupital Bquipenent Expenses and Commits:

30,000

220,000

250,000

30,057

150,939

99,061

7,916
Annoul Plan Project BRSA

Gas Flood Performance Prediction

Improvement

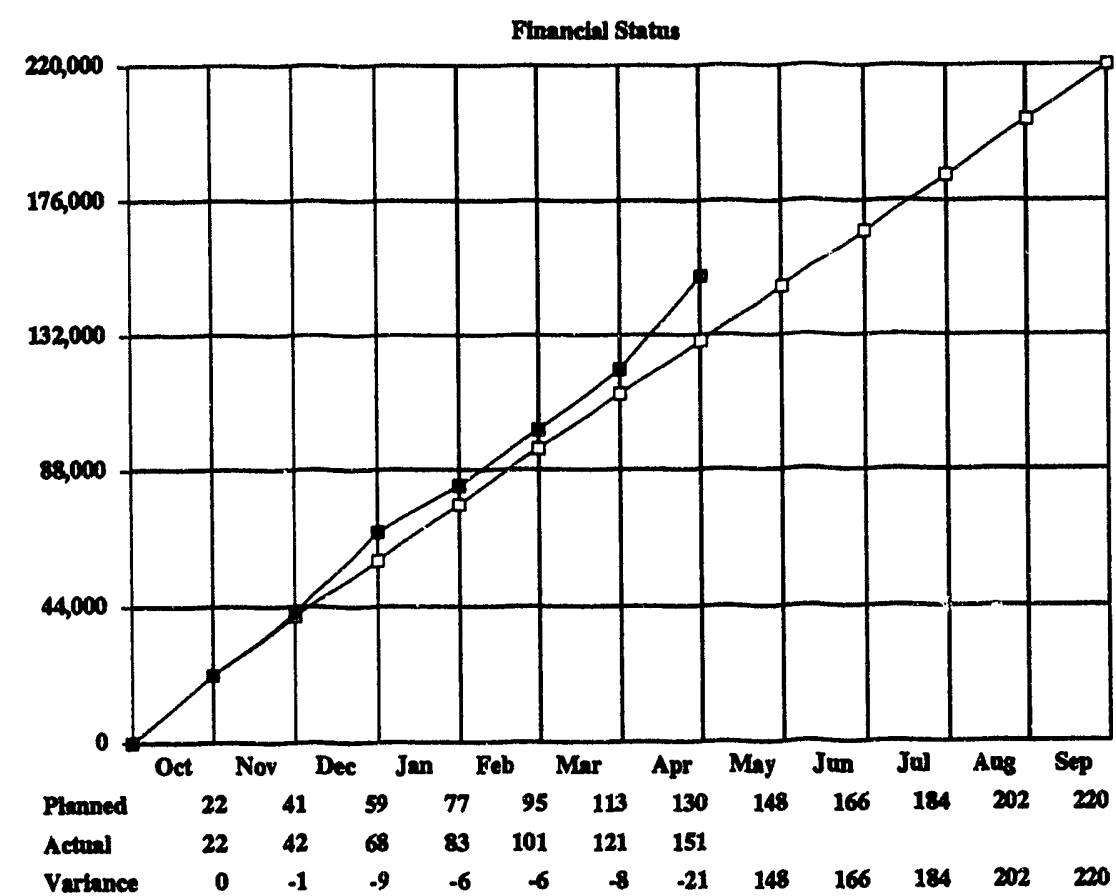

MANPOWER STATUS OF THE PROJECT FOR APRIL

Total Men-boxis:

Men-hours used this Month:

Total Mon-bours nsed to Date:

Nat Avallabie:

2,560
1,415
1,145

Legand for Koy Milectones

$\mathrm{X}=$ Work Completed

C a Finmed Completion Dute

$\mathrm{C}=$ Revied Completion Date

$C^{\prime \prime}=$ Compieted Ahead of Schedule

\section{Koy Mileatone Statns}

\section{0 \\ 1,415 \\ 145}

1 Sabmt Status Report on Envtrommental, Safety, and Health Revier 2 Complete Conetruetion \& Testing of High-Preseare IFT Measurement Apparatus

3 Finalize Studies on PVT Determination of Carbon Dioudde Partitioning Between Hydrocarbon \& Water Phases at Selected Temperature \& Prescure Condtitions

4 Complete IFT Measurements for Water-Hydrocarbon Systems

5 Prepare Chapter for NIPER Final Report Summarteing Accomplishments of Project BESA (Drait Complete by Aprll 15)

6 Tapical Repart Describling Experimental Tochniques \& Carrelations Doveloped for IFT and Carton Dioudde-Partitioning Mensurements
$\mathbf{X X X} \times \mathbf{X X C}$

$\mathbf{x x x} \times \mathbf{x x} \times \mathbf{x x} \times \mathbf{x x c}$

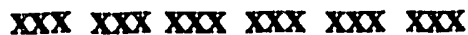

C $\mathbf{X X X}$ C

$\mathbf{x x x} \mathbf{x x x}$ C 


\section{BE5A. GAS FLOOd PERFORMANCE PREDICTION IMPROVEMENT}

\section{Accomplishments}

The objective of this project is to improve prediction techniques for gas miscible displacement through fundamental research in displacement mechanisms. The FY93 studies are to determine (1) the effects of $\mathrm{CO}_{2}$ partitioning in oil and water phases and (2) the significance of $\mathrm{CO}_{2}$ dissolution on water-oil interfacial tension (IFT) and relative permeability.

Milestone 3-Before completing IFT measurements of $\mathrm{CO}_{2}$ systems, the solubilities of $\mathrm{CO}_{2}$ in the aqueous and oil phases have to be determined. To this end, a prediction technique for $\mathrm{CO}_{2}$ solubility in water and brine is being developed.

Milestone 4-Calibration of the equipment for measuring IFT is in progress. The surface tension of pure water at $10^{\circ}$ to $40^{\circ} \mathrm{C}$ and the IFT of n-pentane with water at $25^{\circ} \mathrm{C}$ have been measured successfully and match data reported in the literature. However, the present repeatability of some measurements is unacceptable, and additional tests will be required to assure the IFT measuring method can provide reliable and reproducible data.

Milestone 5-The revised draft of the chapter on gas flooding research has been prepared and is in review.

Manpower and Financial Status

Manpower utilization is on schedule, but financial expenditures are high by $16 \%$ due to concentrated efforts in developing the IFT apparatus and prediction techniques.

\section{Status of Project_Milestones}

Milestones 1 and 2 have been completed. The other milestones are on schedule. 
FINANCIAL STATUS OF TEE PROJECT FOR APRIL

Total Appropration:

Lom Cuptial Equipment:

Appropratition Bahnce:

14,500

360,500

Expendtures for the Month

Total Rexpendetures to Date:

Net Avallable:

Capltal Equipment Rupenses and Commits

Annual Ptan Ploject BESB

Mobility Control, Provele Modification,

and Sweep Improvement in Gas Fooding

MANPOY:RR STATUS OF THE PROJECT FOR APRII

Total Mon-hours:

Min-hours raed this Meath:

Total I Lan-hours noed to Date:

Net A venloble:

531

4,872

2,322

2550

375,000

41,617

217,419

157,581

o
Legend tor Koy Milectones

$\mathbf{X}=$ Wart Cornpleted

$C=$ Pbronod Completion Dute

$C=$ Revinad Cumpiettion Date

C'm Completed Ahead of Sebedule

Key Miledone Statas

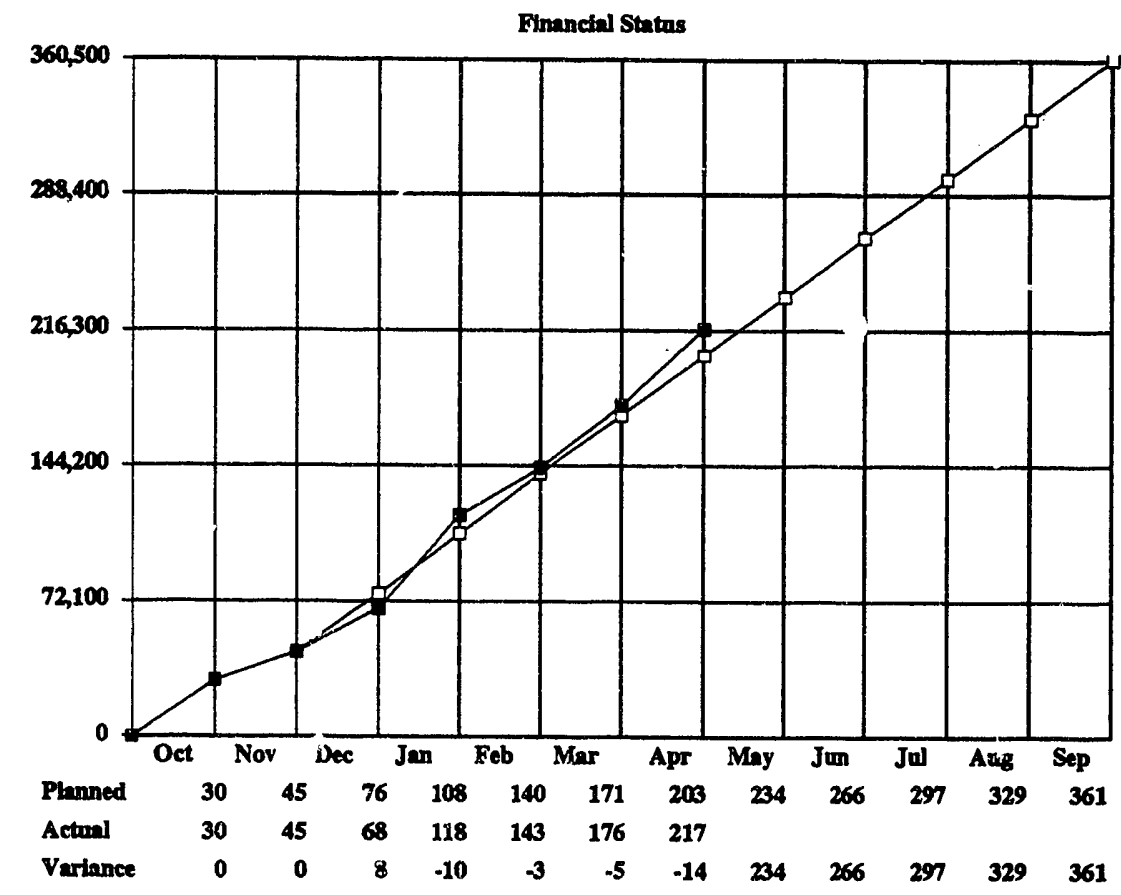

Manpower Status

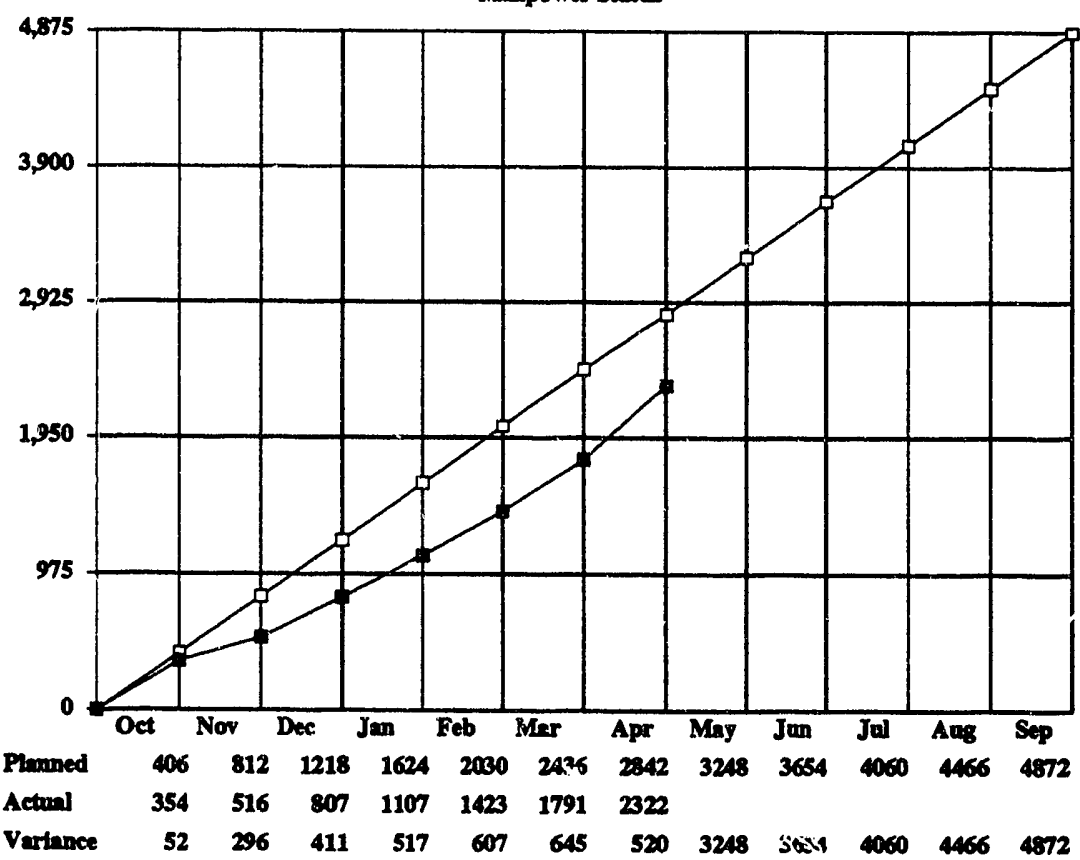

I Sabialt Sutus Report on Project Bnviroammatal, Safety, and Health Anemanint

$\mathbf{x x x} \mathbf{X x C}$

2 Complete Fearlbalty Evalmotion on Use of Alcohol-Ind ceat Salt Prectptution for Procile Modification; Determbe Phase Behavior 2. Salt Prectpitation of Alochol-berne Syztems

3 Complete Studies on Pleepheg of Parous Medth by Alcohol-Induced Salt Prodptitation

4 Prepare Chapter fer NIPER Final Report Surmartatrs Accomplinhmeats of Project BE5B (Drat Complete by Aprll 15)

5 Coanplete Proile Modification Determinations Using Polymer Gets and/er Alechoi-indaced Salt Prectpitation

6 Status Repart Deacribug Reanits of Pronle Modification Studies

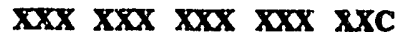

$\mathbf{X X X} \quad \mathbf{X X X} \quad \mathbf{X X X} \quad \mathbf{X X X} \quad \mathbf{X X X} \quad \mathbf{X X X}$ C

$\mathbf{X X X} \mathbf{X X X} \mathbf{X X X}$ c

$\mathbf{x x x}$ C 


\section{EE5B. MOBILITY CONTROL, PROFILE MODIFICATION, AND SWEEP IMPROVEMENT IN GAS FLOODING}

\section{Accomplishments}

The objective of this project is to develop methods for improving sweep cfficiency in gas flooding. Proposed methods for profile modification include the use of polymers, in situ formation of polymer gels, and by precipitation of salts and chemicals.

Milestone 3-Coreflood tests with salt precipitate and ethanol are continuing in order to determine the effects of longer intervals of shut-in time on increased crystal growth and improved permeability reduction. Shut-in times of several weeks duration appear to gradually decrease the permeability.

Other corefloods were conducted with cores at irreducible oil saturation. The cores were then treated with saturated brine and 10\% PV ethanol and shut in for 5 days. A waterflood following the brine/ethanol treatment did not produce any additional oil. These corefloods will be continued using a larger quantity of ethanol.

Milestone 4-A draft final report for gas flooding research has been prepared and is in n:view.

Milestone 5-Testing continued on other polymer systems having potential as profile modification agents for $\mathrm{CO}_{2}$ flooding. Preiiminary tests were made with Curdlan. This biopolymer is soluble only in basic solutions. Solutions of Cur dlan thickened and increased in viscosity by decreasing the solution pH. For example, solutions of $0.5 \%$ polymer in 1.0 and $0.1 \mathrm{I} \mathrm{NaOH}$ had viscosities of 2 and $9 \mathrm{cP}$, respectively. A gel was formed at a pH of about 9. $\mathrm{CO}_{2}$ was contacted with the polymer solution to decrease the solution $\mathrm{pH}$, and the gaseous $\mathrm{CO}_{2}$ reduced the solution $\mathrm{pH}$ sufficiently to form a stable gel. About 5 pore volumes of gaseous $\mathrm{CO}_{2}$ were required to form a gel with a $0.1 \mathrm{~N} / \mathrm{JaOH}$ solution. Properties of this polymer may be useful for profile modification of highpermeability zcines in the formation. These properties include a low solution viscosity during injection, and a gel formation whell the solution is contacted by the $\mathrm{CO}_{2}$ fiood. However, the desirable property of low viscosity during injection would initially require a highly basic polymer solution.

\section{Manpower and Financial_Status}

Financial expenditures are on schedule. Manpower is temporarily below planned projections due to commitments to other DOE projects.

\section{Status of Proiect Milestones}

Project milestones are on schedule. 
FINANCLAL STATUS OF TER PROIECT FOR APRII

Tetal Appreptation:

Lem Copltal Equitpment:

Approprtation Balance:

30,000

310,000

Expendifures for the Month:

Total Expendttures to Dates

Nat A villable:

Cupltal Bqudpment Espenses and Conmits:

Annull Phan Project BEg

Three-Phase Relattive Permeability

Research
340,000

50,153

219,647

120,353

4,745
Finandel Stutus

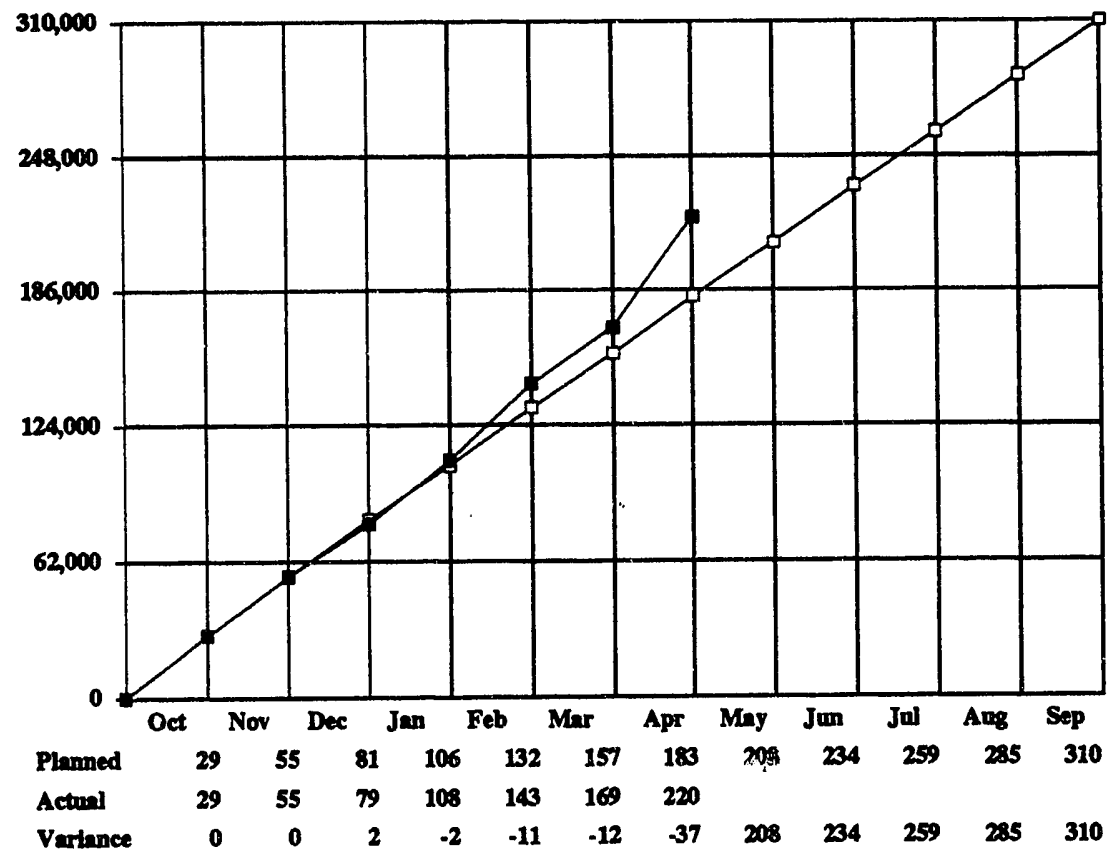

MANPOWER STATUS OF THE PROJECT FOR APRI

Total Man-hours:

Mon-hours used this Month:

Total Man-hours wed to Date:

Net Avalluble:
695

3,780

3,355

425
Legend for Key Mileatones

$X=$ Wark Completed

$C=$ Planned Completion Date

$C=$ Revised Complettion Date

$C^{\prime \prime}=$ Completed Ahead of Schedule

Key Millestone Status

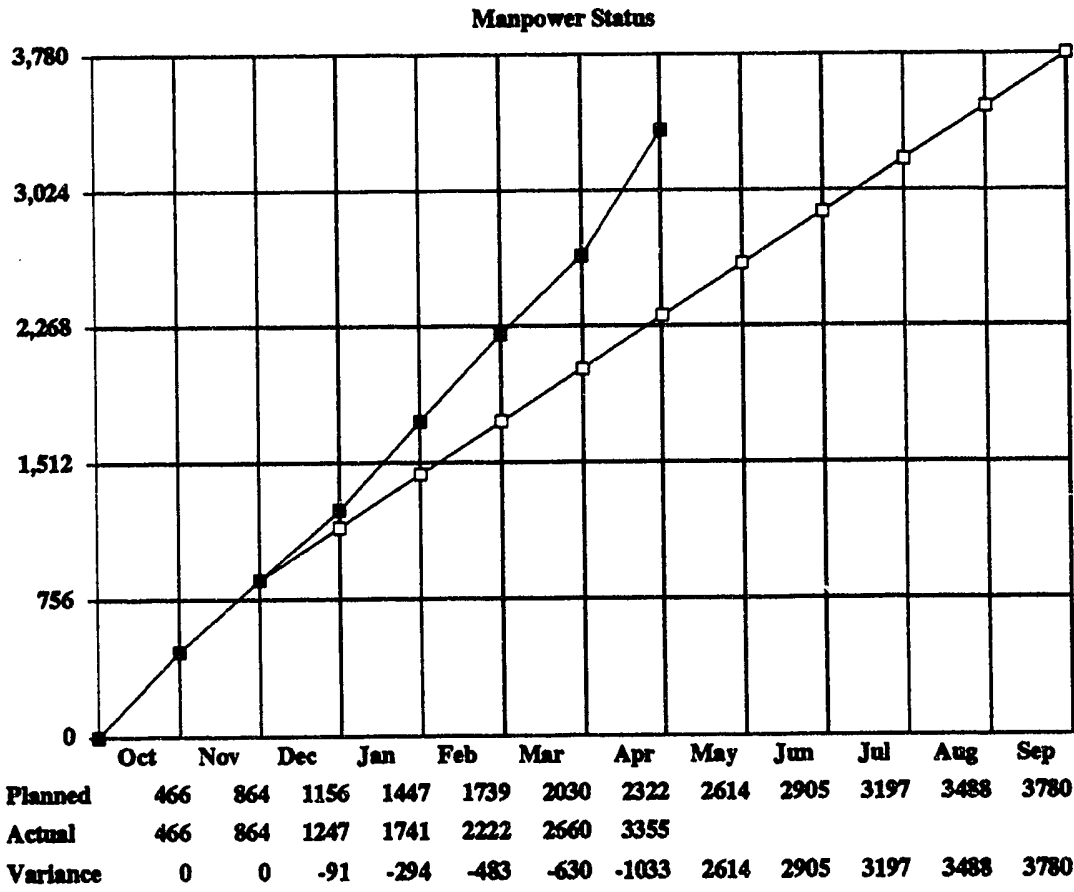

1 Submit Status Report on Environmental, Safety, and Hewith Acesoment

2 Complete Multiphase Relative Permeability Tests at 150 Degrees F on Almond Formation Rock

3 Select \& Charactertze Rock for FY93 Expertmental Program

4 Complete Dedign of Test Fluid \& Equipment for Use in Measuring IFT Under Selected Canditions of Temperature \& Pressure

5 Conclude FY93 Multiphese Relative Permeablitty Experments at

Elevated Condtitions of Temperature \& Pressure

6 Complete Development of Carellood Stmulator

7 Prepare Chapter for NIPER Final Report Summarizing Project

Accomplishments (Drat Complete by Aprll 15)

8 Toploal Repart Deseribing Twa- and Three-Phase Rehative

Permeability \& Other Ërperimenitai Resaits
$\mathbf{X X X} \mathbf{X X C}$

XXX $\quad$ XXX XXX XXC

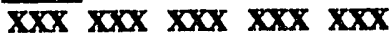
$\mathbf{C}$

$\mathbf{x x x} \quad \mathbf{x x x} \quad \mathbf{x x x} \times$

$\mathbf{X X X} \mathbf{x x \mathbf { x }}$ $\mathbf{X X X}$

C

$\mathbf{X X X} \mathbf{X X X}$ C

$\mathbf{X X X} \mathbf{X X X} \mathbf{X X X} \times \mathbf{X X X}$ 


\section{BE9. THREE-PHASE RELATIVE PERMEABILITY RESEARCH}

\section{Accomnlishments}

The objectives of this project are (1) to improve the reliability of laboratory measurements of three-phase relative permeability for steady- and unsteady-state conditions in core samples; (2) to investigate the influence of rock, fluid, and rock-fluid properties on two- and three-phase relative permeabilities; and (3) to expand the state of the art for measuring relative permeabilities at higher temperatures and pressures.

Milestone 3-Capillary pressure tests will be performed next month.

Milestone 4-A fluid system consisting of methane, propane, and bromopropane is in design. Permeameter designs are under evaluation.

Milestone 5-Laboratory flow tests have been designed, and experiments are expected to start during the next reporting period.

Milestone 6-The Gateway 2000 Model 486DX2/66V computer system was received at the beginning of the month. This computer is equipped with 32 MBytes of memory, a 340 MByte hard drive, and a very fast video adapter with a 38.1-cm color monitor. The hard drive and video adapter operate off a VESA local bus system and provide very fast response. The computer is also equipped with a CD-ROM drive and a tape-cartridge drive for backup. The computer was provided with the DOS 5.0 and Windows 3.1 operating systems. The computer has since been equipped with a beta version of the OS/2 2.1 operating system from IBM. While there are a few bugs in this operating system, it appears to be very versatile, being able to run DOS and Windows 3.1 programs together with OS/2 programs with true multi-tasking. All of the software currently available on DOS or Windows 3.1 appears to run with no problems. Two versions of the Microway FORTRAN compilers-one for DOS extenders and one for OS/2 2.x-have been installed on the computer. These have been used to compile a version of the BOAST simulator for both systems. Some time was required to modify the source code to obtain a working simulator.

The compiled BOAST simulator has been tried on several one- and two-dimensional (1-D and 2-D) simulations. On 2-D data sets involving approximately 3,000 grid blocks, the simulator takes about 30 minutes to perform 600 trials before reaching terminating conditions. For a 1-D data set involving 40 grid blocks, the simulator takes 33 seconds to do approximately 1,000 trials before reaching endpoint. During this 33 second run, the simulator output 36 data files showing the 1-D oil, water, and gas saturations and how the flood front traversed the length of the model during the simulation. Now that the simulator is working properly, it will be used to study 1-D and 2-D models based on permeability, porosity, capillary pressure, and saturation distributions representative of real rock systems under study in the laboratory.

Milestone 7-A first draft of the BE9 final report chapter has been completed.

\section{Mannower and Financial_Status}

Manpower and financial expenditures are above target levels and reflect the effort in meeting the early completion dates for milestones 3 through 6.

\section{Status of Project Milestones}

Milestone 3 is on schedule. Milestone 4 is behind schedule and has proven to be more difficult than anticipated. The other milestones are on schedule. 
BE11A

FINANCIAL STATUS OF THE PROJECT \& OR APRIL

Total Approputation:

Lees Cuptial Bgudpenent:

Appropertation Balanee:

Brpendturres for the Month:

Total Rxpanditures to Date:

Net Avilablo:

Cupital Equipment Expenses and Commits:

Annual Ptan Project BE11A

Thermal Processes for Light On Recovery

MANPOWER STATUS OF THE PROJECT FOR APRII

Total Mnn-bours:

Men-bours used this Month:

Total Man-hours used to Date:

Net Available:
3,429

457

2,875

554
300,000

39,362

234,871

65,129

$\mathbf{0}$
Legend tor Key Milledones

$\mathrm{X}=$ Wark Completed

$\mathrm{C}=$ Plamed Completion Date

$C=$ Revised Complettion Date

$C^{\prime \prime}=$ Completed Ahead al Scheduie

Key Millestone Status
Dinanctal Shatus

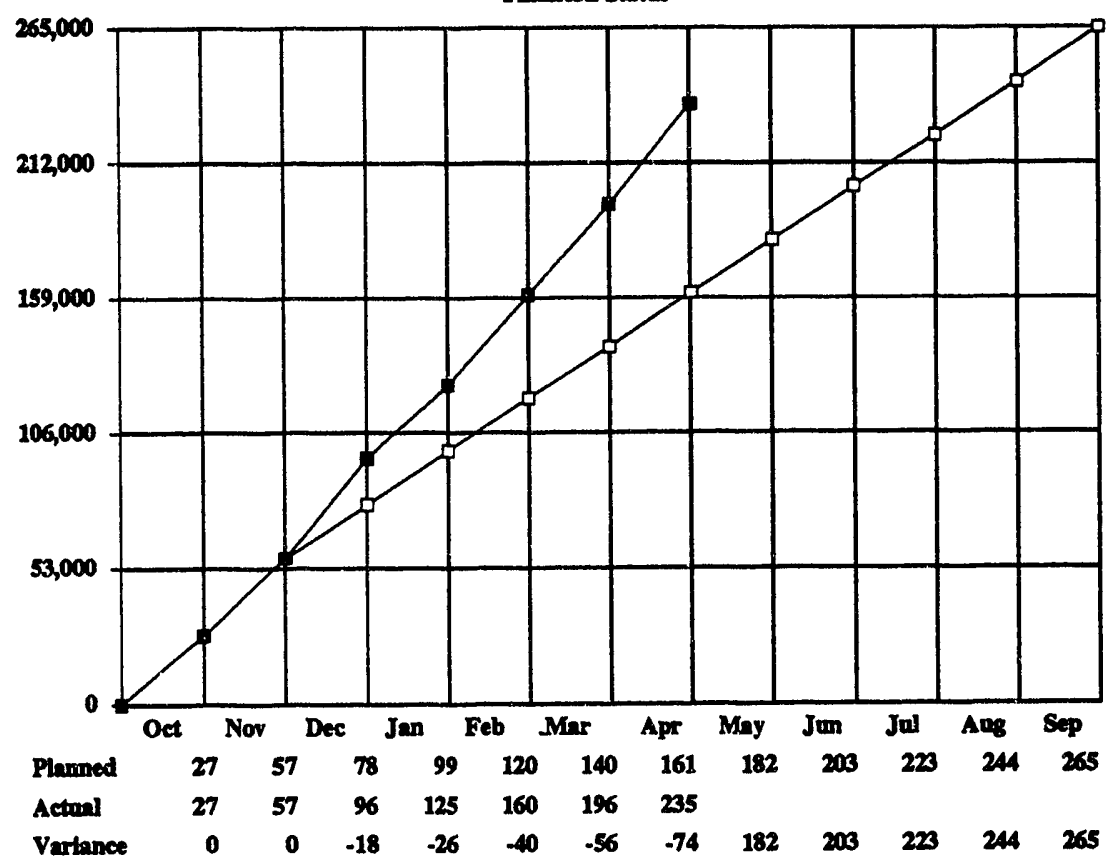

Menpower Status

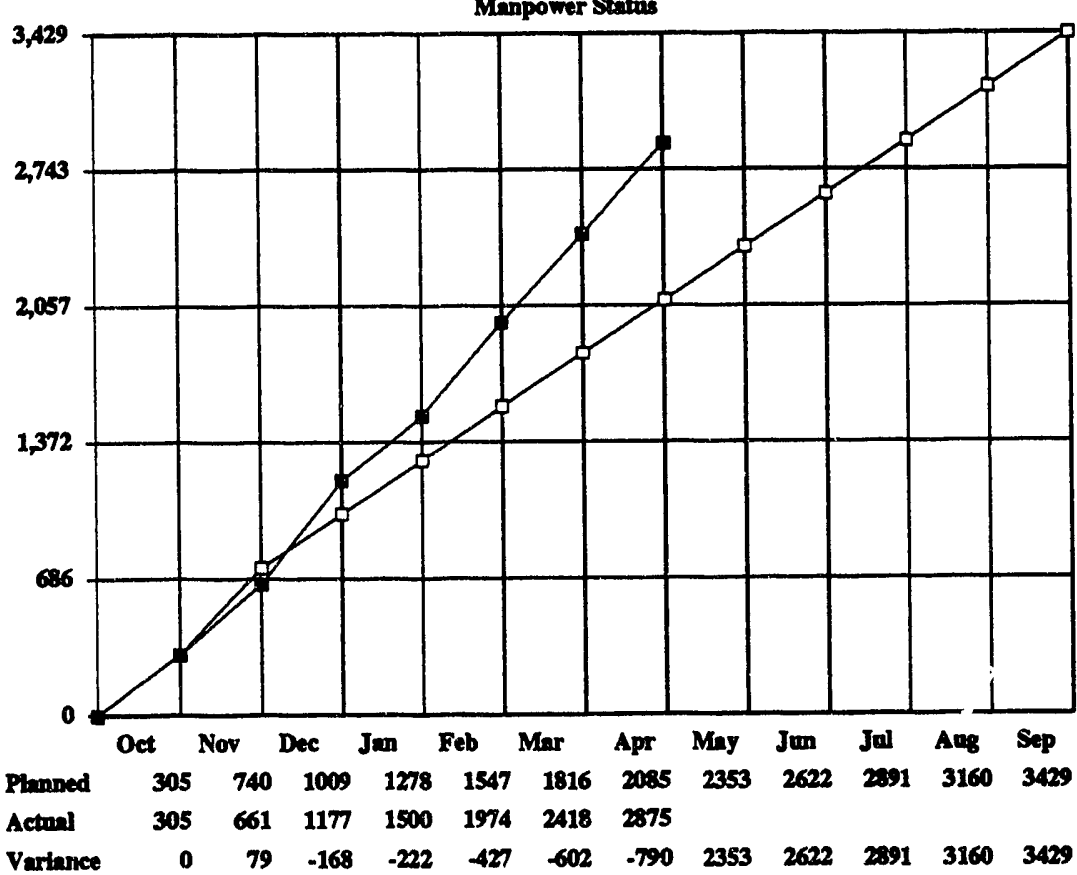

1 Submit Stutus Report ma Project Bnvirommental, Safety, and Heafth Amerinent

2 Topleal Repart on Ascesment of NIPRR Thermal EOR Research

Program Over Past Ten-Year Perlod

3 Complete Sopporting Research on Improved Steamfooding at NPR Na. 3, Teapot Dome (WY) Fiald

4 Develop Procedures \& Apparatus for Measuring Dynamic Saturntion Changes in Steamnooding Using X-ray \& CT-sennning

5 Prepare Chapter for NIPBR Final Report Summariaing Acemanplishments of NIPER's Thermal EOR Program (Drat by Aped 15)

6 Complete Trunder of Thermal Technology Developmental Resench Turough ANNEX IV of the DOEN enezuelen Cooperative Agreement 7 Topical Repart Desaribing Research on Thermal Proceses for Light OI Recovery

\section{$\mathbf{X X X} \times \mathbf{X X C}$}

$\operatorname{XXX}$ XXX XXX XXX XXC

$\mathbf{X X X} \mathbf{X X X} \times \mathbf{X X X} \times \mathbf{X X X}$ XXC

$\mathbf{x x x} \mathbf{x x x}$ $\operatorname{Xxx} \times x \times x \quad \operatorname{xxx}$ C $\operatorname{XxX} \times x \times x \times$ C

$\mathbf{X X X}$ $\mathbf{x x x}$ $\mathbf{X X X} \mathbf{X X C}$

$\mathbf{X x x} \mathbf{x x x} \mathbf{x x x}$ C 


\section{BE11A. THERMAL PROCESSES FOR LIGHT OIL RECOVERY}

\section{Accomplishments}

The FY93 objectives of this project are (1) to perform an environmental, safety, and health (ES\&H) analysis on project tasks; (2) to assess the thermal research performed at NIPER; (3) to develop procedure and apparatus for measuring dynamic saturation changes in steamfloods at field conditions using $\mathrm{X}$-ray and CT scanning and incorporate temperaturc and pressure measurements to calibrate a numerical simulator for predictive purposes; (4) to conduct laboratory research in support of NPR No. 3, Teapot Dome (WY) field light oil steamflood; and (5) to participate in the Annex IV meetings conducted by the DOE and the Venezuelan Ministry of Energy and Mines.

Milestone 2-In completion of this milestone, a topical report, entitled "Evaluation of NIPER Thermal EOR Research, State of the Art, and Research Needs," (NIPER 675) has been delivered to the BPO. This report summarizes NIPER's thermal recovery research over the past 10 years, analyzes contributions of the research, describes the transfer of the technology to potential users, defines current trends in thermal research and thermal oil production, and identifies areas where NIPER can contribute to future advances in thermal oil production.

Milestone 4-A safety review of the proposed new steamflood laboratory has been undertaken and a draft of the report is being reviewed. Submission of the proposal to NIPER management in May is anticipated.

Milestone 5-A draft of the results of the previous 10 years research at NIPER by the thermal group was prepared as a chapter for inclusion in NIPER's final report. The chapter is in review.

Milestone 7-A topical report on the software for laboratory control, data collection, automation, and analysis is being revised and will be submitted for review in May. This software, designed as NIPER LAB WARDEN, was developed as a general laboratory operating software that can easily be customized to meet individual laboratory or pilot plant applications. The topical report contains a guide to the software operation, a copy of the software, and a section to assist those wishing to customize their applications.

At the request of the BPO, three small business innovative research (SBIR) proposals on oil production technologies were reviewed during April.

\section{Manpower and Financia__Status}

Manpower and financial expenditures are high by 38 and $46 \%$, respectively, due to work required in preparing the 10-year reports for milestones 2 and 5. Only the DOE contractors review (July 18-22, 1993) and the topical report for milestone 7 remain to be completed.

\section{Status of Project Milestones}

Milestones 2 and 6 have been completed. All other milestones are on schedule. 
FINANCIAL STATUS OR 'THE PROJECT FOR APRIL

Total Appropitation:

Leso Copttal Bquipment:

Appropatation Balance:

Expenditures for the Month:

Total Expendtures to Date:

Net A vallable:

Capital Bquifoment Expenses and Commits:

Annual Plan Project BE11B

Thermal Processes for Heavy OIl Recovery

MANPOWER STATUS OR THE PROJECT FOR APRIL

Total Man-hourse

Mnn-homs need this Month:

Total Man-hours wed to Date:

Net Avaliable:

423

3,000

1,765

1,315
200,000

29,129

$119,0 \% 0$

80910

o
Legand for Koy Millestones

$\mathbf{X}=$ Work Completed

$C=$ Finned Completion Date

$C=$ Reviad Comphation Date

C" $=$ Completed Ahead of Schedule

Key Mileatone Statns
Rinuncilal Sutus

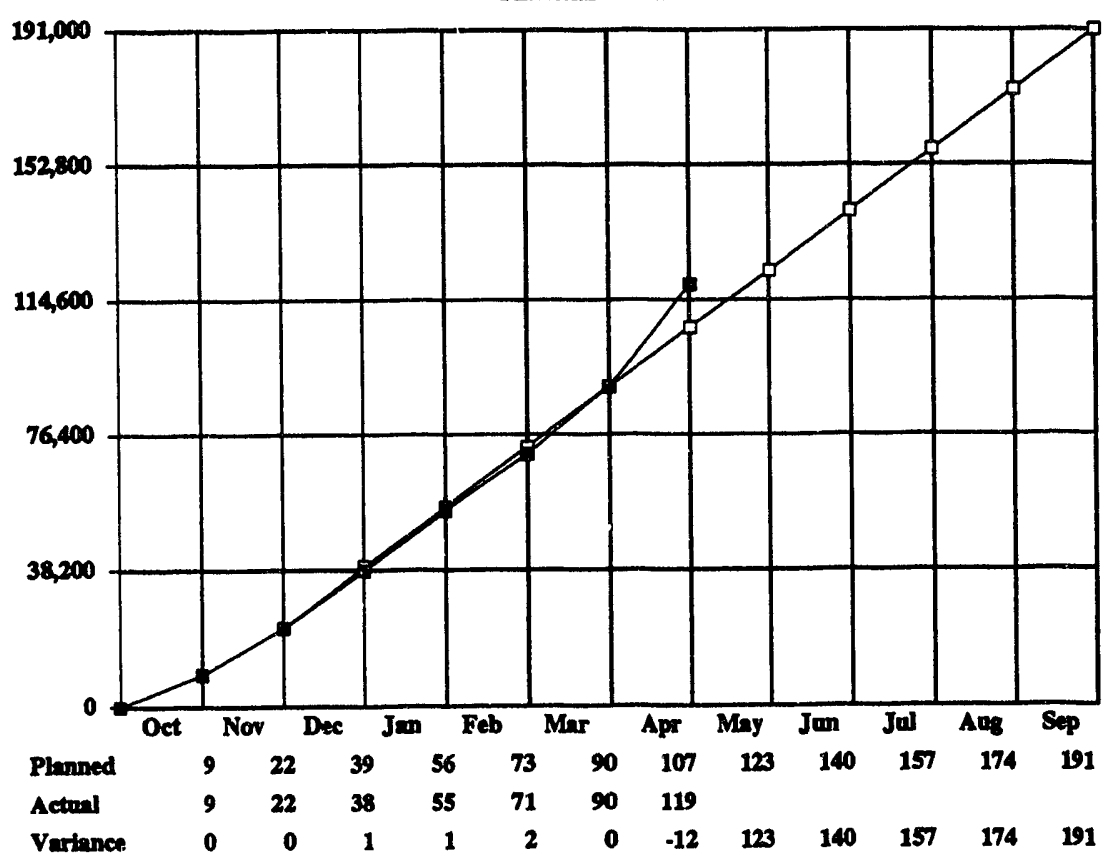

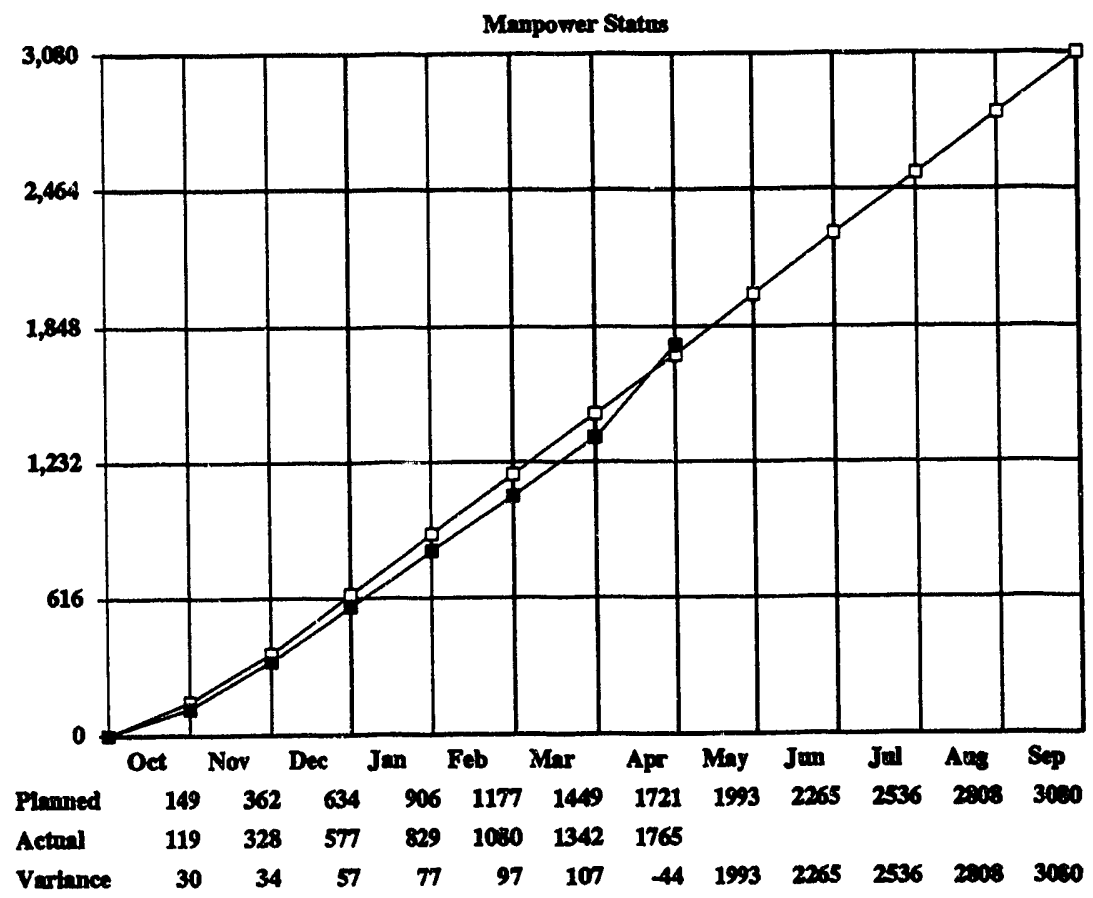

1 Submit Status Report on Project Buvtrommental, Safety, and Health Revien

XXX XXC

2 Complate Sereening \& Identification of Potential Heavy OA Reservolrs

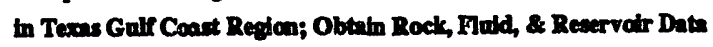
on Most Promisheg Recervotr

3 Topieal Repart on Asesument of NIPBR Thermal EOR Research

Proyram Over Past Ten-Year Perlod

4 Complete Bvaluntion of Mobn's Steamilood Predictive Model

5 Complete Modeling Studies to Determine Applicability of Thermal BOR for Recovery of Heavy 01 in Texes Golf Conet Reservoirs

6 Prepare Chapter for NIPER hmal Report (Drant by Aprll 15)

7 States Report on Reanits of Prodictive Model \& Stmulation Studies

$\mathbf{X X X} \mathbf{X X C}$

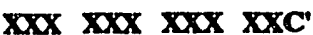

$\mathbf{X X X} \mathbf{X X X} \times \mathbf{X X X}$ $\mathbf{C}^{\prime}$

$\operatorname{XXX} \mathbf{X X X} \times$

$\mathbf{X X X} \mathrm{XXX} \mathbf{X X X}$ C 


\section{BE11B. THERMAL PROCESSES FOR HEAVY OIL RECOVERY}

\section{Accomnlishments}

The FY93 objectives are (1) to analyze the NIPER heavy oil data base to screen Texas Gulf Coast reservoirs for priority ranking and (2) to conduct modeling and reservoir studies to determine the applicability of thermal enhanced oil recovery techniques in Texas Gulf Coast heavy oil reservoirs.

Milestone 3-The topical report for the 10-year assessment of thermal EOR research (NIPER-675) was delivered to BPO and completes work scheduled for this milestone.

Milestone 4-The assessment of Mobil's steamflood prediction model is in progress.

Milestone 5-Numerical simulation of a steamflood in the Taylor-Ina (TX) field is in progress. The feasibility of improving steamflood performance with $\mathrm{CO}_{2}$ as an additive is being investigated. A literature survey of a steamflood using $\mathrm{CO}_{2}$ was undertaken to collect the requisite data for simulation. The Computer Modeling Group's phase behavior model (CMG PROP) will be used in modeling the $\mathrm{CO}_{2}$-steam phase behavior.

Milestone 6-A chapter on thermal EOR research activities for inclusion in NIPER's 10-year report was submitted to NIPER management for review on April 15, 1993.

At the request of BPO, project staff reviewed seven Small Business Innovative Research proposals.

\section{Manpower and Financial_Status}

Manpower utilization is on schedule, but financial expenditures are high by $11 \%$ and reflect staff involvement in preparing the 10-year research report.

\section{Status_of Project_Milestones}

Milestone 3 was completed. The other project milestones are on schedule, 
FINANCUL ETATUS OP TER PROJECT FOII APRI

Total Appropstation:

Lem Coptual Bgutpment:

Appropintattion Babunces

8,000

Expendtures for the Month:

30,000

Total Expenditures to Dater

Net Avelabier

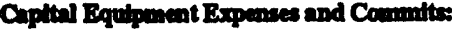

Annoul Pran Praject BE12

Imenge Techniques Applied to the Strody

chides ton Parons Media

350000

44602

240,249

105,751

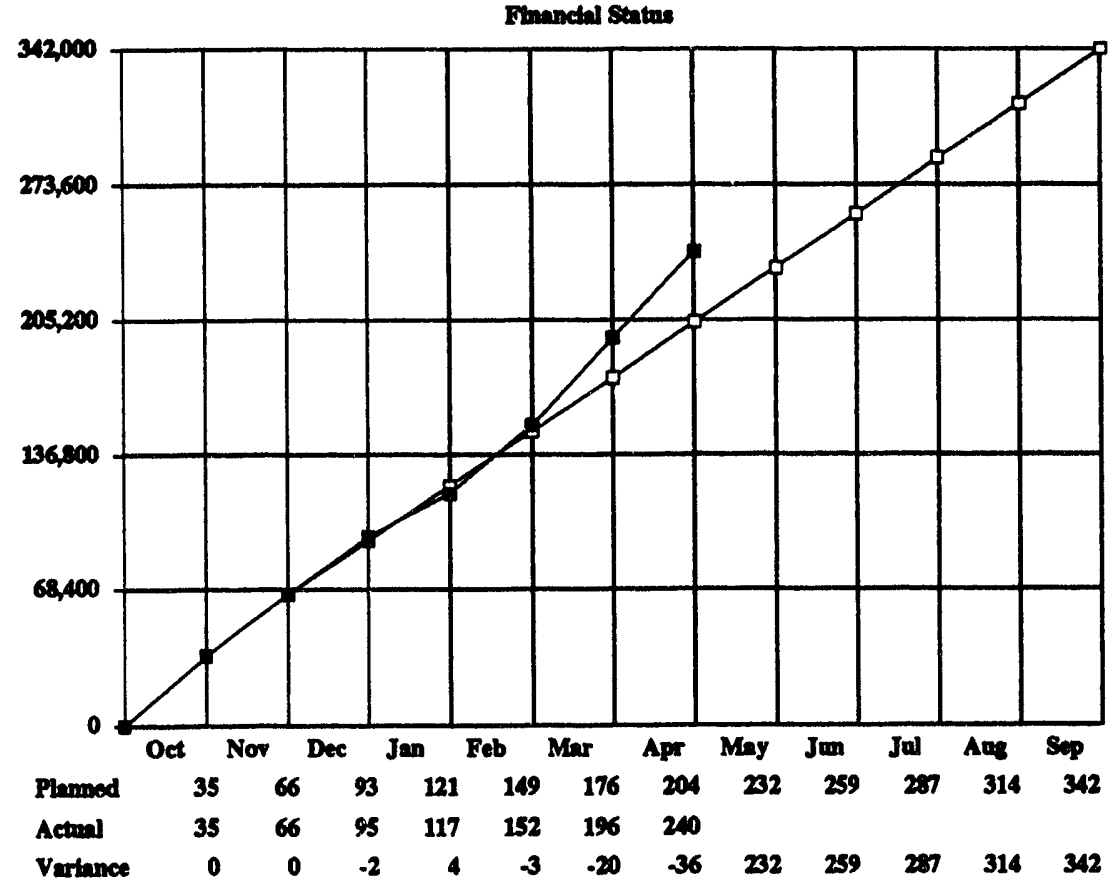

MANPOWER STATUS OR THE PROJECT FOR APRII

Total Man-bows:

Mon-hours med this Month:

Total Man-hours ued to Date:

Net Aviliable:
606

3,164

1,156
Lepend tor Key Milestones

$\mathrm{X}=$ Wark Couploted

$C=$ Pramed Completion Date

$C=$ Revined Conpletion Date

C'= Completed Alead of Schedule

Bey Milleatone Status

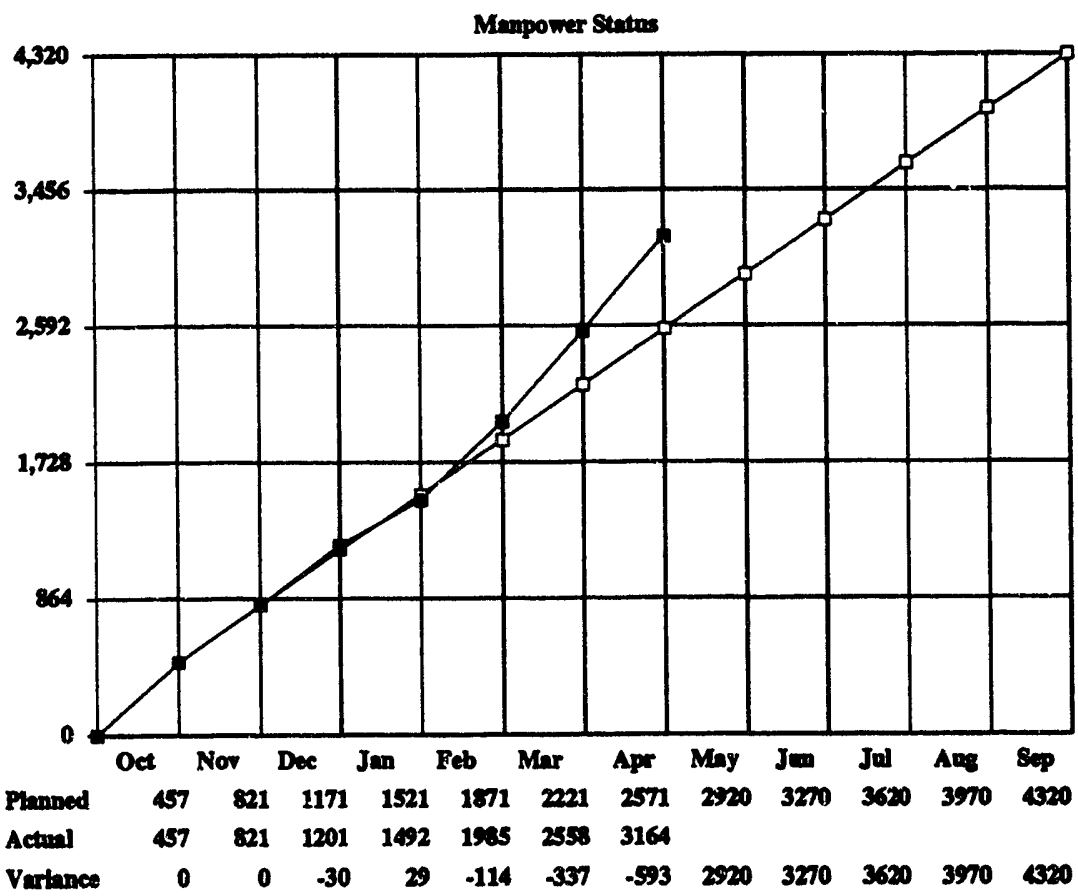

$\operatorname{xxx} \mathbf{x x c}$

$\mathbf{X x X} \mathbf{X x C}$

$\mathbf{x x x} \mathbf{x x x} \times \mathbf{x x x} \mathbf{x x x}$ $\mathbf{C}^{\prime}$

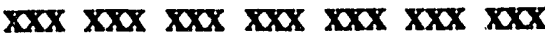
C

XXX XXX XXX XXX XXX XXX XXX C XXX XXX XXX C
C 


\section{BE12. IMAGING TEChNIQUES APPLIED TO THE STUDY OF FLUIDS IN POROUS MEDIA}

\section{Accomplishments}

The objectives of this project are: (1) to develop and correlate reservoir engineering parameters from petrographic image analysis, computed tomography (CT) scanning, and nuclear magnetic resonance imaging (NMRD; (2) to investigate the applicability of imaging technologies in the development of scale-up procedures from core plug to whole core to interwell scale; (3) to develop an industry consortium or industrial advisory panel organized to help plan, review, and participate in the research through the Work-For-Others program and to provide for effective technology transfer, and (4) to strongly encourage collaborative research by industrial participants.

Milestone 3-Because of the possibility of conducting joint imaging research with a major oil company, a request to extend the completion date of this milestone until July 1 has been submitted to the BPO for approval.

Milestone 4-The drainage cycle for relative permeability measurements in a heterogeneous Tallant sample has been nearly completed. Permeability and saturation distributions for fractional oil flow rates of $0.02,0.05,0.1$, $0.2,0.4,0.7,0.9$ have been measured for the $26 \mathrm{cP}$ oil viscosity, and analysis of the data is in progress. Preliminary analysis indicates a possible correlation between the porosity of various rock laminations and the saturation distributions at the various fractional flow conditions.

Milestone 5-Two sizes of small-bore glass capillary tubing have been acquired for NMRI studies of systems having mixed wettabilities. The smaller-bore tubing, 530-microns OD and 140-microns ID, will be cleaned with acid to achieve water-wet conditions. The larger-bore tubing, 630-microns OD and 210-microns ID, will be converted to an oil-wet condition by heating for several hours (at elevated temperatures) while in contact with oil. By blending the two types of tubing into a bundle using Teflon shrink tubing, NMRI phantoms will be made containing both water- and oil-wet surfaces. These phantoms will be used to investigate the feasibility of using NMR microscopy to identify the wettability of specific locations in systems of mixed wettability. In the NMR images, the nature of the surfaces will be identified by the size of the capillary tubing.

Milestone 6-A first draft of the rock-fluid imaging research chapter (containing results and accomplishments of project BE12 and earlier projects BE12A and BE12B) has been prepared for the NIPER final report.

Milestone 7-A paper, entitled "Imaging Technology Applied to Rock and Fluid Imaging in Cores, "will be presented as a part of the series of talks to be given at the New Technology for Independent Producers Workshop, to be held in Denver, CO, May 6-7, 1993. Contacts have continued with three major oil companies regarding cooperative research.

\section{Mannower and_Financial_Status}

Manpower and financial expenditures are higher than planned due to efforts required in meeting the completion dates for milestones 3 and 4.

\section{Status of Project Milestones}

A request to extend the completion date for milestone 3 to July 1, 1993, has been approved by the BPO. The other project milestones are on schedule. 
BFR2

FINANCUAL ETATUS OR IHE PROABCT FOR APRII.

Toed Appropertattea:

Lom Captial Bequpaneat:

Approprtation Balumete

Erpenditures tor tho Moaths

Totel Inpunditurn to Data:

Not Artiakso:

Coptul Equpenent Brponew and Commitu:

Dovelopenent of Amalyticel Methodology

for Amalytu of Heavy Crodies

0
300,000
Amoul Plan Project BFR2

300,000

2,110

204007

5,900

0

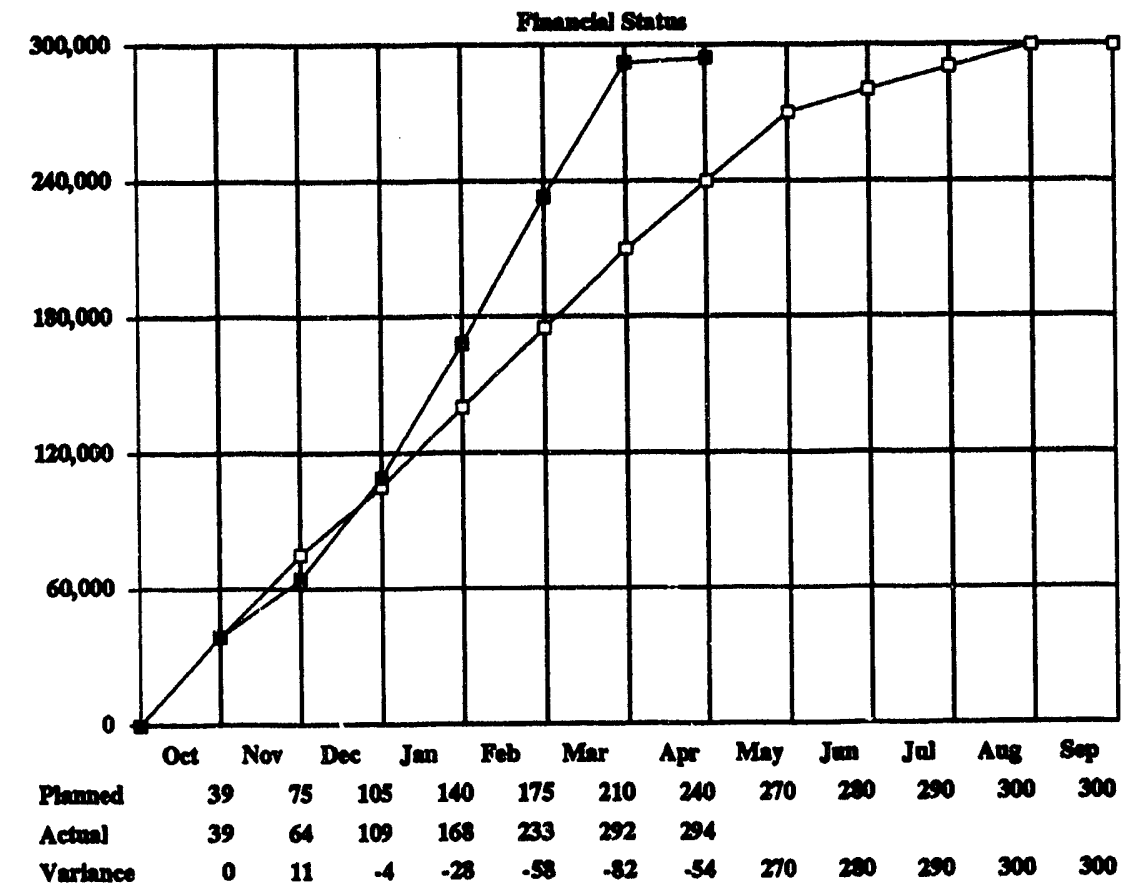

MANPOWER STATUS OR THE PROJECT FOR APRIL

Totel Minhowr:

Mrombours oced thls Menth:

Totel Maphours nod to Date:

Net Avellable:

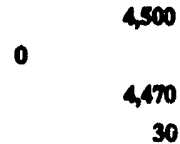

Lopend for Kroy Millewtones

$X=$ Wart Comploted

C E Franned Complettion Date

C'a Revised Completton Date

C"' Completed Aloed of Schedale

Koy Mmetcone Status
4500

4,470

30

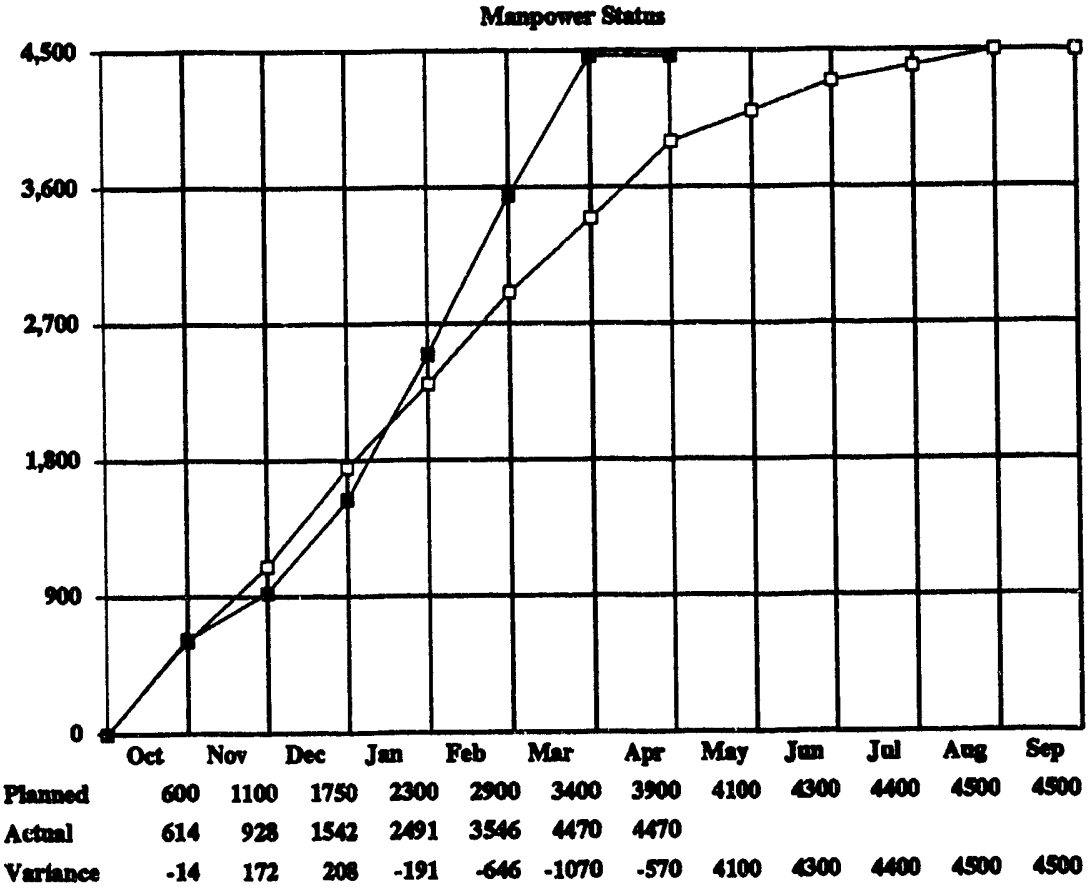

1 Sabmit States Report on Praject Envtrommental, Safety, and Health Ameanant

$\mathbf{X X X} \mathbf{X X X} \times \mathbf{X X X}$ C

ments of Praject BrR2 (Dratt complove by Jaly 30)

3 Complete FY93 Rescarch on Catalytic Crucktog of 650 Degren F Reathe and

Frections; Subant Topieal Report on the Researeh Results

$\mathbf{X X X} \mathbf{X X C}$

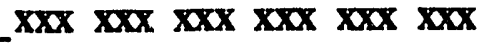

c 


\section{FUELS RESEARCH}

BFR2. DEVELOPMENT OF ANALYTICAL METHODOLOGY FOR ANALYSIS OF HEAVY CRUDES

\section{Accomplishments}

Milestone 2-Work on the 10-year summary report has been initiated.

Milestone 3-Cat cracking of Lagomedio $>650^{\circ} \mathrm{F}$ resid, and chromatographic fractions thereof, has been completed. Solid and liquid products from those runs are currently being analyzed. Analysis of Brass River products also has been completed; those data are being entered into the computer for calculation of material balances for those runs.

\section{Mannowier and Financial Status}

Experimental work has essentially ceased due to the exhaustion of available funds.

\section{Status of Proiect Milestones}

Milestone 2 is on schedule; milestone 3 is ahead of schedule. 
Tatel Approprtations

Lew Coptial Bqupment \& Sabr 0

Approperation Balinez:

Bppenditures for the Moath:

Totel Bipendures to Dates

Nas A vilables

350,000

3500000

$\operatorname{sa,023}$

23360

116,351

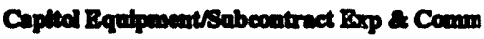

o

Amanel Ptan Profoct BFR3

Thermochematstry \& Thermophydeal Propertics of Orgenic

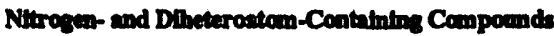

FINANCIAL STATUS OF THE PROJECT POR APRI

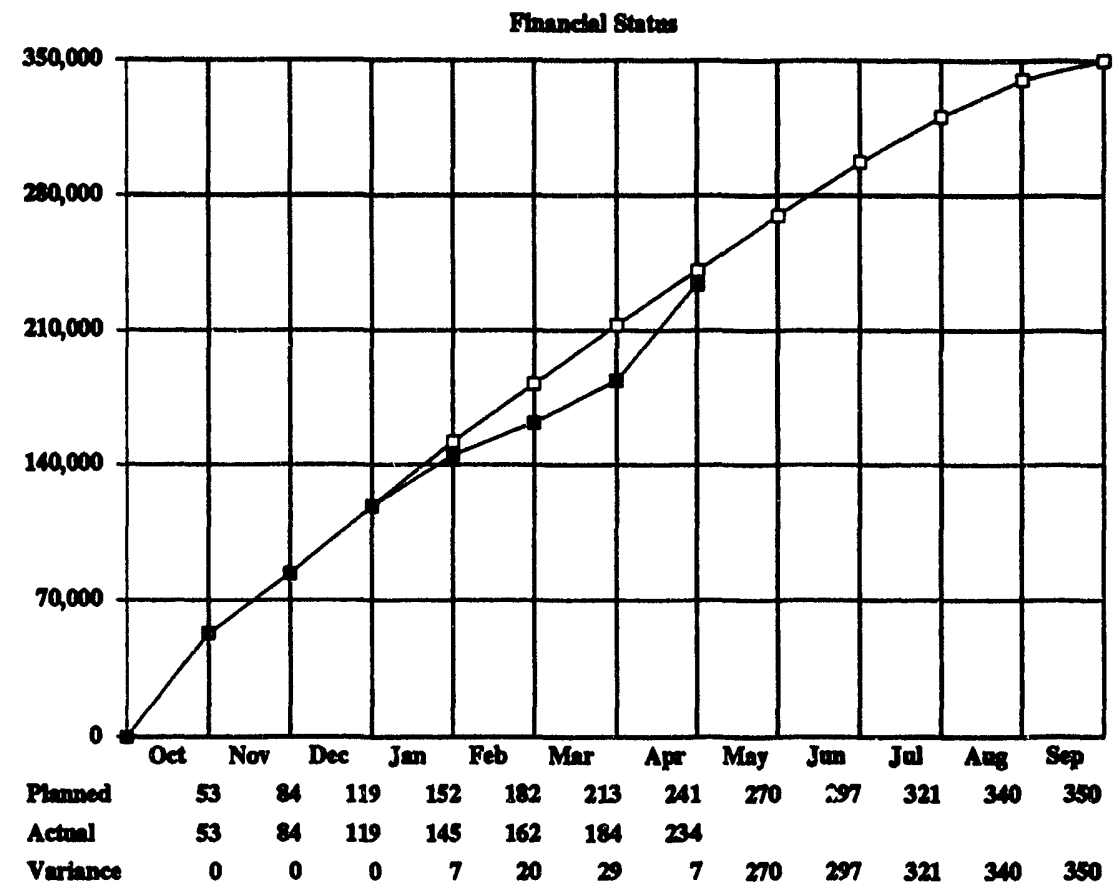

MANFOWER STATUS OF THE PROJECT FOR APRII

Total Man-hours:

Men-hours osed this Month:

$\begin{array}{ll}348 & 4022 \\ & \\ 2,595 \\ 1,427\end{array}$

Net A velloble:

1,427
Lepend for Koy Millectones

$X=$ Work Completed

$C=$ Phanned Completica Date

$C=$ Rerlood Completion Date

C"'= Completed Abeed of Schedale

Kay Milectone Stutas

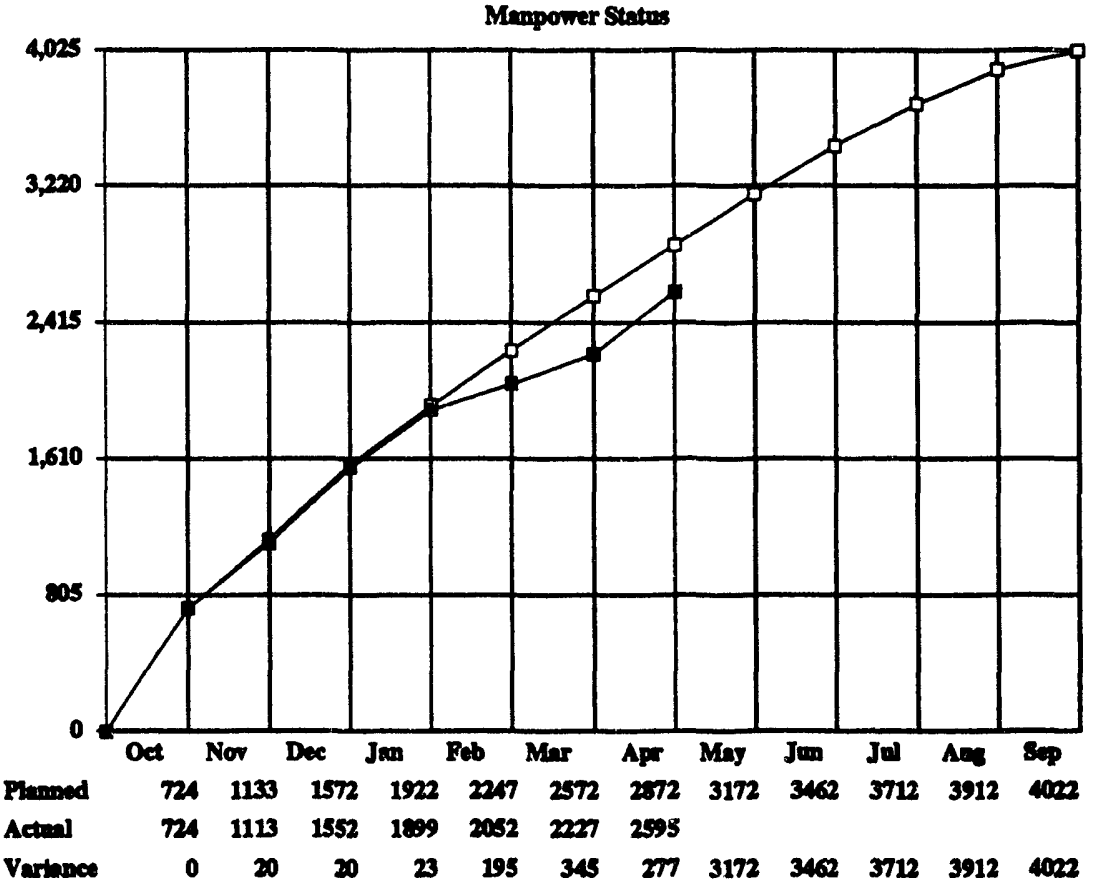

$\mathbf{X x C}$

C

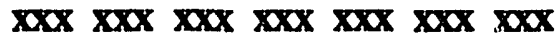
C

C dynowices Reweerch

5 Topieal Repart and Computer Soltware for EPCOP 
BFR3. THERMOCHEMISTRY AND THERMOPHYSICAL PROPERTIES OF ORGANIC NITROGENAND DIHETEROATOM-CONTAINING COMPOUNDS

\section{Accomplishments}

Last month, heat capacity and enthalpy studies on 8-methylquinoline were halted for cryostat repairs. Repairs were completed and the cryostat and calorimeter were calibrated. Preparations for reloading 8-methylquinoline into the calorimeter were begun.

A journal article, entitled "The Thermodynamic Properties of Thianthrene and Phenoxathiin," was accepted for publication in the Journal of Chemical Thermodynamics. month.

Writing of the chapter for the NIPER final report on the accomplishments in this research was completei this

Preparation of a journal article on the thermodynamic properties of 2-methylaniline and transdecahydroquinoline continued. Data analyses are now complete. Updating of all of the relevant tables continues. The article will be submitted to the Journal of Chemical Thermodynamics during the coming quarter.

Enthalpy of combustion studies on 2-methyl- and 8-methylquinolines continued. These compounds are included in a series of measurements scheduled for completion in this quarter.

\section{Mannoprer and Financial Status}

Manpower and financial expenditures are on schedule.

\section{Status of Proiect Milestones} schedule.

The status report to complete the FY92 milestones is in preparation. FY93 project milestones are on 
SGP13

FINANCLAL STATUS OR THE PROJECT FOR APRIL

Total Appropiations

Less Subecidinger:

Appropitation Besanges

R-pundilures for the Mouth:

Total Bppendtures to Date:

Net Aviable:

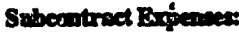

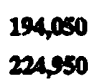

419,000

204,950

1,373
415,254
3,746
200,583

Amnral Pian Project SGP13

Mlexoblab-Bnhanced Waterpooding

Fied Projact

Dinandel Status

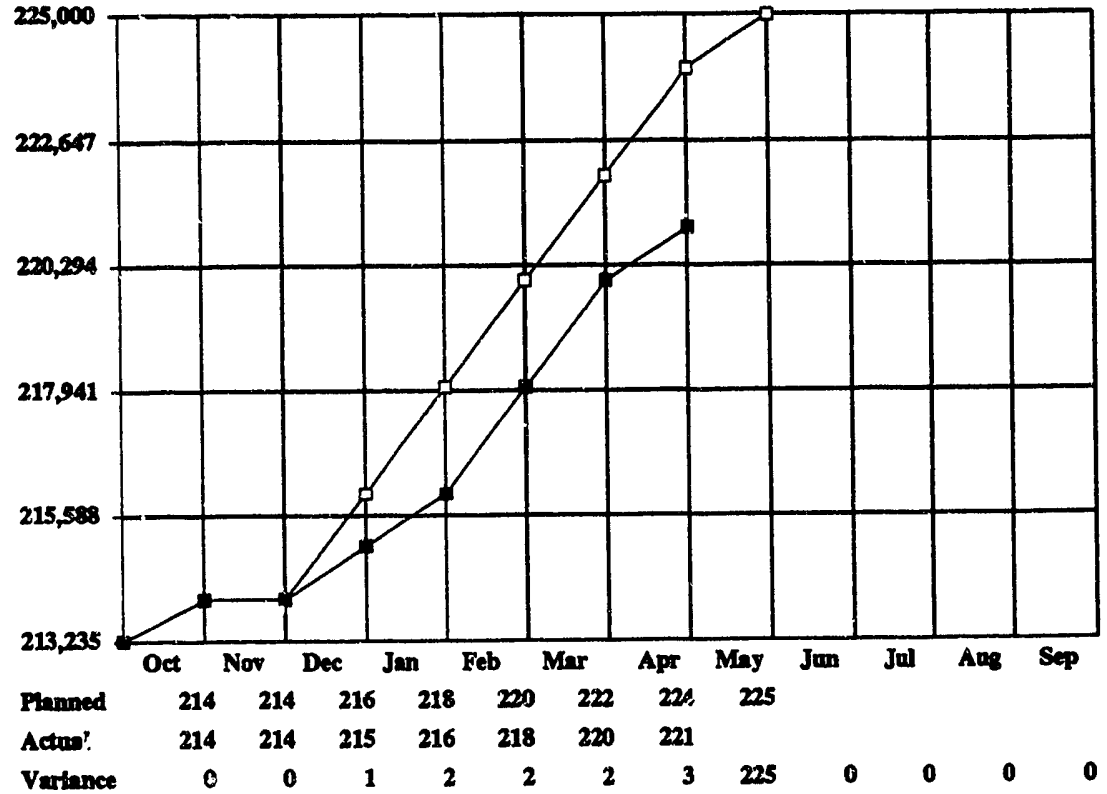

MANPOWER STATUS OF TIE PROJECT FOR APRIL

Total Mandoenre:

Mon-hours owed this Manth:

Totel Man-bours aned to Date:

Net Avalible:
3,340

15

3,280

57
Lepend fer Key Millewtones

$\mathbf{X}=$ Wort Completed

C = Plamed Completion Date

$\mathbf{C}^{\prime}=$ Revied Completion Date

C"' Completed Ahead of Schedrle

Key Miledone Statu

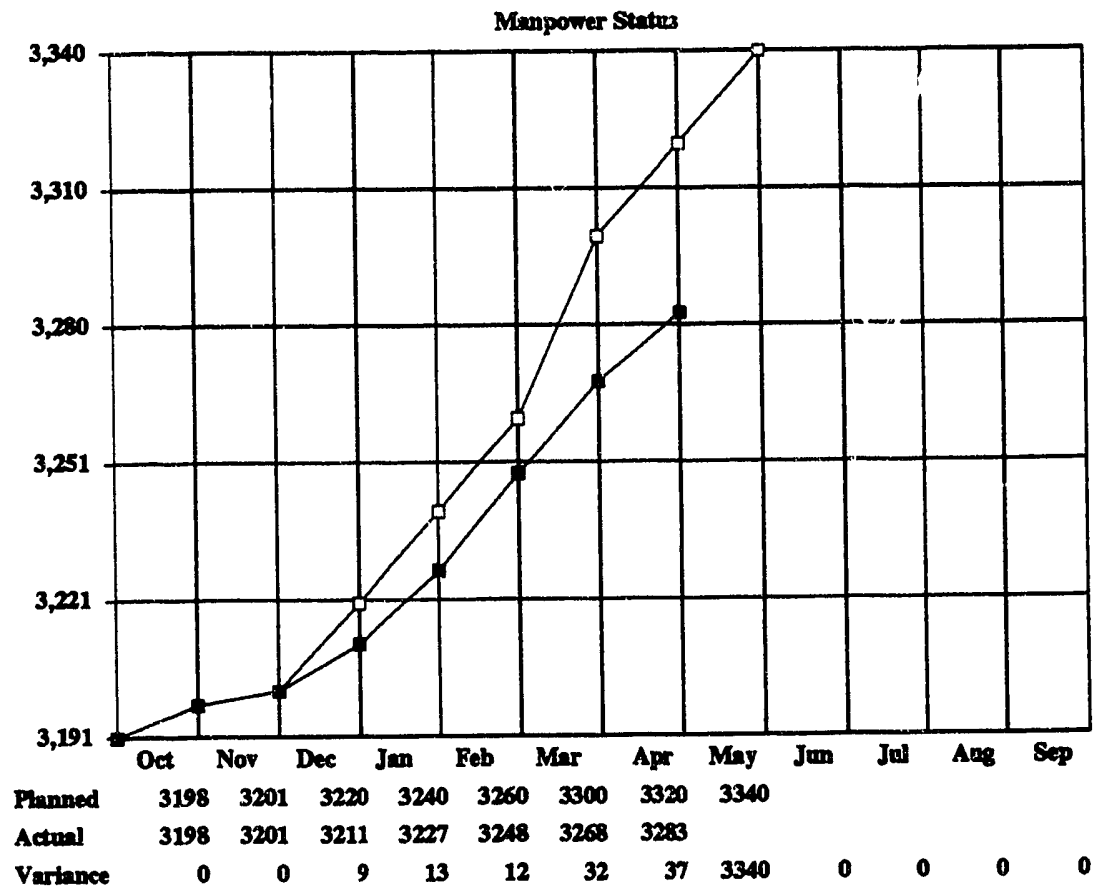

1 Complete On Recovery Monitaring Phase; Submit Topleal Report Describting Performence of MEC'2 Fleld Project
XXX XXX XXX XXX XXX XXX $\mathbf{x x x}$ C 


\section{SUPPLEMENTAL GOVERNMENT PROGRAM}

\section{SGP13. MICROBIAL-ENHANCED WATERFLOODING FIELD PROJECT}

\section{Accomnlishments}

The objectives of this project are to determine the feasibility of improving oil recovery in an ongoing waterflood using microorganisms and to expand the initial pilot and determine the economics of microbial enhanced waterflooding.

The site for the expanded MEOR pilot is located in Section 8, Township 24 North, Range 17 E, of Rogers County. This site is part of the Cheisea-Alluwe field in the Bartlesville formation and was initially developed shortly after Delaware-Childers field. The site is currently under waterflood and is owned by Phoenix Oil and Gas Ltd. This field is in a very isolated area, with virtually no other oil-producing leases nearby. Although this field has much in common with the Mink Unit, there are some significant differences. The Phoenix field is not a freshwater flood; the water is recycled and injected and has an average total dissolved solids value of 3\%. The permeability of the formation is about $20 \mathrm{mD}$.

Milestone 1-Fluorescein tracer (100 bbl at a concentration of $126 \mathrm{ppm}$ ) was injected June 6, 1990, and the microorganisms were injected 14 days later on June 20. Wellhead injection pressures, volumes, and oil production continue to be monitored. Production data through February 1993, indicated an improvement in oil production of $17.4 \%$.

A presentation detailing the results of this field test was prepared for the New Technology for Independent Producers seminar to be held in Denver, CO, May 6-7, 1993.

Mannower and Financial_Status

Manpower and financial expenditures are on schedule.

Status of Project_Milestones

Milestone 1 is on schedule. 
SGP37

FINANCIAL STATUS OF THE PROJECT FOR APRII

Total Appropertation:

Lems Subcontruetse:

Appropetation Balance:

Expenditures for the Month:

Total Expenditures to Date:

Net Avallable:

Subeontract Rrpensess

, 711

Annual Ptan Project SGP37

Feaslbilty Study of Heavy On Recovery

In the Midcontinent Reglon: Oklahoma, Kansas, \& Missouri

MANPOWER STATUS OF THE PROJECT FOR APRII
Man-hours used this Manth:

Total Man-hours used to Date:

Net Avallable:
Total Mnn-hours:
447

12,655

11,462

1,193
Legend for Key Millestones

$\mathbf{X}=$ Work Completed

C $\approx$ Flamed Completion Date

C'a Revised Completion Date

C'= Completed Ahead of Schedule

Key Milectone Status
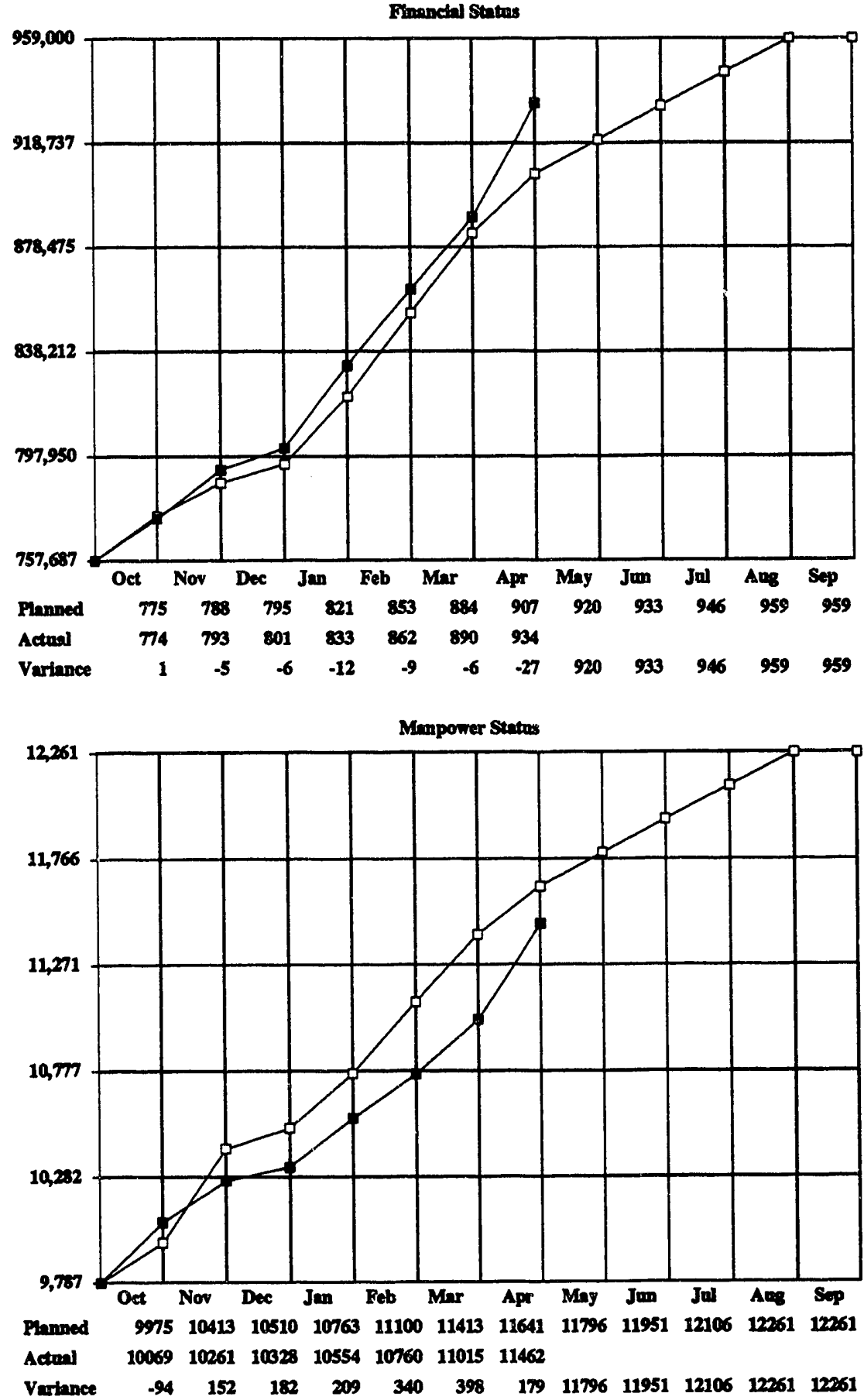

1 Status Report Describing Results of Computer Modeling Stody on Potenthly for Heavy Oll Recovery

$\mathbf{X X X}$ $\mathbf{X X X} \mathbf{X X X} \mathbf{X X}-\mathrm{C}$

2 Complete Detalled Review of Heavy On Potenthal For Gulf Const Reetion

3 Status Repart Discusating Results of U. S. Heary On Reservoir Data Study

XXX XXX XXX XXX XXX XXX XXX C

$\mathbf{X X X}$ C 


\section{SGP37. FEASIBILITY STUDY OF HEAVY OIL RECOVERY IN THE MIDCONTINENT REGION: OKLAHOMA, KANSAS, AND MISSOURI}

\section{Accomnlishments}

The objectives of this research project are (1) to determine the known heavy oil resources of the United States, (2) to evaluate the various economic constraints that may impact development of this resource, and (3) to determine if steam or other EOR processes are applicable to economic production of this resource.

Milestone 1-The computer modeling was completed in March and the results were delivered to the BPO Technical Project Officer. Due to other DOE priority projects, a status report containing results will be delayed until June, and a memo requesting an extended completion date has been submitted to BPO.

Milestone 2-The analysis and update of reservoir data for Texas heavy oil reservoirs was completed this month, and the information is being reviewed for inconsistencies and errors. After the information is reviewed, it will be incorporated into the U.S. heavy oil data base file. Oil production data in the heavy oil data base were updated for several states. Inconsistencies with data from various sources (TORIS public data base, Oil \& Gas Journal EOR report, state publications) and parameter ranges were entered into a separate data base for future clarification.

\section{Manpower and Financial_Status}

Manpower and financial expenditures are on schedule.

\section{Status of Project Milesitones}

As noted above, milestone 1 is running behind schedule and ar extended completion date is being requested. Report NIPER-560, "Feasibility of Heavy Oil Recovery in the Midcontinent Region (Kansas, Missouri, Oklahoma)" is ready for final typing. Report NIPER-606, "Estimates of Future Ragional Heavy Oil Production at Three Production Rates-Background Information for Assessing Effects on the U.S. Refining Industry, "has been delivered to the BPO.

A report updating the trends in heavy oil production and refining in Califomia was presented at the American Chemical Society Symposium on Enhanced Oil Recovery, Denver, CO, Mar. 28-Apr. 2. The reported data will be published in the symposium Proceedings. 


\section{SGP41}

FINANCIAL STATUS OR THE PROJECT FOR APRIL

Total Appropriation:

Les Subecontracts:

111,000

Appropitiation Balances

507,000

Expenditures for the Month:

Toted Expenditures to Date:

Net Avallables

Subcontrnet Bxpenses:

Annual Plar Project SGP41

Surfectunt-Enhaneed Alkaline Flooding

Fleld Project
618,000

10,743

307,413

310,587

45,946
Financhal Stutus

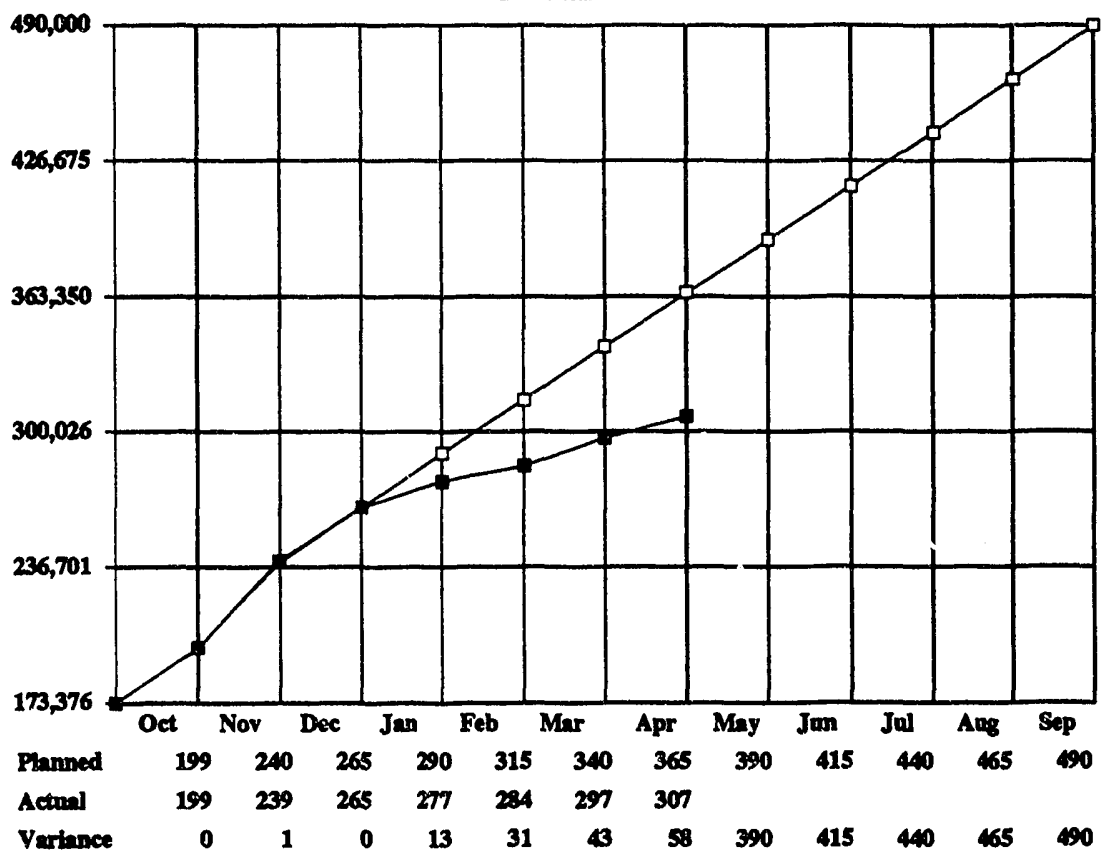

Manpower Status

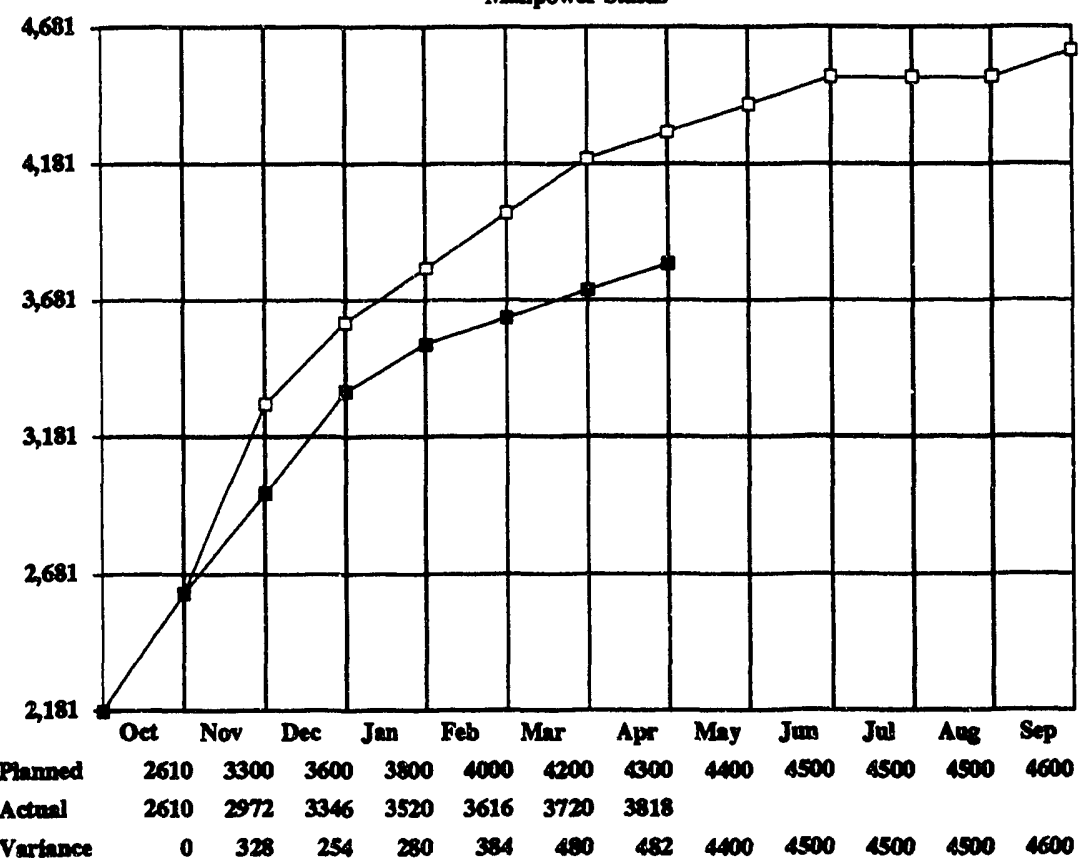

$\operatorname{Xxx} \times x$

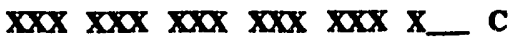

$\mathbf{X x x} \quad \mathbf{X X X} \quad \mathbf{x x x} \quad \mathrm{x}$

$\operatorname{xxx} \mathbf{x x x}$ XXX XXc

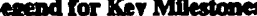

$\mathrm{X}=$ Work Completed

C = Planand Completton Date

$C^{\prime}=$ Revised Complettion Date

C"'s Compieted Abead of Schedule

Key Mmeatene Status
6,000

3,818

2,182
1 Complete Bnvironmental Assedment

2 Findibe Geolodeal Eviluation of Fiald Core

3 Test Chemien System in Feld Core; Finalize Dedign of Chemical System Based on Results Obtinined whth Field Core

4 Prepare Presuntation on Comparison of Mcthods for Evaluating Core from a Midcontiment Flavial-Dombated Deltaic Standetone Reservadr 5 inject Chamionls

6 Complete On Recovery Monttorng Phase; Submit Final Report (FY95 Completion Date)
$\mathbf{C}$ 


\section{SGP41. SURFACTANT-ENHANCED ALKALINE FLOODING FIELD PROJECT}

\section{Accomplishments}

The objectives of this pilot project are (1) to obtain information and data that will help demonstrate the applicability of surfactant-enhanced alkaline flooding as a cost-effective EOR method, (2) to transfer the surfactantenhanced alkaline flonding technology that has been developed under the sponsorship of the DOE to the petroleum industry, and (3) to obtain information regarding procedures for designing and applying this technology that will assist independent producers in sustaining production from mature producing oil fields rather than abandoning marginal wells.

The site selected for the surfactant-enhanced alkaline flooding pilot test is Hepler oil field, which is located in Crawford and Bourbon Counties of the State of Kansas. This near-term application of a promising EOR technology in a fluvial-dominated deltaic type reservoir is consistent with the strategy outlined in DOE's oil research program implementation plan.

Milestone 2-The primary need before implementing the project in the field is a better estimate of the final oil saturation in the area swept by chemical flooding. Final oil saturation has been difficult to estimate from coreflooding experiments due to channeling of fluids through high-permeability streaks in the field cores. In an attempt to better estimate oil saturation in the zone swept by chemicals, corefloods are being performed while monitoring flow patterns via CT scanning. These experiments are being performed under project BEAB, which is supporting this pilot project.

Milestone 3-One remaining task in the final design of the chemical flooding system is to ensure that the sodium bicarbonate originating in western Colorado or Wyoming (North American Chemical Co.) is compatible with the other EOR chemicals. The sample was received this month from North American.

\section{Manpower and_Financial_Status}

Manpower and financial expenditures are behind schedule due to delays that have resulted from unfavorable laboratory testing of cores taken from the area of the field originally selected for the pilot site.

\section{Status of Proiect_Milestones}

Because of unfavorable laboratory core test results, project milestones are running behind schedule. During the month of May, a revised set of milestones will be submitted to the BPO for approval. 
SGP49

FINANCLAL STATUS OF TEE PROJECT POR APRII

Total Appropertation:

Lem Cap Equtp \& Sube:

90,115

Appropetation Bahnece:

$1,433,457$

Eppenditures for the Month:

Total Expenditures to Date:

Net Arallable:

$1,157,424$

366,148

Cap Equipisubeontract Exp \& Commits:

90,115

Ammoal Phan Project SGP49

Procese-Enghncerting Property Measurements

on Heavy Petroleum Components

$1,523,572$

55,174

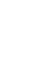

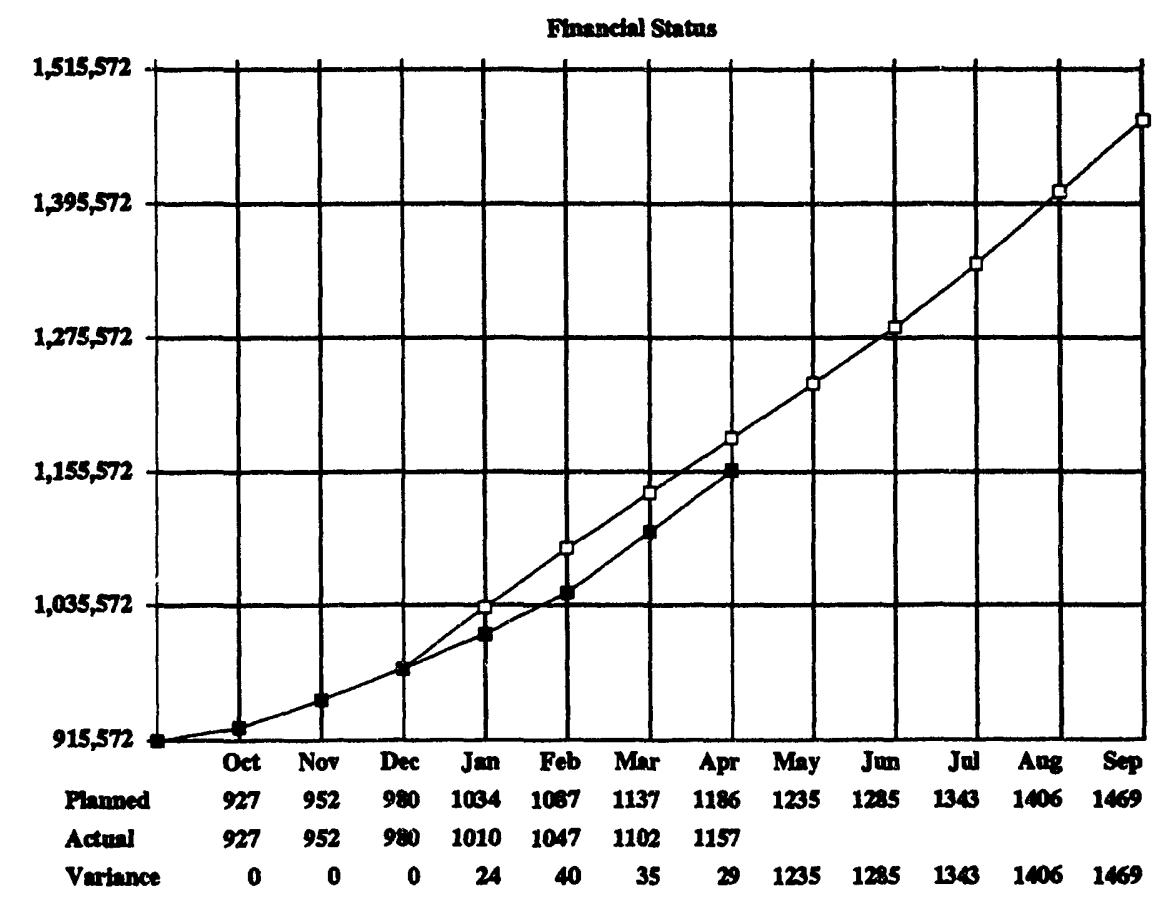

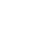

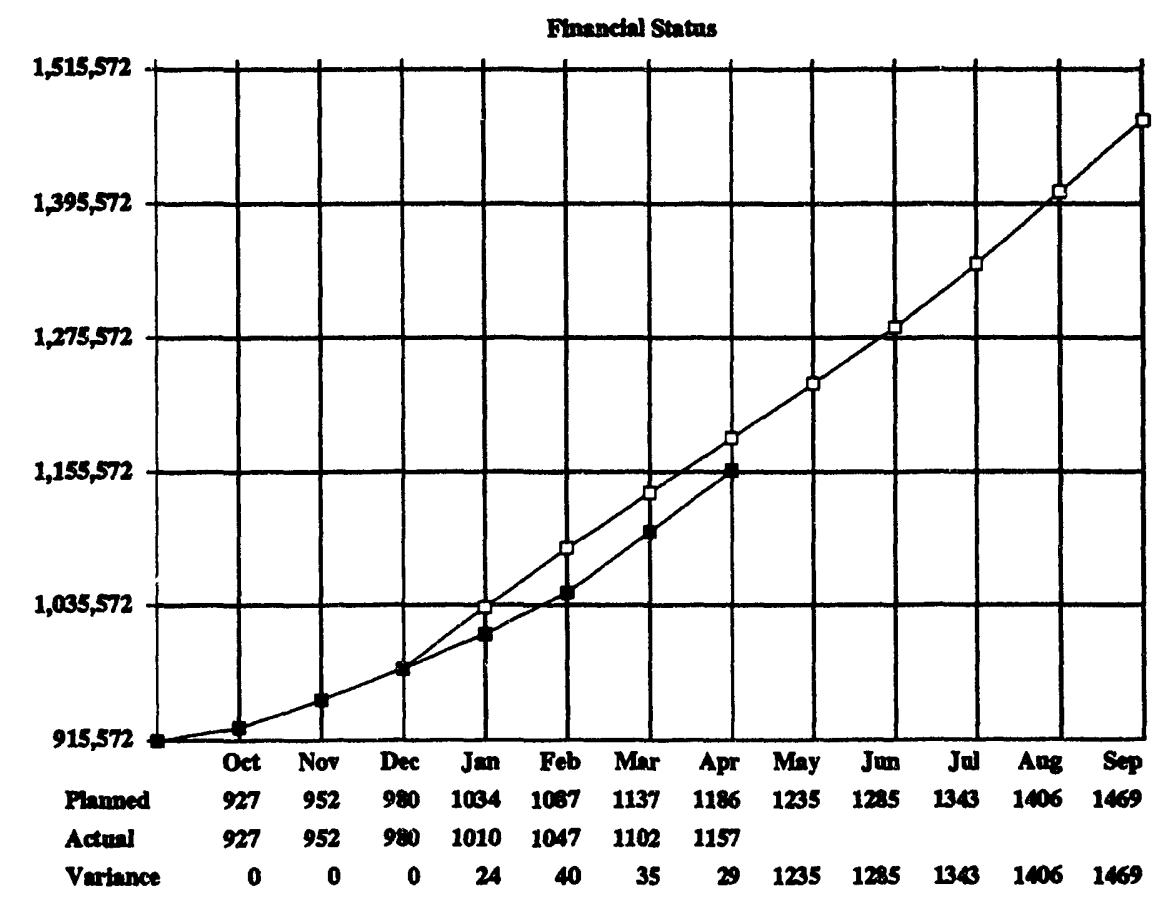

MANPOWER STATUS OF THE PROJECT FOR APRIL

\begin{tabular}{|c|c|c|}
\hline Total Man-hours: & & 18,0005 \\
\hline Man-hours and thts Month: & 674 & \\
\hline Total Minin-houms ased to Dute: & & 14,191 \\
\hline
\end{tabular}

\section{Levend for Rey Milectones \\ $X=$ Wort Completed \\ C $=$ Plamed Completton Date \\ $C^{\prime}=$ Rovised Completion Date \\ C'm Completed Abead a Schedule}

Key Mineatone Sutas
Monpower Stutes

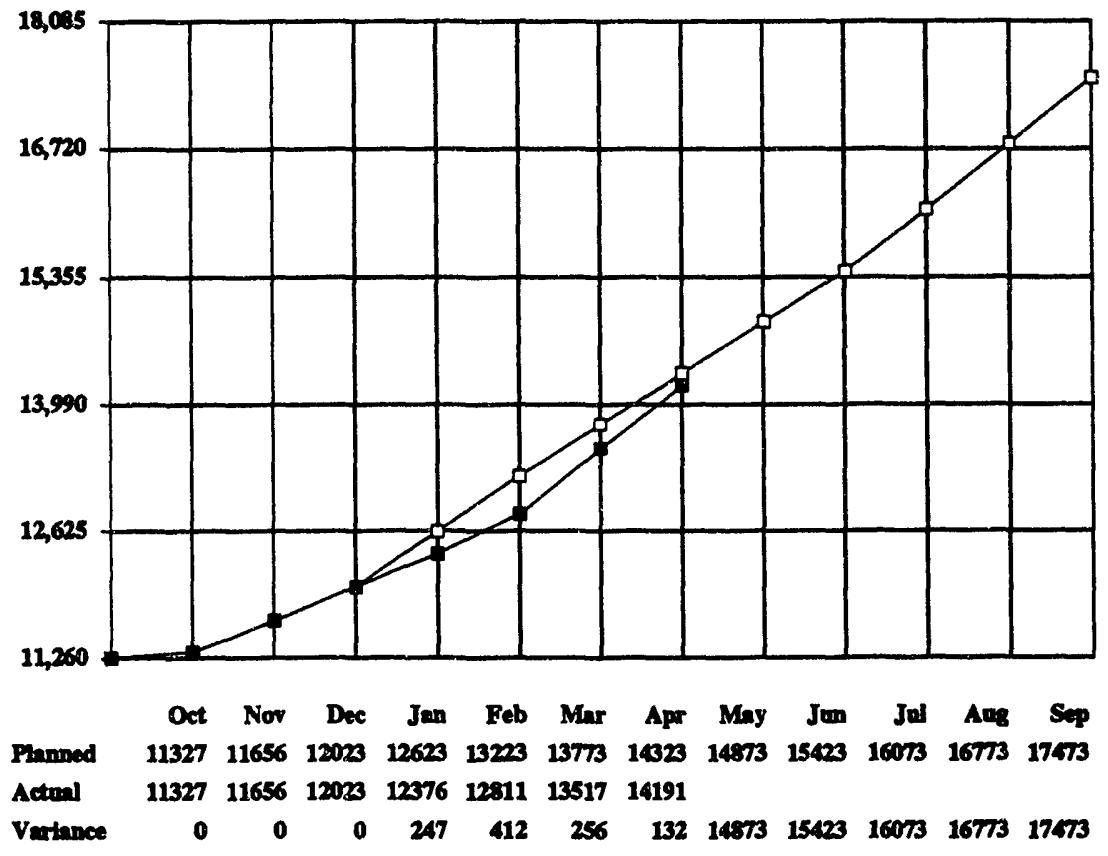

1 Topical Report/Journal Article on the Thermochemical \& Thermophydcal Properties at Bigh Temperature (Approaching the Crttleal Redow) of Phenanthrese \& the Products of Its Hydrogenetion

2 Prepare a Mitumimom of Three Jourmal Articles on the Thermodyramic

$\mathbf{X x x} \mathbf{x x x} \times \mathbf{x x x} \mathrm{x}$

Propertles of Aromattc \& Hydroaromatic Compounds Measured in

This Rewearch

$\mathbf{X X X}$

$\mathbf{X x x} \mathbf{X x x} \mathbf{x x x} \mathbf{x x x}$

C

3 Strtes Report on the Syntheds \& Purtifiation of Key Compounds (FY 94 Completion Date)

4 stutus Repart Summartang Data Aequired, Its Utilty, \& Updated Acecement of Needs for Future Wark (FY94 Completion Date) 


\section{SGP49. PROCESS-ENGINEERING PROPERTY MEASUREMENTS ON HEAVY PETROLEUM COMPONENTS}

\section{Accomplishments}

Heat capacity and enthalpy studies by adiabatic calorimetry on 1,2-dihydronaphthalene were continued this month. Replicate determinations of the enthalpy of fusion were completed and solid-state studies were begun. Two phase transitions were located in the solid phase. Determination of transition enthalpies has begun.

A topical report, entitled "The Thermodynamic Properties to $700 \mathrm{~K}$ of Naphthalene and 2,7-Dimethylnaphthalene," NIPER-678, has been submitted to the BPO. The report fulfills the requirements of FY92 milestone 5. A journal article describing this work was submitted to the Journal of Chemical Thermodynamics. Work on a topical report on phenanthrene and its hydrogenation products continues (milestone 1).

A commercial zone-refining apparatus was received and assembled. Testing and determination of operating parameters has begun. A sample of 1,23,4-tetrahydrofluoranthene, synthesized at Oklahoma State University, will be zone refined once the apparatus is operational.

The topical reprert in which the thermodynamics of hydrogen shuttling are compared for pyrene, phenanthrene, and anthracene, is near completion. This report was not part of the original milestones for this project, but will be completed due to the important insights it provides to the controversy existing in the literature over the mechanism(s) of hydrogen shuttling. Work on the organometallics report (FY92 milestone 3) is also near completion.

Enthalpy of combustion studies on 1,2-dihydronaphthalene and 1,10-trimethylenephenanthrene continued. These compounds are included in a series of measurements scheduled for completion in this quarter.

The staus reports for research completed in FY92 (FY92 milestones 7 and 8) are near completion.

Manpower and Financial Status

Manpower and financial expenditures are on schedule.

Status of Project Milestones

Details of project milestones are given above. 
SGPSO

FTANCIAL STATUS OR THE PROJBCT ROR APRI

Towal Appecoptatlon:

Lom Subocontrects:

Appropratition Balneces

200,000

Enpenditeres tor the Momth:

Total Expendteres to Dotos

Net A volinkle:

27,000

3,730

197,310

s,ost

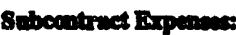

178,237

Amnoul Pien Prajece SGPSO

Tratinges In Development \& Application

at Purclem Production Technoloples

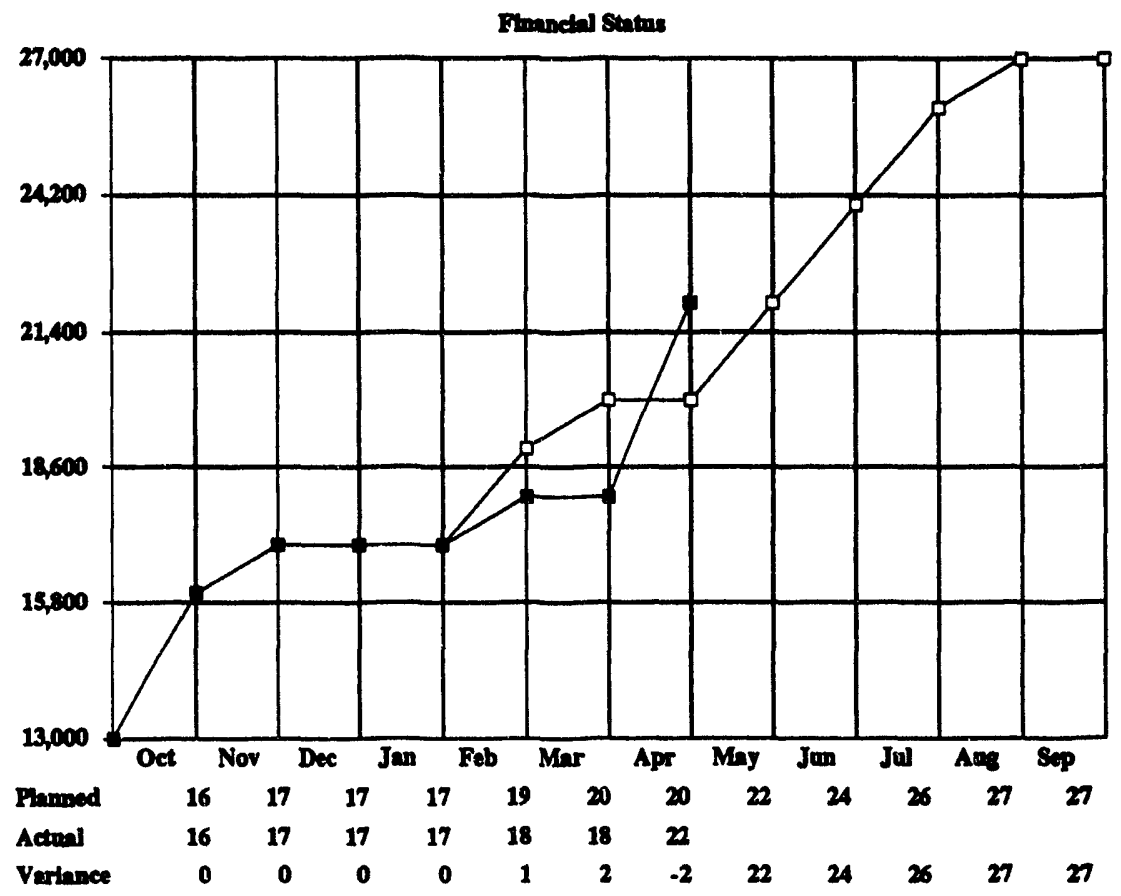

MANPOWER STATUS OF THE PROJECT FOR APRI

Totel Man-hours:

Man-hours wed this Month:

Total Man-hours need to Detes

Net Avedable:
276

182

94

\section{Legund for Key Milleatones \\ $\mathbf{X}=$ Work Completed \\ $C=$ Plamed Complettion Date \\ Ca Revised Completion Date \\ C"m Completed Ahead of Sechedule}

Koy Millectome Status

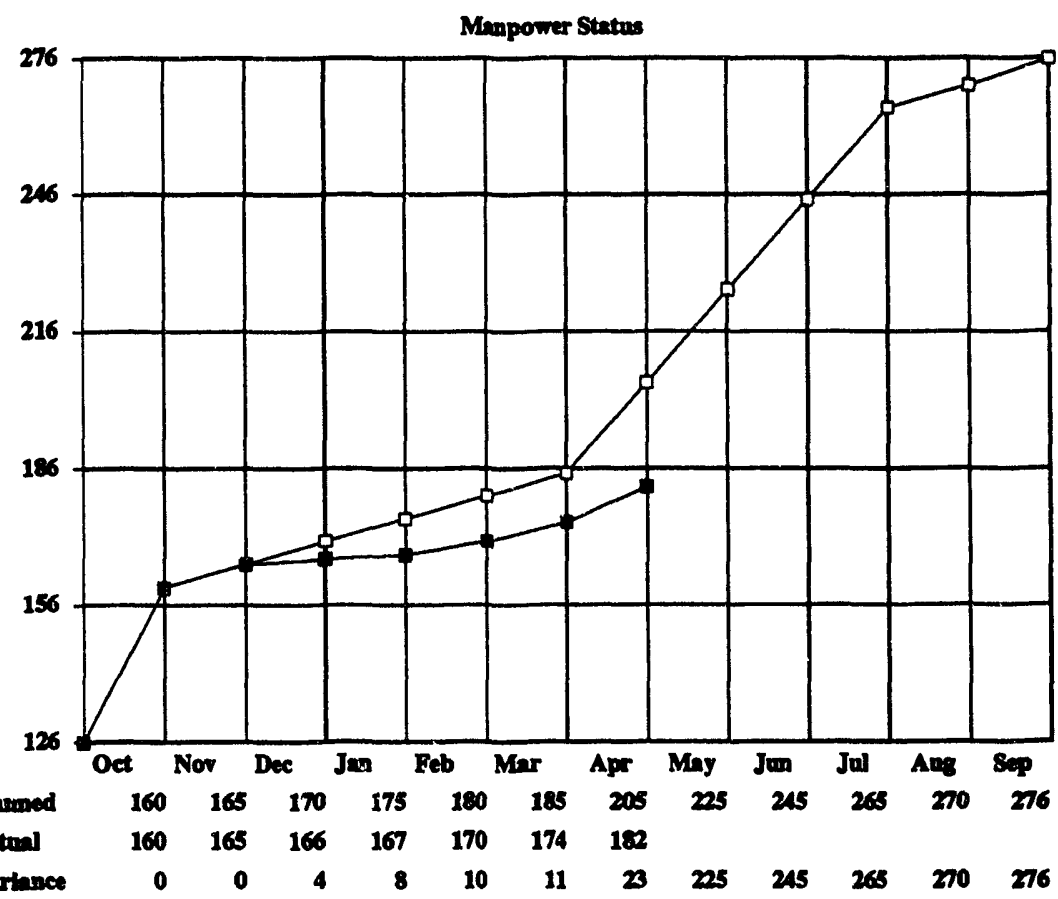

$\mathrm{XXC}$

XXX XXX XXX XXX XXX XXC

$\mathbf{X X X} \mathbf{X X X}$ C
3 Intervior and Select Summer Interns

4 Supervibe and Teach Summer Interns

5 Complete Final Report 


\section{SGP50. DEVELOPMENT AND APPLICATION OF PETROLEUM PRODUCTION TECHNOLOGIES}

Milestones 2 and 3-Nineteen offers to students were made, and all have accepted. A letter was sent to these students informing them of the seminars and meetings planned for this summer which will include one safety training session and eight seminars. The topics of these seminars include geology, primary and secondary recoveries, EOR, biotechnology, and environmental issues associated with petroleum production. George Hirasaki, a professor from Rice University, will give a seminar on wettability. The teacher-interns from NIPER and Phillips are also planning to attend these seminars.

\section{Mannorzer and Financial_Status}

Financial expenditures are on schedule, but manpower is slightly below projection due to extended period (approximately 1 month) in finalizing intern recruitment.

\section{Status of Proiect Milestones}

The work planned for milestone 2 has been completed. The other project milestones are on schedule. 
SGP56

FLANCLAL STATUS OE TER PEOJBCT ROR APRIL

Total Appropothtion

Lem Sebondrates

Appropitation Balane:

Brpmalltures lor the Nonths

Toted Bymaderes to Date:

Nat A whiblet

Sobeontract Brpmon:

Amoul Pran Praject SGPS6

Upurade BPO Crode OI Analyds Data Base

MANPOWER STATUS OR THE PROJECT FOR APRII

Totol Mindorts:

Mimbours ased thes Marth:

Toul Mingours end to Date:

Net A vellable:
106,000

106,000

19,423

66,936

39,014

0
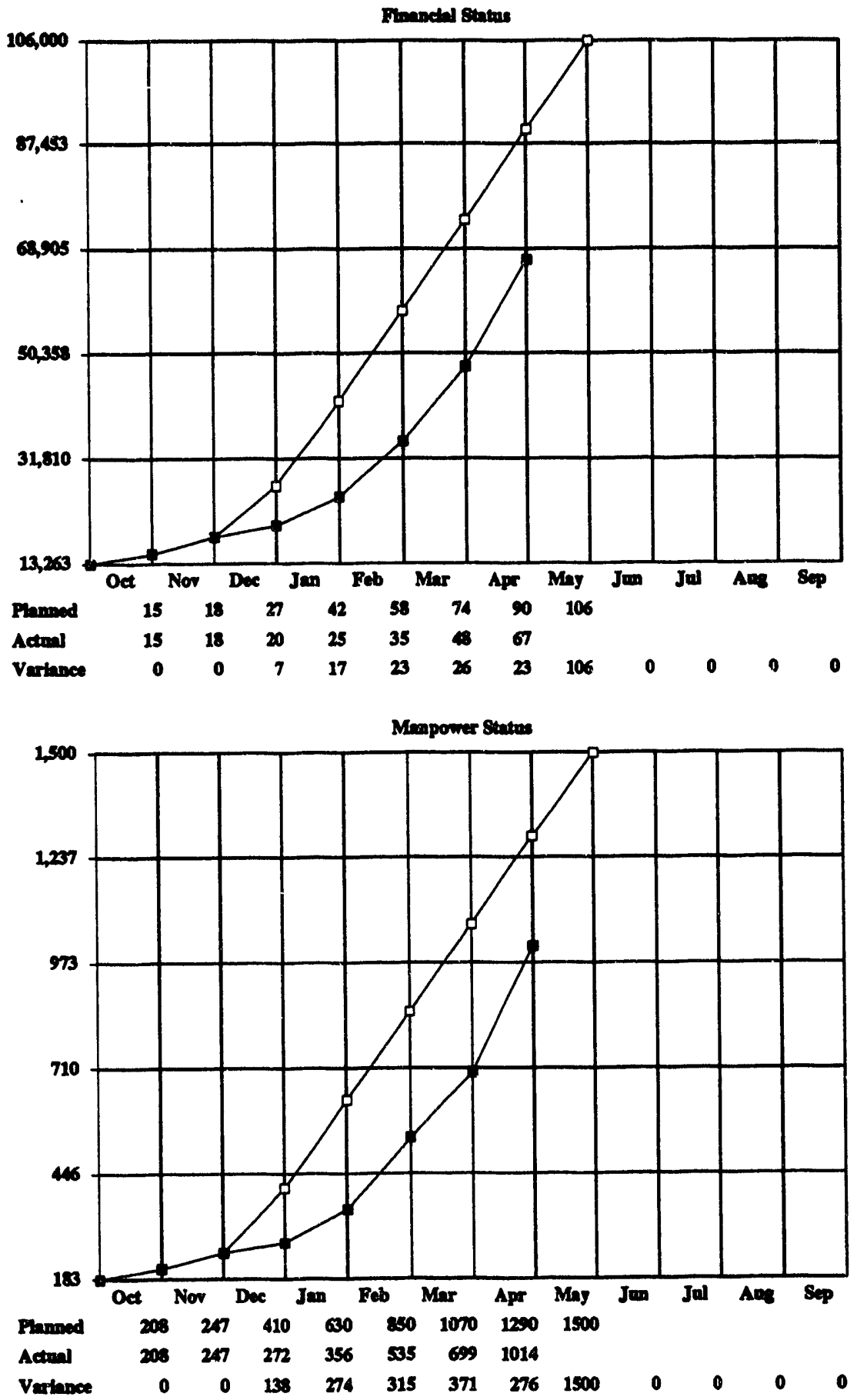

$\mathbf{C}$

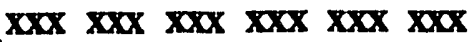

XXX XXX XXX XXX XXX XXX

$\mathbf{x x}$

C c 
SGP56. UPGRADE BPO CRUDE OIL ANALYSIS DATA BASE

\section{Accomplishments}

The objectives of this project are (1) to develop and maintain a high-integrity, on-line, crude oil analysis (COA) data base that is available to the public; (2) to upgrade and update crude oil analyses for inclusion in this data base; and (3) to participate in the UNTTAR analysis round robin.

Milestone 1-A preliminary report, "Third Round Robin on Heavy Crudes and Bitumen Statistical Analysis on Cerro Negro Crude Analytical Data, "was distributed by the United Nations Institute for Training and Research Centre for Heavy Crudes and Tar Sands to project participants for review. A final date for the conference has not been established.

Milestone 2-Computer coding for the on-line data base is progressing. A commercial bulletin board software (BBS) will control the communication between the user and the on-line computer, and commercial data management software will control the file storage and retrieval functions. A written computer code will control the user interface, develop queries, and return results to the user. This month, the user interface was tested using direct screen writes with the BBS. Additional work was done on keyword queries by the user.

Milestone 3-Crude oil samplus will be analyzed for trace metals and for hydrocarbon type. No analytical work was performed this month due to other priority work and required repairs to the ICP spectrophotometer. Hard copy files of crude oil analyses were moved. Analyses that are not in the data base are being identified.

\section{Mannoprer and Financialstatus}

Additional funding has been allocated to this project. A revised milestone schedule and budget will be submitted for approval next month.

\section{Status of Proiect Milestones}

Project milestones are on schedule. 
SGP58

FUNANCLAL STATUS OR THE PROJECT FOR APRAL

Towl Appropotation:

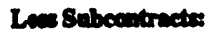

Appropatation Balance:

Expenditures tor tho Moath

Total Expenditures to Dates

Net A villable:

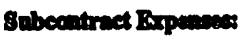

Aneal Pran Project SGPss

Stmaintion Analyds of Stcam-Roem Projecto

MANPOWER STATUS OR THE PROJECT FOR APRII

Toted Manboum:

Min-bours and thls Month:

Totil Minn-bours need to Dates

Nee A rollables

$121 \quad \begin{aligned} & 4,410 \\ & \\ & 1,052 \\ & 3,358\end{aligned}$

Lepend for Key Millotones

$X=$ Wort Completed

C = Pramed Compietion Date

C'= Revised Completion Date

C"= Completed Alead of Schedale

Key Milestone Status

1 Complete Revier of Datu trom Previoas Stcamfood Projects

2 Complete Bade Bistory Match

3 Finaltwo Foll-Puttern Stmulation Stody (FY94 Completion Date)

4 Finel Report on Rewearch Findinges (FY94 Completton Date)
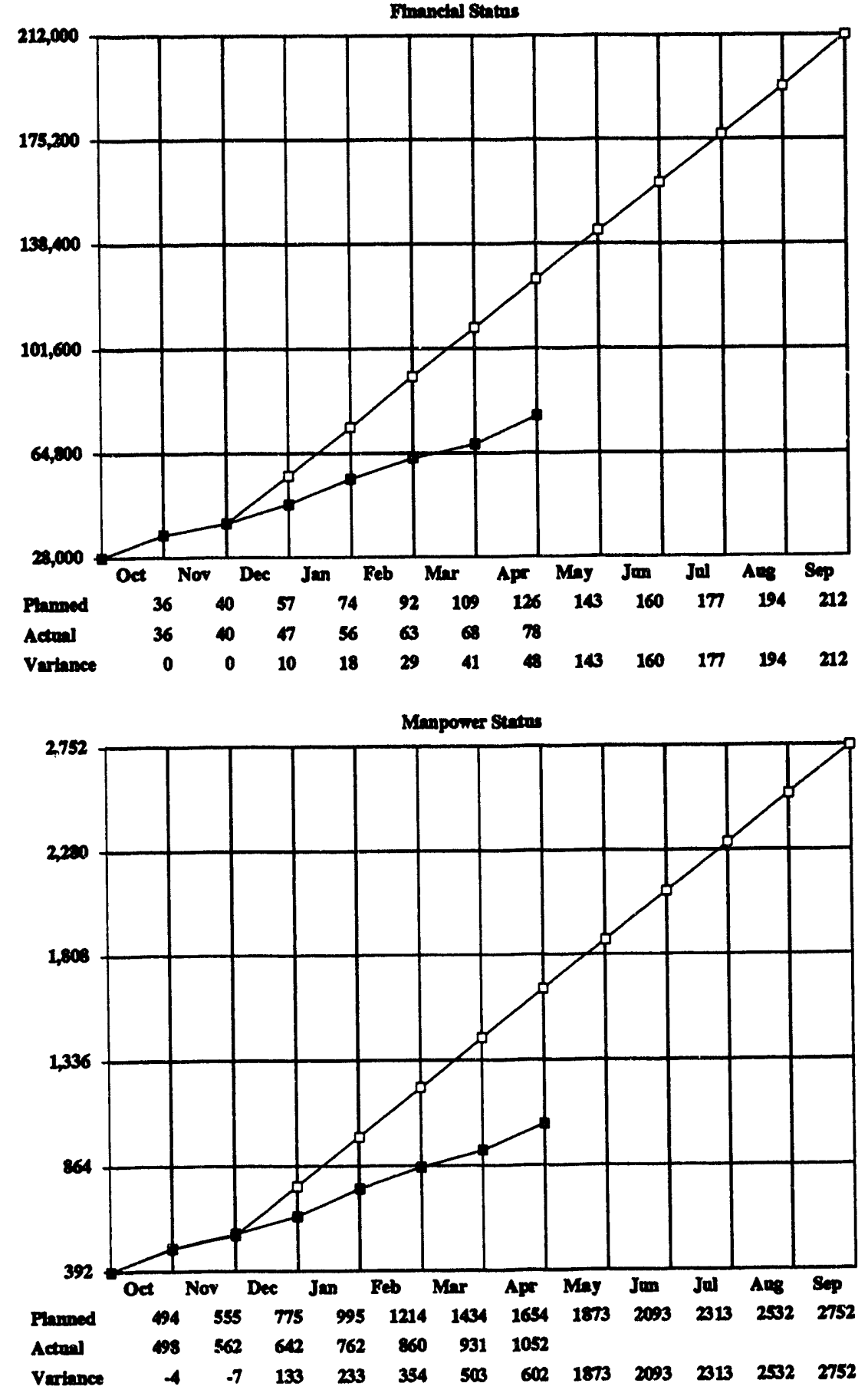

$\mathbf{X X X} \mathbf{X X C}$

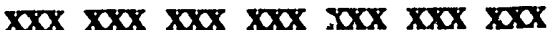
C 
SGP58. SIMULATION ANALYSIS OF STEAM-FOAM PROJECTS

\section{Accomplishments}

The objectives of this research project are (1) to study the viability of the steam-foam process by analyzing data from selected completed steam-foam projects and (2) to assess conditions under which the process is likely to succeed, both technically and economically.

Milestone 2-The history match of Chevron's Section 26-C Steam-Foam Pilot is continuing. As pointed out in the March 1993 Monthly Report, it is difficult to match both the temperature and pressure simultaneously due to the assumption that foam propagates at the same rate as surfactant. In real reservoirs, a foam front lags behind the surfactant front. This month, attempts were made to match both temperature and pressure by retarding the foam propagation rate. The advancement of the foam front can be slowed (1) by increased surfactant adsorption, (2) by increased residual gas saturation, or (3) by both increased surfactant adsorption and residual gas saturation. Only by increasing the surfactant adsorption and residual gas saturation was it possible to improve the simulator's matching ability. Additional simulation runs are planned with further adjustment of surfactant adsonption rate and residual gas saturation values to improve the predictability.

\section{Manporrer and_Financia__Status}

Manpower and financial expenditures are below planned estimates due to senior staff commitments to other DOE priority projects.

\section{Status of Project_Milestones}

Project milestones are on schedule. 
SGP61

FUNANCIAL STATUS OF TEI PROJECT FOR APRIL

Totel Apprepriation:

Lees Sobeantracter

Apprepriation Balance:

Bependitures fior the Month:

Toul Rependitures to Date:

Net Avinable:

Sobcoutract Bopentex:

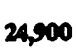

85,100

110,000

2,817

46,063

$\mathbf{6 , 9 3 7}$

18,005

Ammoul Pinn Pralect SGP61

DOE Rducutional Intibutive Froject

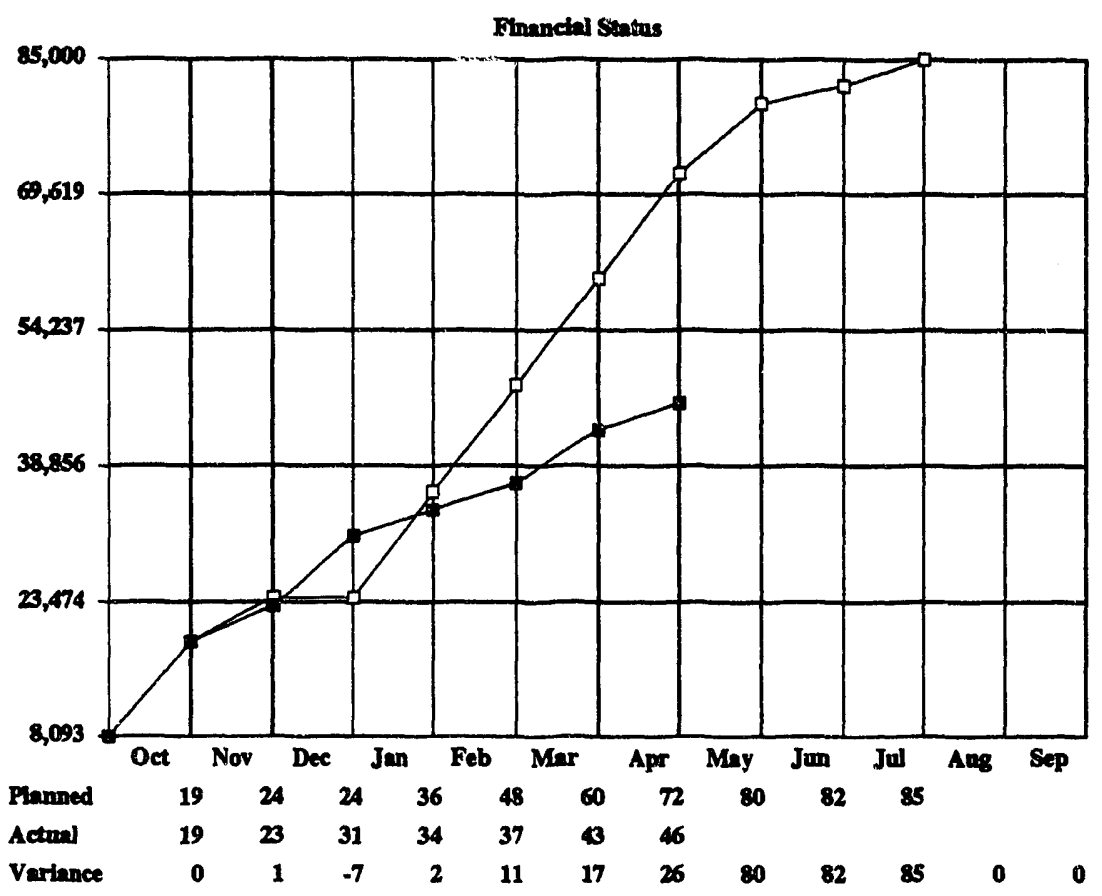

MANPOWEX STATUS OF THE PROJECT FOR APRIL

Totil Minnbourt:

Mom-hours ased this Month:

Totil Minh-bours noed to Date:

20

80

Net Avallable:

(11)

Legand for Key Milestones

$X=$ Wart Cospleted

C = Plamed Completion Date

$C=$ Reviead Cosmpletion Date

$C "=$ Completed Abead of Schednle

Rey Milectone Stuto:

1 Complete Ascoment of School Needs \& Community Resources

2 Complete Developeneat of Solence Cineroous Support Bortan

3 Coordimate Staf Derelopesent Opportunities for Teachers

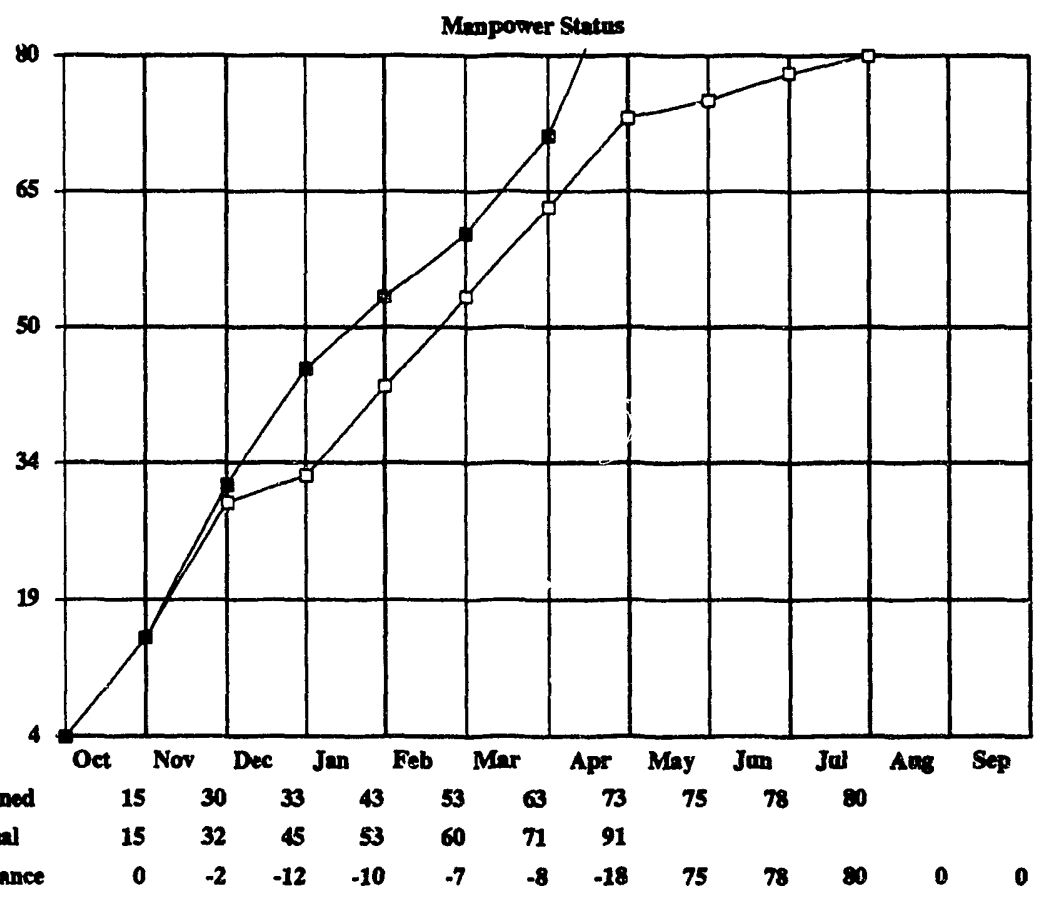

XXX XXC

XXX XXX XXX XXX XXX XXX XXX XXX XXX $\overline{\mathbf{X X X}} \mathbf{X X X}$ C 


\section{SGP61. DOE EDUCATION INITIATIVE PROJECT}

\section{Accomnlishments}

The objective of the DOE Education Initiative Project is to enrich the science programs of public schools in the northeastern part of Oklahoma by developing partnerships between the schools, communities, businesses, and other interested groups.

Milestone 2-In coordinating the DOE Regional Science Bowl for Oklahoma, responses to the evaluation forms were tabulated and sent to the Science Bowl Committee, and Science Bowl Officials. Judy Kokesh accompanied the Edmond Memorial High School team and coach to the National Science Bowl competition in Washington, D.C., Apr. 16-19. She also served as point of contact at the National Science Bowl for the Oklahoma team.

Milestone 3-Ms. Kokesh met with Duane Wilson of Conoco, Inc., to discuss the Oil and Gas Exploration curriculum and to seek support for the "Train the Trainers" workshop in Tulsa. A follow-up letter was sent to Mr. Wilson.

A brochure explaining the Oil and Gas Exploration Module workshop in Oklahoma City, summer 1993, was developed and mailed to:

All high school principals in the state

Otlahoma Science Teachers' Association members

Science coordinators and earth science teachers in Oklahoma County

Mike Bernard, president of the Midcontinent Oil and Gas Association, was provided information pertaining to the Oil and Gas Exploration curriculum. He was very interested and suggested that a presentation be made at the next meeting of the organization. Likewise, Mickey Thompson, executive vice-president of the Oklahoma Independent Petroleum Association, was contacted and was also quite interested in the curriculum. A presentation was made to their Board of Directors in Norman, April 30. The OIPA is interested in supporting education projects but currently does not have the necessary $501 \mathrm{c} 3$ status. However, this is in process of being worked out, and the organization may be in position to provide funding for the teacher kits at future workshops. NIPER has been invited to make a presentation at the OIPA Annual Convention, in mid-June.

For the Teacher Internship Program, application information for the joint Phillips-NIPER teacher intemship project was mailed to 60 teachers in Bartlesville and surrounding districts. Teacher applications will be reviewed by supervising researchers in early May.

\section{Mannower and Financial_Status}

Financial expenditures are low, while manpower is higher than originally scheduled. This is due to the inability to plan accurately for the type of activities involved.

\section{Status of Project Milestones}

Milestones 2 and 3 are on schedule. 
SGP63

FINANCIAL STATUS OF THE PROJECT FOR APRL

Total Appropedation:

Less Subcontractes

Appropertation Balances

Bupenditures for the Month:

Totel Expenditures to Date:

Net Avilable:

Subcontract Expensecs

Annwil Fian Project SGP6O

Field Application of Foans for on

Production Sympodium

$\begin{array}{rr}\text { JECT FOR APRH } \\ 0 & 50,000 \\ 50,000 & \\ & 2,720 \\ 40,499 \\ 9,511 \\ \end{array}$

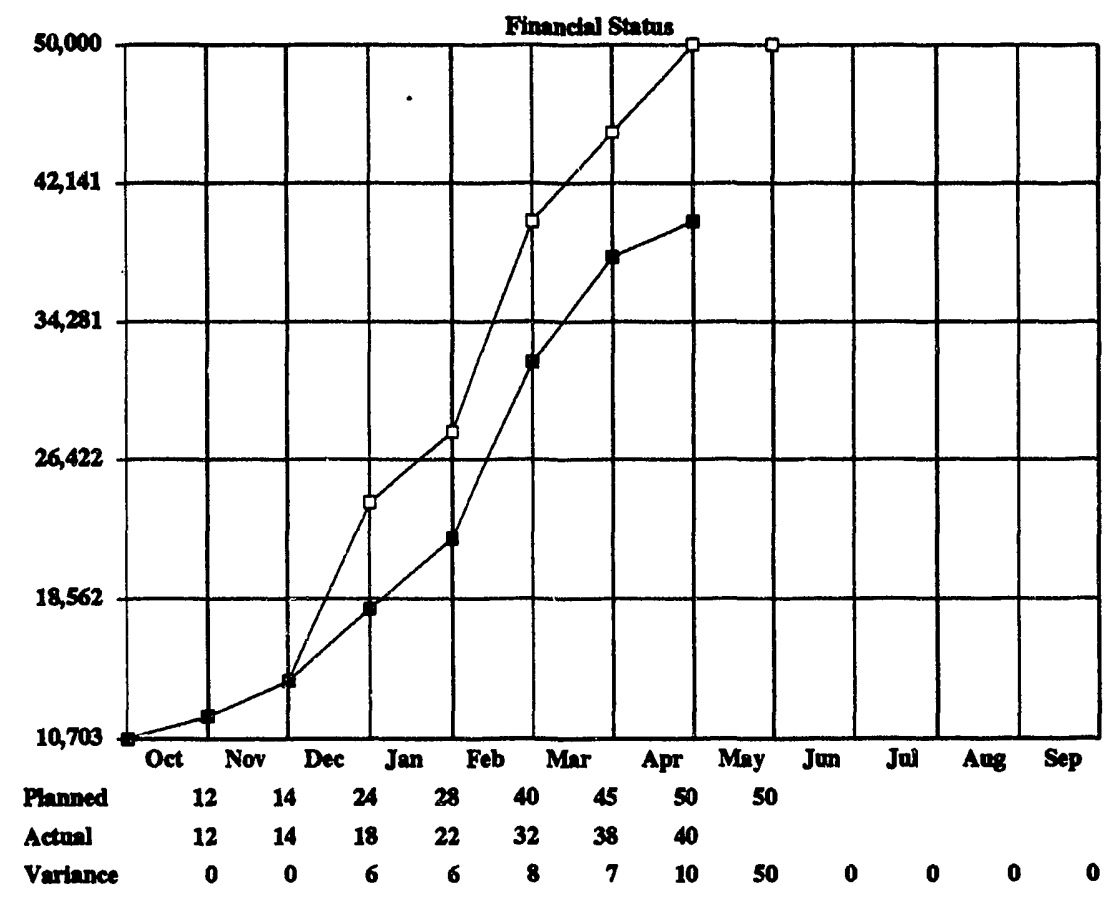

MANPOWER STATUS OF THE PROJECT FOR APRIL

Totil Men-hours:

Mom-bours used this Month:

Totul Minn-hours wed to Date:

Net Arallable:
475

511

(36)
Lepand for Key Mileatones

$X=$ Wort Compieted

$C=$ Fiamed Completion Date

$C^{\circ}=$ Revised Completion Date

$C^{c \prime}=$ Completed Abead of Seluedule

Key Miliectone Sthtes

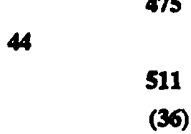

1 Oreante \& Coudect a Sympodum on Field Applicention of Foams 2 Comple Summary of Technical Cormments Obtumed Durting Symotion

3 Complite Procedings for DOE Bandl Eneres Report

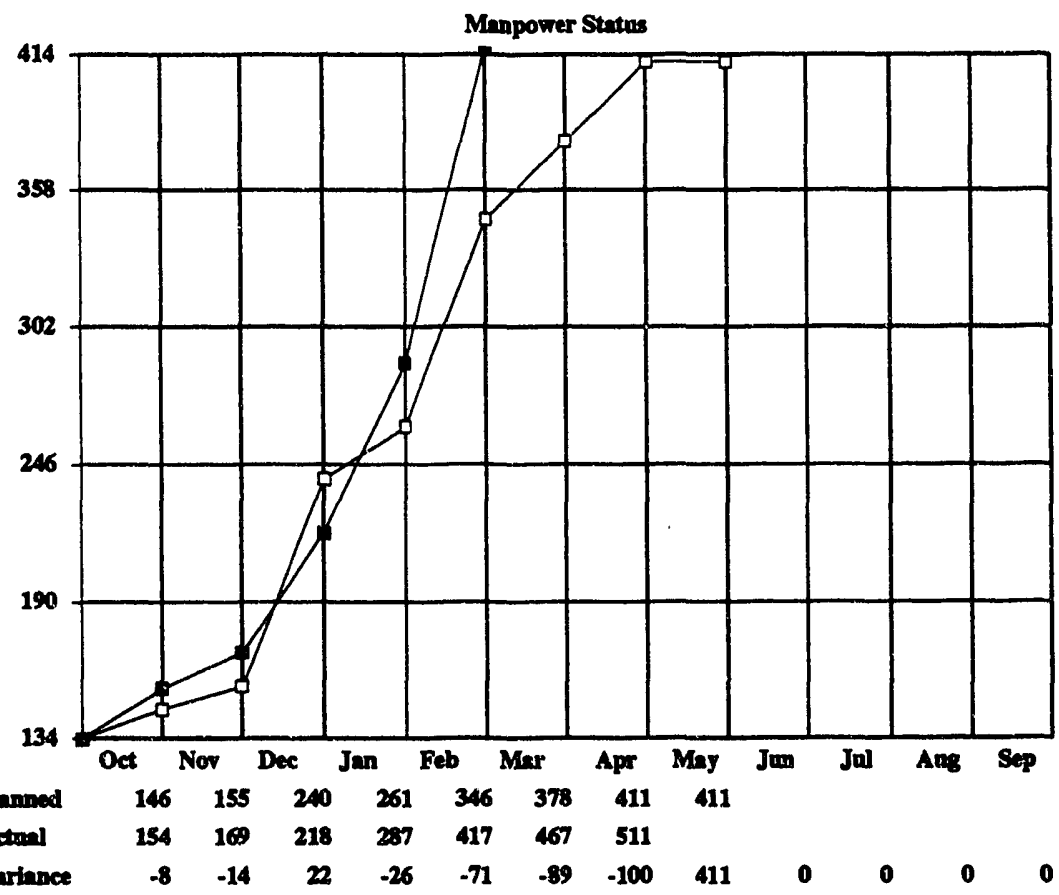

$\operatorname{xxx} \mathbf{x x x} \operatorname{xxx} \mathbf{x x x} \mathbf{x x c}$

XXX XXC

XXX XXX XXX 


\section{SGP63. FIELD APPLICATION OF FOAMS FOR OIL PRODUCTION SYMPOSIUM}

\section{Accomolishments}

The DOE and NIPER cosponsored a day and a half symposium on the field application of foams for oil production at the Red Lion Inn, Bakersfield, CA, Feb. 11-12, 1993. Seventy-two individuals from seven countries were in attendance and actively participated in the discussions and panel presentations on the current status of foam technology. The agenda included 13 technical papers and 8 poster sessions. Responses from the participants indicated that the symposium was an overwhelming success, and many wanted to see additional process-specific meetings of this type.

Milestoner 3-The symposium Proceedings have been submitted to the reviewers for comment, and it is anticipated the report (NIPER-669) will be ready for submittal to the BPO early next month. The Proceedings will be distributed to the attendees and the public following publication as a DOE/FE report.

A status report (NIPER-681) on the future of foams and problems associated with the application of foams has been prepared at the request of BPO. The report is in review.

\section{Manpower and Financial_Status}

Manpower usage is above projections due to the extra time involved in preparing a summary on the benefits of the foam symposium. Financial expenditures are low because some invoices associated with the symposium are still outstanding.

\section{Status of Proiect Milestones}

Milestone 3 is on schedule. Following the symposium, more than 20 requests were received for copies of the Preprints; however, all available copies had previously been distributed. A listing of these unfulfilled requests will be provided to the BPO for distribution as Proceedings when they are printed as a DOE/FE report. 
SGP64

FINANCLAL STATUS OF THE PROJECT FOR APRIL

Total Appropatation:

Leses Subcontracte:

Appiopretation Balance:

Expendttures for the Month:

Tatal Bxpendtitures to Date:

Net A vallable:

Sobecentract Expensecs:

124,350

50,000

174,350

3,353

37,539

136,811

o

Annoal Plan Project SGP64

Technolozy Trander to Independent Producens

MANPOWER STATUS OF THE PROJECT FOR APRII

Total Man-hours:

350

Mon-hours need this Month:

Totul Man-hours ued to Date:

25

Net Avillable:

\section{5}

55

Lepend for Key Millestones

$X=$ Wark Completed

C = Plamed Completion Date

C" $=$ Revised Complettion Date

$C^{\prime \prime}=$ Completed Abead of Schedule

Key Milectorae Status

1 Review Reaponse to First Semmar; Complete Dedign for Additional Sembers

2 Conduct Sertes of One-Day Sembern

3 Sabmit Final Repart Describing Project Results
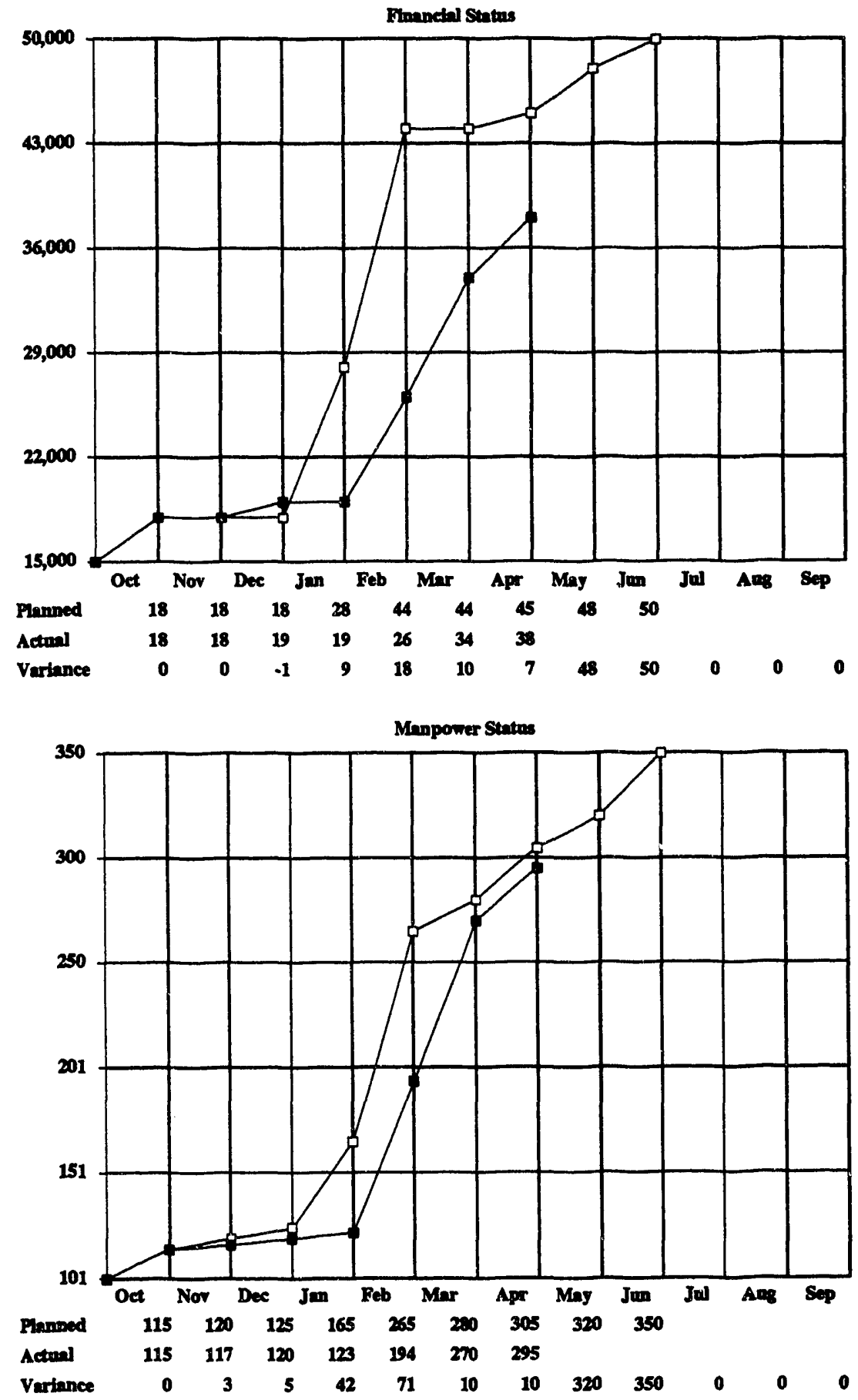

$\mathrm{XXX} \times \mathrm{XXC}$

$\mathbf{x x x} \mathbf{x x x} \mathbf{x x C}$

$\mathbf{X x x} \mathbf{x x x}$ C 
SGP64. TECHNOLOGY TRANSFER TO INDEPENDENT PRODUCERS

\section{Accomnlishments}

The objective of this project is to transfer information, through a series of seminars, on oil and gas related subjects which have been identified by independent operators as having the highest priority.

Milestone 3-A first draft of the final report analyzing the technology transfer activities in this project has been completed. In addition to the analysis, the report also includes comments by independent producers, survey results, and recommendations for funure projects.

\section{Manpoprer and Financial_Status}

Manpower usage is on schedule, and financial expenditures are approaching planned estimates.

\section{Status of Project_Milestones}

Milestone 3 is on schedule. 
FINANCLAL STATUS OF THE PROJECT FOR APRIL

Total Appropitatloa:

Lom Subcoutract:

Appropstation Balance:

Expanditures tor the Month:

Totel Buppondtures to Date:

Net A milable:

$\begin{array}{rr} & 23,750 \\ 23,750 & \\ & 100 \\ 8,501 \\ 15,249\end{array}$

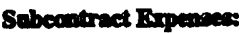

Amnow Plan Project SCPG

Complastions and Aralysis of Onterop Date from the Muddy and Amond Formations

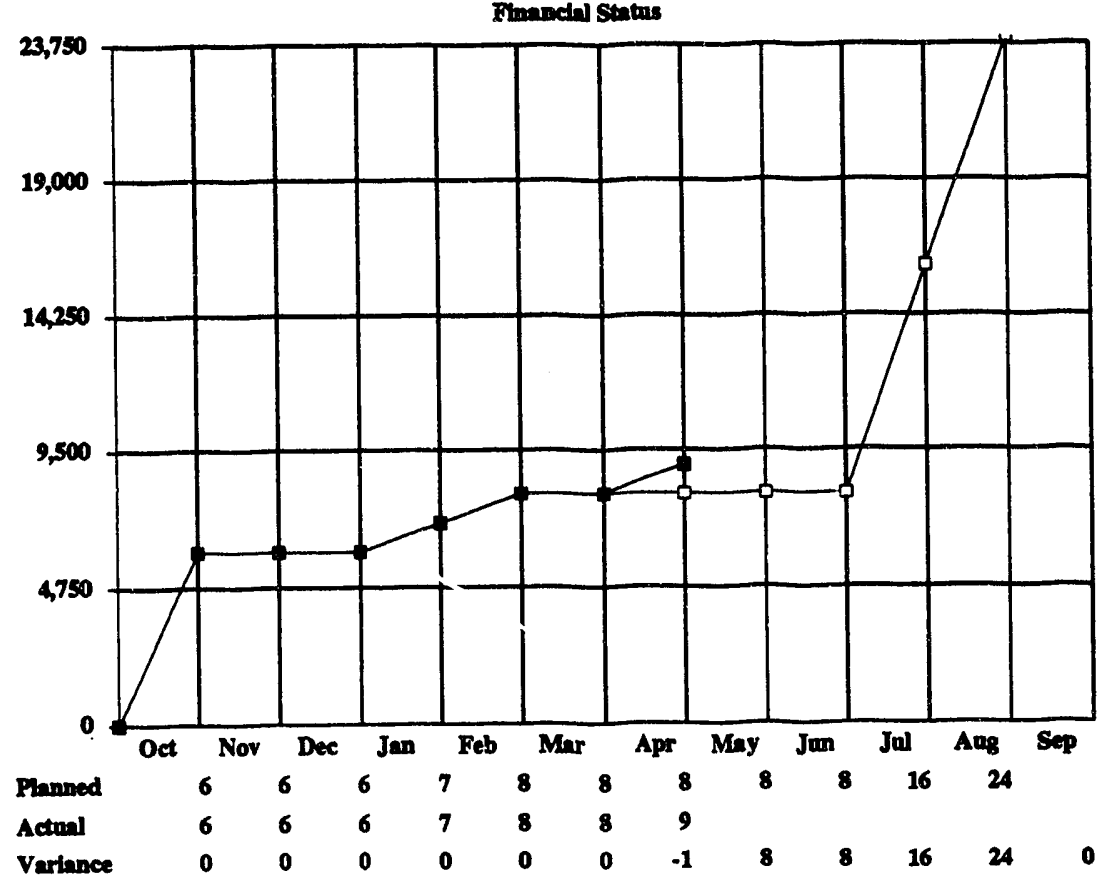

MANPOWER STATUS OF THE PROJECT FOR APRIL

Total Man-hours: 212

Man-bours used this Manth:

Total Mandoours noed to Date:

94

Net Avillable:

118

Legend for Key Miliestones

$X=$ Work Completed

C $\Rightarrow$ Plamed Completton Date

$C^{\prime}=$ Revised Complettion Date

C"= Completed Abead of Schedule

Key Milestone Status

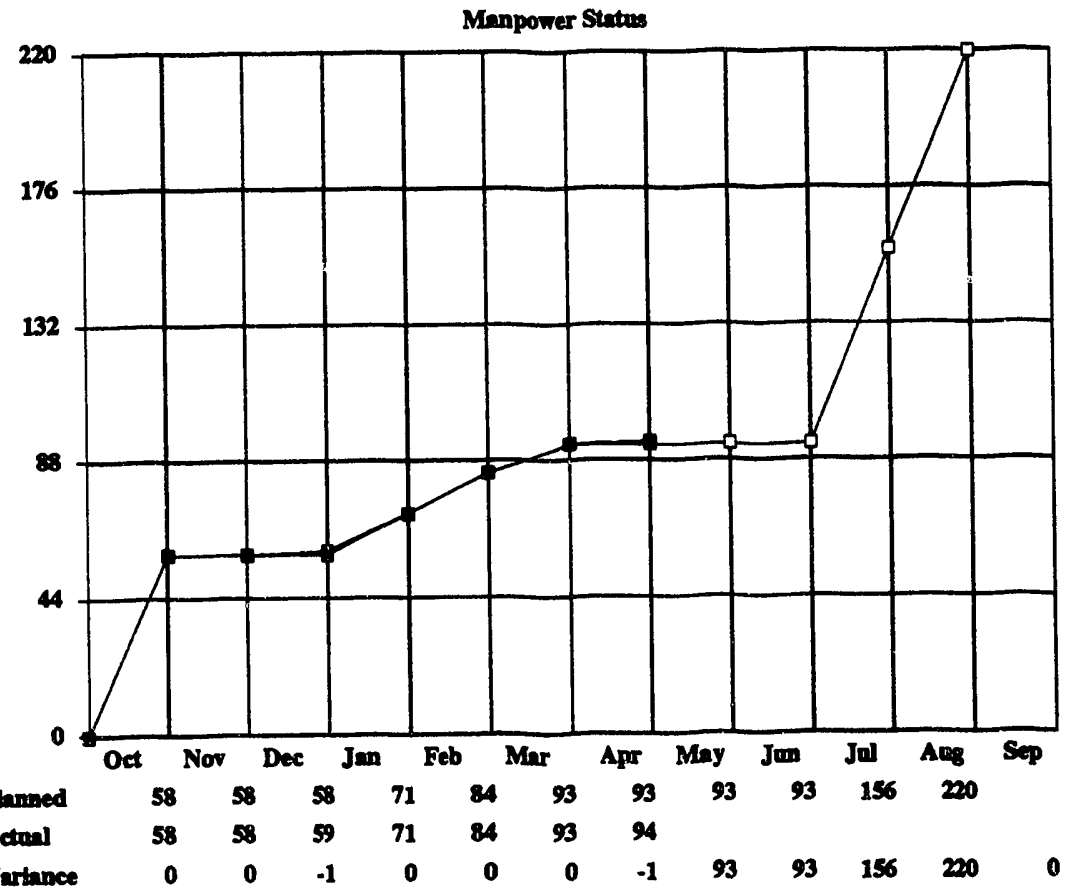

1 Supply Mining Data, Interpretations, \& Analyees of Outerop Data Collocted

2 Correlate Minfparmeameter \& CT Dandty Data with Sedimentolopfoll

Features in Core Well No. 2

3 Comple Ahnond \& Moddy Forsuation Odterop Data tnto Tranderable Farmat \& Prepare Ilustrations \& Documentation of Data Fles

4 Topical Report Contuinting a Compelatien of Data Collected \& Amalyzed

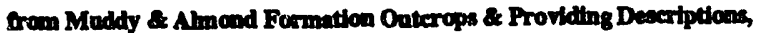

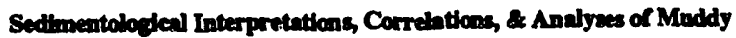
8. Almond Formation Outrerop Sections Stadiad

5 Submit Bectroutc FDes of Permeablity \& Poroetty Data, Grain Stze, \& Fecles Data from Middy \& Almoad Farmetton Outerops
$\mathbf{X x X} \mathbf{X x C}$

$\mathbf{x x O}$

C

C

C

C 


\section{SGP69. COMPILATION AND ANALYSIS OF OUTCROP DATA FROM THE MUDDY AND ALMOND FORMATIONS}

\section{Accomnlishments}

The objectives of this project are (1) to compile outcrop data from the Muddy and Almond formations; (2) supply missing data, interpretations, and analyses where needed; and (3) put data in a transferable format for use by interested parties.

No work was performed on this project this month. Work will resume in June.

Mannower and Financial Status

Financial expenditures and manpower have been rescheduled with permission of the BPO.

Status of Proiect Milestones

Milestones have been extended to accommodate manpower and financial rescheduling. 
FINANCIAL STATUS OF THE PROJECT FOR APRIL

Toul Appropintition:

Inplementation of OII and Ges Technology Transefer Infthative
Lom Solbecontracte:

Appropetation Balance

Brpeoditures for the Month:

Total Expenditures to Date:

Net Avelabib:

Sabeontriet Erpenoces:

Annom Ptan Project SGP72

25,0000

75,000

0

589

99,411

o

MANPOWER STATUS OF THE PROJECT FOR APRIL

Total Minnhours

Mrom-hoars used this Month:

Total Man-hours need to Date:

o

Net Avellabile:
0

o
Legend far Key Milestones

$\mathbf{X}=$ Wort Completed

C = Phrmed Conpletion Date

C' $=$ Revied Completion Date

C" = Completed Abead of Schedule

Koy Miretone Sutus

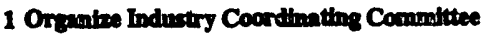

$\mathbf{X X X} \times \mathbf{X X C}$
Finnelal Sintme
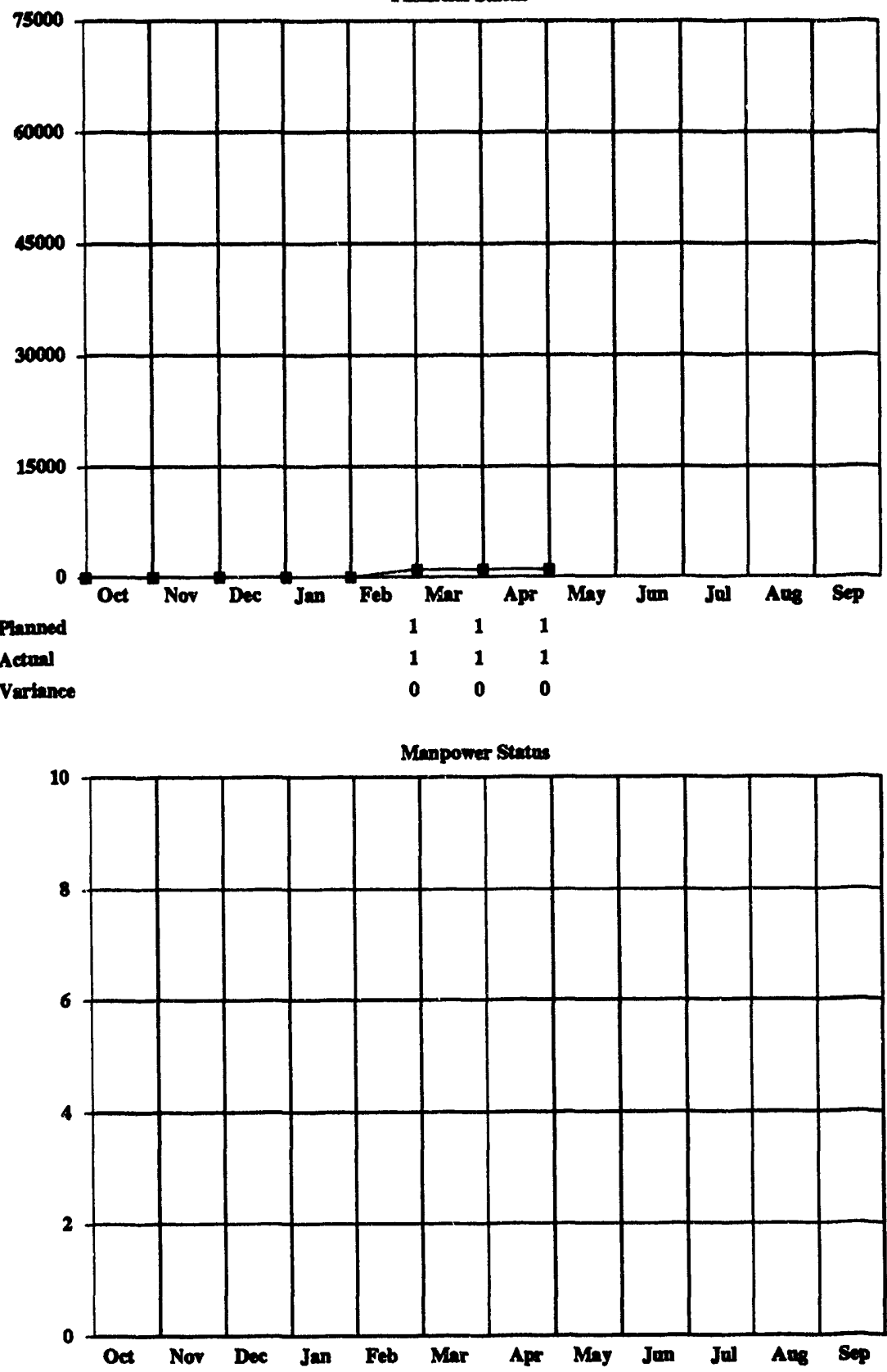

Ptanned

Actual

Vartance

2 Prepare Repart on Reccommendations for Deden and Implementation of a Comprehenedve National Technoloy Trander Progrum C 


\section{SGP72. IMPLEMENTATION OF OIL AND GAS TECHNOLOGY TRANSFER INITIATIVE}

\section{Accomnlishments}

The objectives of this project are to achieve effective coordination of technology transfer efforts among DOE and the diverse organizations that are part of the petroleum industry and to provide feedback to DOE regarding technology needs of the petroleum industry.

Milestone 1-An organizational meeting was held Jan. 18, 1993 in Austin, TX, to liscuss formation of an industry committee to facilitate transfer of oil and gas technology to the domestic petroleum industry. Invitees to the meeting included 26 representatives from various sectors of the petroleum industry, societies, and trade associations and five observers from DOE and national laboratories. Presentations were made by IPAA representatives regarding approaches for implementing a technology transfer program. Representatives from TIPRO, TORP, the Illinois Geological Survey, and the New Mexico Petroleum Recovery Research Center made brief presentations about ongoing technology transfer programs. A majority of those attending selected the name of the coordinating committee to be the Petroleum Technology Transfer Council (PTTC). This completed milestone 1.

Milestone 2-A working group meeting of the PTTC was held in Dallas on Feb. 8-9, 1993, to work on preparation of a report on design and implementation of a comprehensive national technology transfer program for submission to DOE. Debra Rowell, Vice-President of Economics with the IPAA, is serving as the coordinator for preparation of the report. The meeting focused on discussions of the elements of the technology transfer program and the structure of the report to DOE. A draft of the report has been prepared and is currently being reviewed and revised by members of the committee. The committee expects to submit a draft of the report to DOE near the end of the month.

\section{Mannower and Financial Status}

No direct labor is being charged on this project. Only direct costs associated with the project are being charged. There is no manpower allocated to the project; and, because of the uncertainty in the timing of expenditures, it is not possible to predict the schedule for financial expenditures. The financial charts reflect only actual expenditures and not any budget projections.

\section{Status of Proiect Milestones}

Milestone 1 has been completed. Milestone 2 is on schedule. 
SGP73

FINANCIAL STATUS OF THE PROSRCT POR APRI

Totel Appropration:

Lemsebountroctie

Appropatation Balunces

Inpendituren for tho Moenth:

Total Bappendurese to Date:

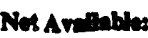

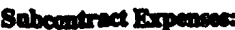

Amnual Pran Project SGPT3

Hartroutal Well Production from Fractured Reservotrs

MANPOWER STATUS OF THE PROJECT FOR APRII
Toul Marbours:

Mon-hours used this Masth:

Totel Man-bours uned to Date:

Net Avilable:

$\begin{array}{rr} & \$ 0,000 \\ 0 & \\ 40,000 & \\ & 6,229 \\ & 7,874 \\ & 32,120\end{array}$
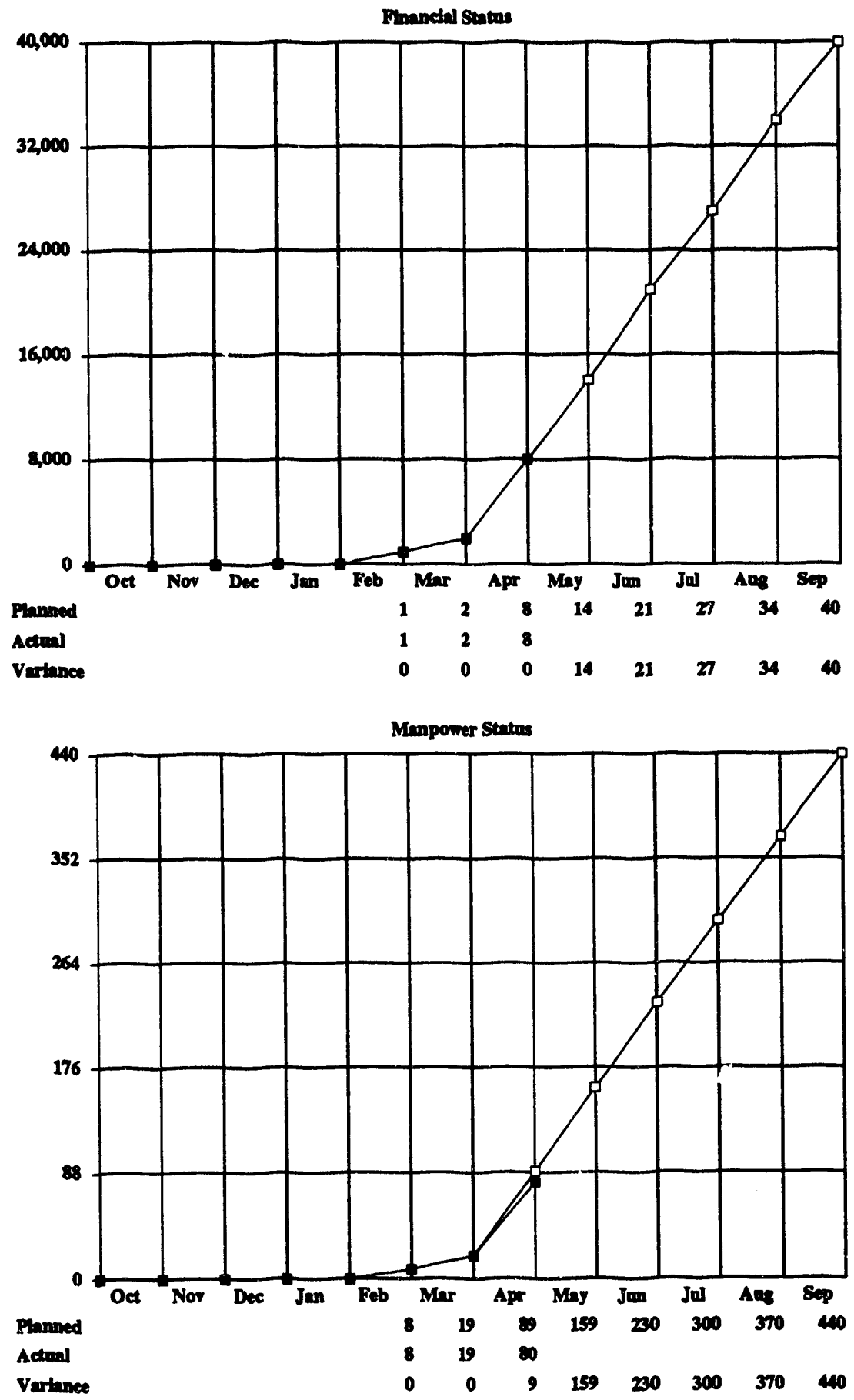

$\mathbf{x x X} \mathbf{X x c}$

$\mathbf{X X X} \mathbf{X X X}$
1 Complete Fracture Deta Coilection tran Reservetr and Outerop 2 lopprove Trameser Function Between Rock Matrts and Fracture 3 Funalime Developenent of Fracture Recervotr Model

4 Conduct Numarieal Simnhation of Harbontal Production trem Fractured Reanvotrs

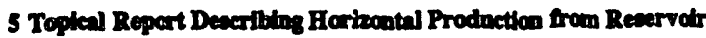
C 


\section{SGP73. HORIZONTAL WELL PRODUCTION FROM FRACTURED RESERVOIRS}

\section{Accomplishments}

The objective of this project is to determine effects of natural fractures on horizontal well production using numerical simulation to provide guidelines, screening criteria, or analytical predictions of horizontal well production. completed.

Milestone 1-The collection of fracture density and distribution patterns from reservoirs and outcrops has been

Milestone 2-The shape factor in the transfer function was calculated by solving the three-dimensional diffusivity equation of a rock matrix block under unsteady-state production. The diffusivity equation in the $x, y$, and $z$ coordinate was solved in two cases by assuming different boundary conditions of (1) constant fracture pressure and (2) constant flow rate. This is the first time that the shape factor was derived under the condition of unsteady-state production in contrast to the condition of pseudo steady state assumed by other studies denoted in the literature.

Shape factor values are high at the initial depletion stage under unsteady-state conditions. When the fracture pressure is constant, the shape factor converges to $\pi^{2} / \mathrm{d}^{2}, 2 \pi^{2} / \mathrm{d}^{2}$, and $3 \pi^{2} / \mathrm{d}^{2}$ for one-, two-, and three-dimensional rock matrix, respectively, at the dimensionless time (tD) of about 0.5 . The ' $d$ ' value in the shape factor formula is the length of rock matrix. The period of 0.5 for tD ranges from less than 1 day for commonly encountered fractured reservoirs to months for large and tightly fractured rock.

When the flow rate from the rock matrix to the fracture is constant, the fracture pressure varies with location on the rock surface. Based on the average fracture pressure, the shape factor decreases with production time until a tD value of 0.05 is reached. The shape factor values increase with time when the tD value is greater than 0.05 , and the shape factor values at 0.05 are $10.2 / \mathrm{d}^{2}, 20.4 / \mathrm{d}^{2}$, and $30.6 / \mathrm{d}^{2}$, for one-, two-, and three-dimensional rock matrix flow, respectively. The shape factors calculated from the case of constant flow rate are less than those from the case of constant fracture pressure when the tD value is less than 0.1 .

The shape factor values calculated from unsteady state production are higher than those proposed by Kazemi (SPEJ, Dec. 1976) and by Coats (SPE paper 18427), but less than those by Warren and RootS (SPEJ, SepL. 1963).

\section{Manpower and Financial_Status}

Manpower and financial expenditures are on schedule.

\section{Status of Project_Milestones}

Milestone 2 has been completed. The other milestones are on schedule. 


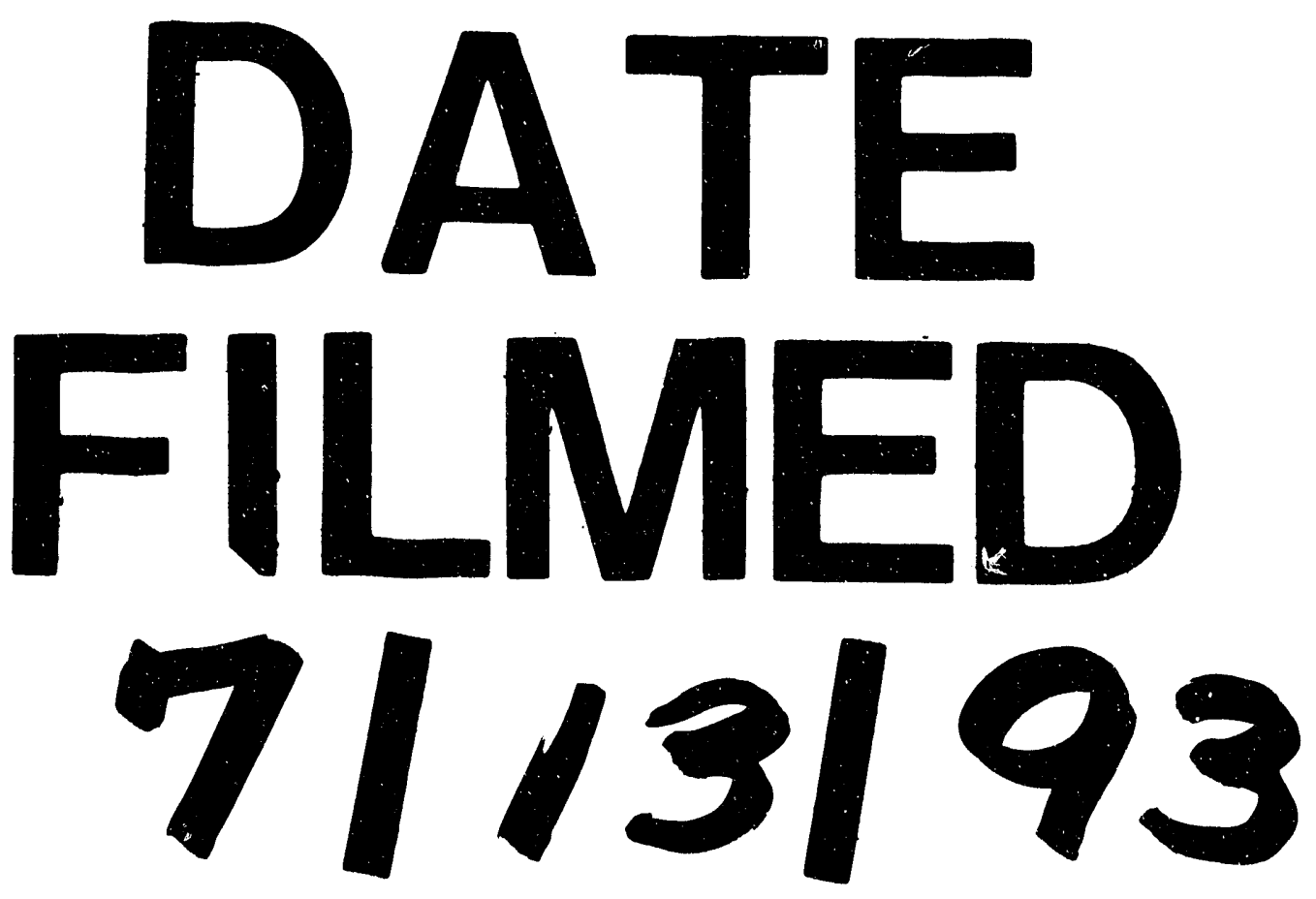

